\title{
A novel form of macropinocytosis mediates ultra-rapid transfer of pathological alpha-synuclein to lysosomes
}

Running title: Trafficking of pathological $\alpha$-synuclein

Armin Bayati, Emily Banks, Chanshuai Han, Wen Luo, Cornelia Zorca Wolfgang E. Reintsch,

Benoit Vanderperre, Heidi M. McBride, Edward A. Fon, Thomas M. Durcan, and Peter S.

McPherson

\author{
Materials and Correspondence \\ Dr. Peter S. McPherson \\ Department of Neurology and Neurosurgery \\ Montreal Neurological Institute \\ McGill University \\ 3801 University Street \\ Montreal, QC H3A 2B4 \\ Canada \\ phone: (514) 398-7355 \\ Email: peter.mcpherson@mcgill.ca
}


Trafficking of pathological $\alpha$-synuclein

\section{Abstract}

The nervous system spread of alpha-synuclein fibrils leads to Parkinson's disease (PD) and other synucleinopathies, yet the mechanisms underlying internalization and cell-to-cell transfer are enigmatic. Here we use confocal and superresolution microscopy, subcellular fractionation and electron microscopy (EM) of immunogold labelled alpha-synuclein pre-formed fibrils (PFF) to demonstrate that this toxic protein species enters cells using a novel form of ultra-rapid macropinocytosis with transfer to lysosomes in as little as 2 minutes, an unprecedented cell biological kinetic for lysosomal targeting. PFF uptake circumvents classical endosomal pathways and is independent of clathrin. Immunogold-labelled PFF are seen at the highly curved inward edge of membrane ruffles, in newly formed macropinosomes, and in lysosomes. While many of the fibrils remain in lysosomes that continue to take up PFF for hours, a portion are transferred to neighboring naïve cells on the external face of vesicles, likely exosomes. These data indicate that PFF uses a novel internalization mechanism as a component of cell-tocell propagation. 
Trafficking of pathological $\alpha$-synuclein

\section{Introduction}

A classic hallmark of Parkinson's disease (PD) is the formation of Lewy Bodies (LBs). First discovered in 1912 (Lewy, 1912), LBs are cytoplasmic inclusions composed of fragments of membranous organelles and filamentous proteins (Shahmoradian et al., 2019; Tanaka et al., 2004). LBs are also seen in PD-related disorders such as Lewy body dementia. Alpha-synuclein (a-syn), encoded by the SNCA gene, is a major component of LBs and is implicated in their formation (Conway et al., 1998; Spillantini et al., 1997). The physiological function of $\alpha$-syn in membrane trafficking and membrane curvature is becoming clear (Fortin et al., 2004; Jao et al., 2004; Nakamura et al., 2008; Vargas et al., 2017), and increased knowledge of its protein structure and the conformation of altered variants has led to enhanced understanding of $\alpha$-syn misfolding and aggregation in disease (Lee et al., 2002; Li et al., 2002; Sandal et al., 2008).

Since the early 2000s, the Braak hypothesis has stated that PD develops with the spread of $\alpha$ syn throughout the brain (Braak et al., 2003), a model that gained traction with the observation that proteinaceous inclusions spread from brain tissue into implanted embryonic stem cells in humans and animal models(Li et al., 2008) (Desplats et al., 2009b; Li et al., 2010; Recasens and Dehay, 2014; Recasens et al., 2018). This propagating pathology is also observed when the fibril form of a-syn, is injected into localized brain regions of mice (Betemps et al., 2014; Luk et al., 2012; Masuda-Suzukake et al., 2014). This tendency to spread, along with the ability of $\alpha$ syn fibrils to disrupt the conformation of endogenous $\alpha$-syn in neurons, has led to the prion theory of $\alpha$-syn spread (Masuda-Suzukake et al., 2013; Mougenot et al., 2012). However, major questions remain as to the cell biological itinerary of $\alpha$-syn propagation, notably the mode of cellular entry.

We found approximately 40 studies examining a-syn fibril endocytosis with variable conclusions (Table 1). Most studies conclude that $\alpha$-syn is internalized via clathrin-mediated endocytosis 
Trafficking of pathological $\alpha$-synuclein

(CME) based on the use of dynamin and clathrin inhibitors (dynasore and pitstop, respectively) and clathrin heavy chain (CHC) colocalization (Konno et al., 2012; Liu et al., 2007; Rodriguez et al., 2018). It is generally thought that following CME, PFF traffic to lysosomes via the endosomal system. However, it has been shown that Dynasore and pitstop have off-target effects, (Gu et al., 2010; Oh et al., 1998; Park et al., 2013; Pelkmans et al., 2002; Preta et al., 2015) and the late time course of many $\alpha$-syn internalization studies may miss important early events. Apart from CME, it is suggested that PFF enter cells via direct permeation of the plasma membrane (Danzer et al., 2007), via the formation of tunnelling nanotubes that allow direct connections between cells (Dieriks et al., 2017), or through caveolae-dependent endocytosis (Madeira et al., 2011). Thus, there is no consensus regarding the nature of cellular entry of PFF.

Macropinocytosis, a highly conserved evolutionary mechanism for internalization (King and Kay, 2019), allows cells to engulf fluid and cargo in large endocytic vesicles referred to as macropinosomes. Macropinocytosis has been shown to facilitate viral entry into cells (Mercer and Helenius, 2009), and its upregulation is linked to cancer and enhanced cell survival (Zwartkruis and Burgering, 2013). Multiple growth factors induce the formation of membrane ruffles, precursors to macropinosomes (Yoshida et al., 2018). Although macropinocytosis has been shown to be largely clathrin- and caveolae-independent process (Mayor and Pagano, 2007), it shares common characteristics with clathrin pathways, notably, a dependence on dynamin (Mulherkar et al., 2011; Schlunck et al., 2004) and colocalization with endosomal markers including Rab5 and EEA1 (Stephen et al., 2007). Like early endosomes, macropinosomes mature into late endosomes through the recruitment of Rab7 and a decrease in $\mathrm{pH}$, which eventually leads to the transfer of macropinocytic cargo to lysosomes (Humphries et al., 2011). This maturation takes about $30 \mathrm{~min}$ in both receptor-mediated endocytosis and macropinocytosis (Kerr and Teasdale, 2009; Rink et al., 2005). 
Trafficking of pathological $\alpha$-synuclein

In examining PFF endocytosis, we discovered that PFF enter cells through a novel form of macropinocytosis, which transport PFF to lysosomes in as little as $2 \mathrm{~min}$. Macropinosomes containing PFF fail to localize with markers of early endosomes. Moreover, we demonstrate that PFF drive the formation of membrane ruffles. We confirmed these results in multiple cell lines, primary human astrocytes, and neurons derived from induced pluripotent stem cells (iPSC). The novel use of gold labelled PFF allowed us to observe these trafficking pathways directly. While the majority of the PFF remains in lysosomes over long time periods, a portion of PFF are transferred to naïve cells along with markers of multivesicular bodies (MVBs). Intriguingly, we observe that prior to the release, endocytosed PFF are seen on the outer edge of MVBs. Taken together, our data unveils a completely novel form of macropinocytosis that mediates PFF internalization and allows for endocytosis to be coupled to release. 
Trafficking of pathological $\alpha$-synuclein

\section{Results}

\section{PFF are rapidly endocytosed to lysosomes}

We used fluorescently labeled PFF (Del Cid Pellitero et al., 2019; Maneca et al., 2019) (Fig. S1A/B) with live cell imaging and a trypan blue exclusion assay (Karpowicz et al., 2017) that quenches extracellular PFF fluorescence (Fig. S1D) to examine PFF internalization at the earliest possible time points. PFF are rapidly internalized in U2OS cells and are targeted to lysosomes where they colocalize with Lysosomal Cytopainter within as little as 2 min (Fig. 1A). Similar results are seen when incubating cells with PFF at $4^{\circ} \mathrm{C}$ for 30 min and then transferring the cells to $37^{\circ} \mathrm{C}$ (Fig. S1E). We confirmed the live imaging findings in fixed samples of U2OS cells. PFF are significantly internalized within 2 min and continue to accumulate within cells for up to $72 \mathrm{~h}$ (Fig. 1B/D). Nearly all labeled PFF that enters cells is colocalized with LAMP1TurboRFP by 2 min and this stays stable (i.e, all newly entering PFF goes to lysosomes) for up to $60 \mathrm{~min}$ (Fig. 1C). As fixation makes cells permeable to trypan blue, for fixed cell experiments we used trypsin to proteolyze extracellular PFF (Fig. S1F/G). Rapid uptake of PFF and transport to lysosomes within 2 min was also observed in U87 (Fig. S2A/D) and U251 (Fig. S2B/E) glioblastoma cells.

To confirm the rapid transport of PFF to lysosomes using an independent approach, we incubated U2OS cells stably expressing HA-TMEM192-RFP, a lysosomal protein, with PFF for various time periods, then lysed the cells and purified lysosomes with HA-magnetic beads (AbuRemaileh et al., 2017). The enrichment of lysosomes was confirmed in the immunoprecipitated fractions with antibodies recognizing LAMP1 and 2 (Fig. 1E). Rab7 also enriched in the lysosome fractions whereas Rab5 and LRRK2 were not detected. CD63/LAMP3, a marker of lysosomes and MVBs was the most highly enriched marker. PFF were enriched in the lysosome fractions as early as 2 min, confirming their rapid transport to lysosomes (Fig. 1E). The enriched lysosomes were placed on coverslips and visualized through their RFP tag with fluorescently 
Trafficking of pathological $\alpha$-synuclein

labelled PFF (Fig. 1F/G). PFF were detected in the lumen of the lysosomes, which was most readily seen using STED superresolution microscopy (Fig 1G). Thus, PFF are rapidly endocytosed and transported to lysosomes in as little as $2 \mathrm{~min}$, an unprecedented time frame for lysosomal targeting.

\section{Rapid transfer of PFF to lysosomes in nervous system cells}

Human cortical neurons derived from iPSCs (Fig. S1H) were incubated with fluorescently labelled PFF and co-localization with lysosomes was examined using a fixable form of Lysotracker. PFF were rapidly endocytosed in the neurons with lysosomal co-localization observed as early as 2 min (Fig. S2C/F), although lysosomes continued to accumulate in PFF. We next examined internalization of PFF in human dopaminergic neural progenitor cells (NPCs) derived from iPSCs and in dopaminergic neurons derived from the NPCs (Fig. S1H). In both cell types, PFF rapidly internalize and are detected at lysosomes within 2 min (Fig. 2A,B,D,E). Human astrocytes (Fig. S1H) also robustly endocytose PFF with rapid co-localization with lysosome markers (Fig. 2C/F). Thus, in multiple cell types, including those from the human nervous system, PFF are transported to lysosomes with an unprecedented trafficking kinetic.

In U343 human glioblastoma cells, PFF that are transferred to lysosomes remain in the organelle where they accumulate for up to 10 days (Fig. S3). In contrast, internalized epidermal growth factor dissipates from lysosomes (Fig. S3). The accumulation of internalized PFF in lysosomes is also observed in human dopaminergic neurons (Fig. 3A) and in human astrocytes (Fig. 3B).

\section{PFF traffic to lysosomes avoiding early/recycling endosomes}

It is a consensus view that internalized $\alpha$-syn follows the endosomal pathway to lysosomes (Lee et al., 2005; Lee et al., 2008; Lee et al., 2016), but considering the speed at which PFF reach 
Trafficking of pathological $\alpha$-synuclein

lysosomes, this seems unlikely as endosomal maturation generally takes 10-15 min (Huotari and Helenius, 2011). We thus sought to explore the trafficking itinerary of PFF upon cellular entry. Transferrin (Tf), a well-studied marker of early and recycling endosomes (Trischler et al., 1999) was added along with PFF to compare their trafficking pathways. As early as 2 min, and for as long as $30 \mathrm{~min}$, Tf and PFF do not colocalize and therefore appear to use separate pathways for intracellular trafficking (Fig. S4A/D). Moreover, internalized PFF do not colocalize with EEA1, a marker of early endosomes (Mills et al., 1998), even at time points as early as 2 min (Fig. S4B/E). This led us to examine colocalization of PFF with Rab4, Rab5, Rab8, Rab9, and LAMP1 at 5 and 60 min (Fig.S4C). PFF colocalize only with Rab9 and LAMP1 at both timepoints. A similar lack of colocalization was observed with another early endosome marker, Rab5 (Fig. S4F/G). Thus, PFF reach lysosomes independently of the early and recycling endosomal systems.

\section{Endocytosis of PFF is clathrin-independent}

There is no known mechanism by which cargo that enters cells can gain access to lysosomes in 2 min while bypassing early endosomes. To test if the novel endocytic pathway involves clathrin, we used an established genetic approach involving knockdown of $\mathrm{CHC}$ with previously validated siRNA (Galvez et al., 2007; Kim et al., 2011). Immunoblot reveals effective CHC knockdown in U2OS cells (Fig. 4A). We then plated cells treated with control siRNA or CHCtargeting siRNA as a mosaic in the same well and incubated them with PFF. We observed no difference in internalization of PFF when comparing knockdown and control cells (Fig. 4B/C). Thus, it does not appear that CME is a major route for the internalization of PFF.

\section{Internalization of PFF occurs through macropinocytosis}

Holmes et al. (Holmes et al., 2013) demonstrated that tau fibrils utilize macropinocytosis and that fibril $\alpha$-syn colocalizes with tau during uptake, suggesting a potential role for 
Trafficking of pathological $\alpha$-synuclein

macropinocytosis in the internalization of fibril a-syn. Consistently, Zeineddine et al. (Zeineddine et al., 2015) found that $\alpha$-syn fibrils induce membrane ruffling, an early step in the formation of macropinosomes. We thus sought to test if macropinocytosis is involved in the internalization of PFF. At a concentration of $20 \mu \mathrm{M}$, EIPA, an established and specific inhibitor of macropinocytosis (Commisso et al., 2014; Koivusalo et al., 2010; Nakase et al., 2015) that disrupts the $\mathrm{Na}^{+} / \mathrm{H}^{+}$exchanger, decreasing cytosolic $\mathrm{pH}$ and inhibiting the activation of $\mathrm{Cdc42}$ and Rac1, required for macropinocytosis (Koivusalo et al., 2010), inhibits PFF uptake in human astrocytes (Fig. 4D/E). Latrunculin B (LatB), which inhibits macropinocytosis by disrupting actin polymerization (Williams and Kay, 2018), also blocks PFF uptake at $5 \mu \mathrm{M}$ (Fig. 4D/E). In contrast, neither drug had an influence on the uptake of EGF (Fig. 4D/F), which at the concentration used, enters cells via CME (Sigismund et al., 2005). In addition to astrocytes, we confirmed our findings in dopaminergic NPCs. Latrunculin A (LatA), which like LatB is a potent actin polymerization inhibitor (Fujiwara et al., 2018), demonstrates a dose-dependent inhibition of PFF uptake with uptake reduced by $81 \%$ compared to control at $2 \mu \mathrm{M}$ (Fig. 4G).

Consistent with a role for macropinocytosis in the endocytosis of PFF, we found that PPF induce the formation of actin-rich membrane ruffles, precursors of macropinosomes (Condon et al., 2018) (Fig. S5A/B). More specifically, we observe that PFF induce the recruitment of Rac1 to actin-rich membranes on the cell surface, a characteristic of macropinocytosis (Grimmer et al., 2002) (Fig. S5A). The ability of PFF to induce membrane ruffling is also readily observed by EM (Fig. S5C). As controls, we examined the influence of EGF that induces membrane ruffles, even though it does not use macropinocytosis for internalization (Bryant et al., 2007) and Tf, which does not induce membrane ruffling nor use macropinocytosis for internalization. As expected EGF causes the recruitment of Rac1 to the surface, where it colocalizes with F-actin, whereas no Rac1 recruitment is seen upon addition of Tf (Fig. S5D). Thus, PFF stimulate 
Trafficking of pathological $\alpha$-synuclein

membrane ruffles and use macropinocytosis to gain access into cells although the time course of transfer to lysosomes is unique.

\section{Trafficking itinerary of PFF revealed by immunogold EM}

To directly observe the trafficking itinerary of PFF we labeled them with gold (Fig. S1C) and followed their trafficking by EM. At 2-3 min post PFF addition, astrocytes were fixed and processed for EM with uranyl acetate staining. Gold-labelled PFF appear under membrane ruffles and in intracellular macropinosomes formed by ruffle closure (Fig. 5Ai/ii). The immunogold-labelled PFF remain in the lumen of the macropinosomes/endosomes that begin to demonstrate inward invagination of vesicles (Fig. 5Aiii/iv). In contrast, gold-labelled dextran is never see at ruffles but instead is observed at highly curved vesicular profiles (Fig. 5B). At 3-5 min the PFF can be found in the lumen of intracellular membranes that gradually acquire electron density, indicating that they are lysosomes (Fig. 5C/D; Fig. S6A-F).

Remarkably, gold-labelled PFFs are often found in close association with regions of membrane curvature of approximately $50 \mathrm{~nm}$ in diameter as they begin to bud inward into electron lucent organelles approximately 300-400 nm in diameter (Fig. 6A). Thus, PFF may be contributing to the formation of MVBs. In fact, PFF are readily detected on the surface of vesicles in MVBs (Fig. 6B). MVBs containing PFF are also detected at the light level using STED microscopy on fluorescently-labelled PFF (Fig. 6C). Live cell studies were performed to examine the dynamics of these structures, which appear to undergo multiple rounds of fusion and/or membrane budding (Fig. 6D/E). Thus, PFF enter cells via macropinocytosis and rapidly appear in lysosomes and MVBs.

\section{PFF are transferred to naïve cells along with markers of exosomes}


Trafficking of pathological $\alpha$-synuclein

The spread of PFF throughout the nervous system requires that the fibrils must escape cells and be transferred to neighbouring naïve cells. Exosomes provide a mechanism for cell-to-cell transfer of protein, lipids and other cellular molecules, and the presence of PFF in MVBs suggests a potential mechanism for cellular release. To test this hypothesis, U2OS cells with stable expression of CD63-GFP were incubated with fluorescently-labelled PFF for $24 \mathrm{~h}$ and then washed with trypsin and buffer before being re-plated with PFF-naïve cells with stable expression of LAMP1-RFP. From 12-24 h following the start of co-culture, PFF were observed to transfer from the CD63-positive cells to the LAMP1-positive cells (Fig. 7A/C). Moreover, we also observed the transfer of CD63 (Fig. 7A/B), strongly supporting that transfer of PFF involves exosomes. Similar results are seen with transfer to naïve cells expressing CD9-RFP (Fig. S7A/B). Importantly, the transfer of both CD63 and PFF is blocked by the addition of manumycin A, a compound known to disrupt exosome release (Fig. 7A-C). Finally, we took CD63 donor cells and incubated them with gold-labelled PFF for $24 \mathrm{~h}$ before extensive trypsin/buffer wash. The cells were then re-plated on their own for $48 \mathrm{hr}$ before the media was collected, spun at low $\mathrm{g}$ to remove any cells or cell debris, and the supernatant was transferred to naïve cells. Most remarkably, we were able to capture images of extracellular vesicles, decorated with PFF in contact with the cells, sometime seemingly near sites of membrane ruffles and forming macropinosomes (Fig. 7D). Thus, PFF that have entered cells by macropinocytosis and have ended in MVBs appear to be delivered on exosomes to neighbouring cells. 
Trafficking of pathological $\alpha$-synuclein

\section{Discussion}

The mechanisms of the uptake of PFF remain unresolved (Bieri et al., 2018; Grozdanov and Danzer, 2018). Most studies investigating internalization of $\alpha$-syn or PFF evaluate uptake hours following addition to cells (Desplats et al., 2009a; Hansen et al., 2011; Konno et al., 2012; Lee et al., 2008; Liu et al., 2007; Luk et al., 2016; Luk et al., 2009; Madeira et al., 2011; Rodriguez et al., 2018; Sung et al., 2001; Volpicelli-Daley et al., 2014; Volpicelli-Daley et al., 2011). These assays lack the temporal resolution to thoroughly understand the pathways involved in endocytosis, an early event. We performed a detailed analysis of early events in PFF endocytosis and were surprised to discover a unique cell biological mechanism for the internalization of PFF that allows the toxic species to reach lysosomes within 2 minutes, bypassing the early endosomal system.

When examining early events in PFF internalization, we found no evidence for the trafficking of PFF through early or recycling endosomes. This is inconsistent with a CME pathway. Most studies suggesting CME of PFF have used dominant-negative dynamin or CME inhibitors, specifically dynasore and pitstop (Desplats et al., 2009a; Hansen et al., 2011; Lee et al., 2008). The inhibition of dynamin, whether through knockdown or expression of dynamin dominantnegative constructs, can affect multiple cellular processes, including the inhibition of other endocytic pathways and actin remodelling (Gu et al., 2010; Henley et al., 1998; Iversen et al., 2012; Krueger et al., 2003; Mayor and Pagano, 2007; Oh et al., 1998; Schlunck et al., 2004). Moreover, dynasore and pitstop have off-target effects, limiting their ability to act as specific inhibitors of CME (Park et al., 2013; Preta et al., 2015; Willox et al., 2014). Using a previously established pool of CHC siRNA (Bayati et al., 2021; Galvez et al., 2007; Kim et al., 2011), we attained $\sim 95 \%$ knockdown efficiency, with no influence on PFF endocytosis. 
Trafficking of pathological $\alpha$-synuclein

We found that PFF induce the formation of actin- and Rac1-rich membrane ruffles. These ruffled membranes can be induced by multiple growth factors, including EGF, and are the precursors of macropinocytic vesicles (Cox et al., 1997; Grimmer et al., 2002). This indicates that exposure to PFF induces a downstream pathway involving membrane ruffling. We next examined if PFF exposure merely induces membrane ruffling, as for EGF, or whether it utilizes actin ruffling for internalization. For this, we used inhibitors of micropinocytosis (Commisso et al., 2014; Koivusalo et al., 2010; Zwartkruis and Burgering, 2013). Using EIPA, LatA and LatB (Erami et al., 2017; Furstner et al., 2007; Morton et al., 2000; Wakatsuki et al., 2001), we found that the drugs significantly inhibited PFF uptake at every time point while not affecting EGF uptake. Our findings point to PFF endocytosis using a novel form of macropinocytosis, where macropinosomes either mature into MVBs and lysosomes or fuse with pre-existing LAMP1positive compartments. Recent papers show promising results regarding the role of actin in PFF internalization (Underwood et al., 2020; Zhang et al., 2020).

Most importantly, our study indicates a novel type of macropinocytosis, in which proteins are delivered to lysosomes with an unprecedent time course. This direct transport to lysosomes and the circumventing of canonical markers of endocytosis and the Rabs involved has not been described. Despite this novel pathway of entry, our findings do corroborate previous studies. First, although much slower, previous research demonstrates fusion of macropinosomes with lysosomes and not endosomes (Yoshida et al., 2018). Second, the findings of previous studies on dynamin inhibition and reduction in PFF uptake can also be explained since dynamin plays a major role in macropinocytosis and is involved in actin remodelling (Gu et al., 2010; Krueger et al., 2003; Mulherkar et al., 2011). In fact, at high concentrations, we observed that dynasore does block PFF internalization (data not shown). Finally, amilorides, such as EIPA, have been shown to have neuroprotective effects in PD (Arias et al., 2008). 
Trafficking of pathological $\alpha$-synuclein

Although previous studies attempted to look at the localization of exogenous a-syn using immuno-EM (Volpicelli-Daley et al., 2011), we are the first to conjugate PFF with gold and follow its endocytosis. As it has recently been reported, many antibodies to $\alpha$-syn cannot distinguish different conformations of $\alpha$-syn (Kumar et al., 2020), making the direct conjugation of PFF a necessity for the most accurate results. Building upon our previous data regarding the role of membrane ruffling and actin in PFF endocytosis, we were able to visualize the membrane ruffling/protrusions and examine the internalization of PFF into cells at the EM level. Consistent with previous literature (Vargas et al., 2017), we also found that throughout its trafficking, PFF is almost always in close association with membranes whether at the cell surface, during internalization, and while in MVBs and lysosomes.

Localization of PFF-gold in lysosomes by EM is consistent with our findings using confocal and immunoprecipitation experiments; however, due to the high resolution of EM, we were able to ascertain the role MVBs play in PFF trafficking. Early following PFF internalization, MVBs containing PFF were spotted, and the formation of vesicles through invaginations of MVBs with PFF were clearly seen. At longer time points, using EM, we also found that PFF are being transported via exosomes, which we corroborated with confocal microscopy, and found that these exosomes are CD63 positive. Two important conclusions can be made as a result of this: first that the transmission of PFF is at least partly due to the exosomal transport of PFF, as described previously (Bieri et al., 2018); secondly, we found that PFF reside on the outsides of exosomes, rather than being contained in the exosomal lumen. This is a previously unobserved phenomenon for both PFF transmission and for exosomal transport in general. We then used Manumycin A, a drug that blocks the release of CD63-positive exosomes(Datta et al., 2017), and found that Manumycin A disrupts PFF transmission from cell-to-cell. We suspect that since PFF resides on the outside of exosomes, that drugs like EIPA, LatA, and LatB that blocked its initial uptake, can be used to block PFF spread from cell-to-cell. 
Trafficking of pathological $\alpha$-synuclein

Although all evidence reported here indicates that PFF use a novel macropinocytic pathway to gain access into cells, we are also cognizant that the membrane curvature and protrusions could be driven by the properties of $\alpha$-syn itself. As previously observed, PFF associates and may even drive membrane curvature (Vargas et al., 2017; Westphal and Chandra, 2013). This could mean that PFF drive their own internalization into the cell by causing membrane curvature, and then, once trafficked to MVBs/lysosomes, it drives membrane invaginations, resulting in exosomal formation and eventually its release. This might be one explanation for the lack of identity in the macropinosomes formed (i.e., no colocalization with Rab4, Rab5, Rab8, and EEA1). Once released, PFF then go on to disrupt other cells, all the while remaining on the outside of exosomes, allowing it to drive membrane curvature that would drive its internalization in neighboring cells. Although PFF is only an oligomer, it certainly has many prion-like characteristics. Above all else, PFF may be taking advantage of the $\alpha$-syn's interaction with membranes to drive its own endocytosis, exocytosis, and drive the production of more aggregated $\alpha$-syn. It is this evolutionary drive for PFF to create more fibrillated forms of $\alpha$-syn, that truly makes it more than just an oligomer, and more like a prion. 
Trafficking of pathological $\alpha$-synuclein

\section{Materials and Methods}

Production and characterization of PFF

Production and characterization of recombinant $\alpha$-syn monomers and PFF have been described previously (Del Cid Pellitero et al., 2019; Maneca et al., 2019). Both electron microscopy and dynamic light scattering were used for the characterization of $\alpha$-syn monomers and PFF (Fig.

\section{S1A-B).}

\section{Nano-Gold labelling of PFF}

Previously characterized PFF, was then conjugated with $5 \mathrm{~nm}$ gold beads (Cytodiagnostics, cat\# CGN5K-5-2), immediately before experimental use. Cytodianostic's conjugation protocol was used to conjugate gold onto PFF. Following conjugation, some PFF was collected for characterization on carbon-covered grids (Electron Microscopy Sciences, cat\# FCF400CU50) (Fig. S1C).

\section{Cell lines}

HeLa, U2OS, U87, U251, U343 were obtained from American Type Culture Collection (ATCC). Human fetal astrocytes were obtained from Cell Applications. For studies with iPSCs, we used the line AIW002-2 obtained from the Neuro's C-BIG Biorepository. This line was reprogrammed from peripheral blood mononuclear cells of a healthy donor with the Cytotune reprogramming kit (ThermoFisher). The process of reprogramming and quality control profiling for this iPSC was outlined in a previous study (Chen et al., 2021). The use of iPSCs in this project is approved by the McGill University Health Centre Research Ethics Board (DURCAN_IPSC / 2019-5374).

\section{Cell culture}

Except for astrocytes and neuronal cells derived from iPSCs, all cells were cultured in DMEM high-glucose (GE Healthcare cat\# SH30081.01) containing 10\% bovine calf serum (GE 
Trafficking of pathological $\alpha$-synuclein

Healthcare SH30072.03), $2 \mathrm{mM} \mathrm{L-glutamate} \mathrm{along} \mathrm{with} \mathrm{penicillin} \mathrm{and} 100 \mu \mathrm{g} / \mathrm{ml}$ streptomycin (Wisent 609065, 100 IU; Wisent 450201). Human fetal astrocytes were cultured in HA Growth Medium (Cell Applications 821-500). Cell lines were checked routinely for mycoplasma contamination using mycoplasma protocol kit (biotool B39038).

AIW002-2 hiPSC cultures were maintained as feeder-free cultures following the protocol described previously (Chen et al., 2021). AIW002-2 hiPSCs were plated onto Matrigel (Corning, 354277)-coated plates containing mTeSR1 medium (Stemcell Technologies, 85850, 85857). The culture medium was changed daily until cells reached $\sim 80 \%$ or required confluency (usually 5-7 days after plating). The cells were then passaged, frozen, or differentiated. A previously described protocol was used to generate ventral midbrain dopaminergic neural progenitor cells (Jefri et al., 2020). Dopaminergic neural progenitor cells were dissociated with StemPro Accutase Cell Dissociation Reagent (ThermoFisher; A1110501) into single-cell suspensions. 50,000 cells were plated onto coated coverslips in 24-well plates with neural progenitor plating medium (DMEM/F12 supplemented with N2, B27 supplement). To further differentiate into dopaminergic neurons, neural progenitor medium was switched to dopaminergic neural differentiation medium (Brainphys Neuronal medium, STEMCELL Technologies 05790) supplemented with N2A Supplement A (STEMCELL Technologies; 07152), Neurocult SM1 Neuronal Supplement (STEMCELL Technologies; 05711), BDNF (20 ng/mL; Peprotech; 45002), GDNF (20 ng/mL; Peprotech; 450-10), Compound E (0.1 $\mu \mathrm{M}$; STEMCELL Technologies; 73954), db-cAMP (0.5 mM; Carbosynth; ND07996), Ascorbic acid (200 M; Sigma; A5960) and laminin (1 $\mu \mathrm{g} / \mathrm{mL}$, Sigma; L2020).

The identity of all cells was confirmed using antibody markers such as glial fibrillary associated protein (GFAP) for astrocytes and glioblastomas, $\beta$ III tubulin for neural progenitor cells, microtubule associated protein-2 (MAP2) for mature neurons, Forkhead box protein A2 
Trafficking of pathological $\alpha$-synuclein

(FOXA2) for dopaminergic neural progenitor cells, and tyrosine hydroxylase (TH) for differentiated dopaminergic neurons (Fig. S1H)

\section{Plasmids and lentivirus}

EBFP2-Lysosomes-20, tdTurboRFP-Lysosomes-20 were gifts from Michael Davidson (Addgene plasmid \# 55246 and 58061). pLJM1-Tmem192-mRFP-3xHA was a gift from Roberto Zoncu Addgene plasmid \# 134631. pLJC5-Tmem192-3xHA was a gift from David Sabatini (Addgene plasmid \# 102930. CD63-pEGFP C2 was a gift from Paul Luzio (Addgene plasmid \# 62964). LAMP1-RFP lentivirus was obtained from abmgood.

\section{Antibodies}

LAMP1 rabbit and mouse antibody are from Cell Signaling (9091S and D4O1S). EEA1 antibody is from BD Biosciences (610457). Rab4, Rab5, Rab8, and Rab9 are from abcam (ab109009, ab18211, ab188574, ab179815). Rab5 antibody used for western blot and IP is from Cell Signaling (3547S). CHC antibody is from Cell Signaling (4796S). Rac1 antibody is from Abcam (ab155938). Conjugated Phalloidin antibody is from Abcam (ab176759). GFAP antibody is from Invitrogen (ASTRO6). MAP2 antibody is from Abcam (ab5392). TH antibody is from Millipore Sigma (AB9702). $\beta$ III Tubulin is from Abcam (ab18207). FOXA2 is from Abcam (ab108422). Alexa Fluor 405, 488, 568, 633, and 647 conjugated secondary antibodies are from Invitrogen.

\section{Chemicals and inhibitors}

For nuclear staining, one of the following three were used: Hoeschst (Abcam; ab228551), DAPI (Invitrogen; D1306), DRAQ7 (Abcam; ab109202). For fluorescent lysosomal staining, either Lysosomal Cytopainter from Abcam (ab176827) or Lysotracker Red from Invitrogen (L7528) were used. Chemical inhibitors used were Ethylisopropyl amiloride (EIPA) from Sigma-Aldrich (A3085-25MG), and Latrunculin B (LatB) from Abcam (ab144291). For transfection, we used 
Trafficking of pathological $\alpha$-synuclein

Lipofectamine 3000 from Invitrogen (L3000015). For blocking and permeabilization, we used bovine serum albumin (BSA) from Wisent (800-095-LG) and Triton X-100 from Sigma-Aldrich (X100-1L). For post-fixation staining of the plasma membrane, wheat germ agglutinin (WGA) from Invitrogen (W21404) was used. Transferrin (Tf) and Epidermal Growth Factor (EGF) tagged with Alexa Fluor 488 was obtained from Invitrogen (T13342 and E13345). Dako fluorescent mounting medium from Agilent (S3023) was used for mounting coverslips onto glass slides.

\section{Trypan blue exclusion assay}

HeLa cells were grown on poly-L-lysine coated $35 \mathrm{~mm}$ glass-bottom dishes from MatTek for 48 $\mathrm{h}$ to $50 \%$ confluency. When ready for imaging, cells were stained with Hoescht for 30 min and dishes were placed in the pre-heated live imaging chamber of the Zeiss LSM-880 confocal microscope. Imaging was commenced before the addition of PFF tagged with Alexa Fluor 488 (PFF488) at a speed of 1 frame/sec. PFF was added during live imaging.

\section{PFF live internalization assay}

U2OS cells were grown on poly-L-lysine coated $35 \mathrm{~mm}$ glass-bottom dishes from MatTek for 72 $\mathrm{h}$ to $70 \%$ confluency. Before imaging, cells were stained with Lysosomal Cytopainter for 30min. Dishes were placed in the pre-heated live imaging chamber of the Zeiss LSM-880 confocal microscope. Imaging was commenced before the addition of PFF at a speed of 1 frame/sec using the Airy imaging mode for higher resolution ( $\sim 1.3 x$ resolution of conventional confocal microscopy). PFF488 was added during imaging.

\section{Live MVB assay}

These live experiments were carried out the same way as above. For the hollow lysosome morphology, the "Find Edges" processing was used on ImageJ (https://imagej.net/software/fiji/). 
Trafficking of pathological $\alpha$-synuclein

Lysosomal staining in fixed samples

Lysosomal staining was achieved in one of the following ways: transfection with plasmids stated above with the aid of Lipofectamine 3000 transfection reagent, fixable Lysotracker for staining of lysosomes in neurons and neural progenitor cells, or with the use of LAMP1 antibody.

Transfection was done $24 \mathrm{~h}$ prior to experimentation. Staining with Lysotracker was done 30 min before experimentation. LAMP1 antibody staining was done following fixation and permeabilization.

\section{Treatment with inhibitors}

EIPA, LatA, and LatB were the only inhibitors used in this study. Cells normally incubated in media with serum were washed 3 times with serum-free media to remove any remaining serum. Serum-free media was added with a final concentration of either $20 \mu \mathrm{M}$ of EIPA, $0-2 \mu \mathrm{M}$ of LatA, $5 \mu \mathrm{M}$ of LatB. Cells were then incubated at $37^{\circ} \mathrm{C}$ for $30 \mathrm{~min}$ before experimentation for EIPA and LatB, and $1 \mathrm{~h}$ for LatA.

\section{PFF endocytosis assays}

Cells mounted on coverslips were grown in 24 well plates at $37^{\circ} \mathrm{C}$ with $200 \mu \mathrm{l}$ of media in each well. Immediately prior to experimentation, cells were taken out of incubators and placed in the cell culture hood. PFF aliquots were then removed from dry ice, diluted with serum-free media, and added to each well. Cells were then incubated at $37^{\circ} \mathrm{C}$ for $0,2,10,30 \mathrm{~min}$. Cells were then placed on ice and washed with trypsin for $90 \mathrm{sec}$ (to remove extracellular PFF). Following 2 washes with PBS, cells were fixed. In experiments where trypsin was not used, cells were washed 3 times with PBS and fixed. In experiments with longer incubation times, the same protocol was used. 
Trafficking of pathological $\alpha$-synuclein

\section{Lysosomal Immunoprecipitation}

U2OS cells stably expressing HA-TMEM192-RFP were incubated with PFF for varying lengths of time, washed with Trypsin 3 times to remove extracellular PFF, and then trypsinized and pelleted. Lysosomes were immunoprecipitated based on the protocol described in AbuRemaileh et al. (2018). Briefly, cells were washed twice with KPBS and centrifuged at $4^{\circ} \mathrm{C}$ for 2 minutes at $1000 \times \mathrm{g}$. Pelleted cells were resuspended in lysis buffer (20 mM HEPES pH 7.4, $100 \mathrm{mM} \mathrm{NaCl}$, and protease and phosphatase inhibitor cocktail) and manually homogenized with 25 up and down strokes. Homogenates were centrifuged for $2 \min$ at $4^{\circ} \mathrm{C}$ at $1000 \times g$ and $10 \%$ of the total volume for each IP was reserved for starting material (SM) fractions. Homogenates were incubated with gentle rocking at $4^{\circ} \mathrm{C}$ for 3 minutes with $100 \mu \mathrm{L}$ anti-HA magnetic beads pre-washed with KPBS. After collecting the total IP volume for the unbound materials (UM), immunoprecipitates were washed three times with KPBS using a DynaMag-2 Magnet before resuspension in 1X SDS-PAGE sample buffer. Protein aliquots were then analyzed by SDS-PAGE and Immunoblot. LRRK2 antibody (c41-2, Abcam), LAMP2 (H4B4, Abcam), LAMP1 (D2D11, Cell Signaling), Hsc70 (13D3, Invitrogen), HA antibody (6E2, Cell Signalling), CD63 antibody (NK1/C3, Abcam), Rab5 antibody (3A4, Abcam), Rab7 antibody (EPR7589, Abcam), and alpha-synuclein antibody (syn211, Abcam) were used to identify the lysosomal fraction and whether that fraction contained PFF.

For samples to be processed via confocal microscopy, $20 \mu \mathrm{L}$ pre-washed anti-HA beads were used in the IP and were resuspended in using PFA to resuspend and fix them. The sample was then pelleted and resuspended with PBS and mounted onto slides.

\section{PFF intercellular transfer assay}

U2OS cells were transfected with CD63-EGFP or LAMP1-tdTurboRFP using Lipofectamine 3000 transfection reagent and incubated for $24 \mathrm{~h}$. Cell media was then changed, and cell 
Trafficking of pathological $\alpha$-synuclein

selection process was initiated through the addition of Neomycin (Gibco cat\# LS21810031). U2OS cells stably expressing CD63-GFP were exposed to PFF or PBS (vehicle control) for 24 h. CD63-GFP (donor cells) were then trypsin washed three times, pelleted, trypsinized again, pelleted and PBS washed, prior to being co-plated with acceptor cells (PFF naïve cells stably expressing LAMP1-tdTurboRFP). Donor and Acceptor cells were then incubated for 12 or $24 \mathrm{~h}$. Half of the $24 \mathrm{~h}$ sample were given Manumycin A (MA) at 1.2 $\mu \mathrm{M}$ while the other half was given DMSO (vehicle control) at the time of plating. Cells were then fixed, mounted and imaged.

\section{Fixation and antibody staining}

Fixation was done with $2 \%$ freshly made PFA for $10-15$ min on ice. In experiments where antibody staining was done, cells were then blocked and permeabilized for 30 min using $0.05 \%$ Triton X-100 in PBS along with 5\% BSA. Coverslips were then transferred into a wet chamber and incubated with 1:500 dilution of the antibody in $0.01 \%$ Triton X-100 and 5\% BSA. Cells were incubated with the diluted antibody for $2 \mathrm{~h}$ at room temperature. Coverslips were then gently washed 3 times with PBS, and 1:500 dilution of secondary antibody was added in 0.01\% Triton X-100 and 5\% BSA. Cells were then washed 2 more times with PBS and stained with DAPI for $10 \mathrm{~min}$ at $1 \mu \mathrm{g} / \mathrm{ml}$ concentration (not all experiments used DAPI staining). Coverslips were then mounted on a glass slide using Dako. All fixed samples were then imaged using a Leica TCS SP8 confocal microscope. STED samples were then imaged using Abberior STED superresolution nanoscope.

We initially found that PFF staining was severely affected following permeabilization limiting our ability to use antibodies in our experiments. We found that in cells with higher uptake of PFF (e.g., astrocytes), we could permeabilize samples and still retain some PFF fluorescence. We also found that instead of fixation and permeabilization with methanol or PFA and high concentrations of Triton X-100 (i.e., 0.1-0.5\% Triton volume/volume), that a softer fixation with 2\% PFA and low concentration of Triton X-100 for permeabilization (i.e., $0.05 \%$ Triton) allowed 
Trafficking of pathological $\alpha$-synuclein

for the preservation of PFF fluorescence. Following our understanding of how to mediate the deleterious effects of permeabilization on PFF fluorescence in fixed samples, we could then employ antibodies in our experiments to stain for endosomal markers.

\section{CHC knockdown}

U2OS cells at $60 \%$ confluency were transfected with $\mathrm{CHC}$ siRNA retrieved from Dharmacon (SMARTpool: ONTARGETplus; L-004001-01-0010) or control siRNA (Dharmacon; ONTARGETplus CONTROL) using Lipofectamine 3000 (Invitrogen). At $24 \mathrm{~h}$ following transfection, cells were passaged, with some cells retrieved for imaging experiments and mounted onto coverslips. At 48 h, cells were collected in HEPES lysis buffer (20 mM HEPES, 150 mM sodium chloride, $1 \%$ Triton X-100, pH 7.4) accompanied with protease inhibitors. Cells in lysis buffer were then placed at $4^{\circ} \mathrm{C}$ and gently rocked for $30 \mathrm{~min}$. Lysates were then spun at $238,700 \times \mathrm{g}$ for $15 \mathrm{~min}$ at $4^{\circ} \mathrm{C}$. Lysates were run on $5-16 \%$ gradient polyacrylamide gel and transferred onto nitrocellulose membranes. Subsequently, proteins were visualized using Ponceau staining. Blots were then blocked with $5 \%$ milk for $1 \mathrm{~h}$. Antibodies were then incubated overnight at $4 \%$ in bovine serum albumin/TBS/0.1 Tween 20 . The secondary antibody was incubated at 1:2500 dilution in 5\% milk/TBS/0.1 Tween 20 for $1 \mathrm{~h}$ at room temperature. Concurrently, cells mounted onto coverslips underwent the endocytosis assay with both knockdown and control cells mounted onto the same coverslips.

\section{LatA inhibition in dopaminergic NPCs}

Dopaminergic NPCs were seeded in polyornithin/ laminin coated 384 well plates (Corning, cat\# 353962) at 4000cells/ well. After $24 \mathrm{~h}$ LatA (Cayman Chemical, cat\#:10010630) was added.

After $1 \mathrm{~h}$, Alexa488-PFF was added. After another $24 \mathrm{~h}$ incubation period, the wells were washed twice with PBS and the cells fixed with $2 \%$ FA/PBS. Cells were counterstained with Hoechst33342 and imaged on a high content imager (CellInsight CX7, ThermoFisher Scientific). 
Trafficking of pathological $\alpha$-synuclein

The amount of intracellular Alexa488-PFF was measured as the total intensity of Alexa488 fluorescent stain in the perinuclear area. Nuclei count and nuclear area $\left(p x^{\wedge} 2\right)$ were also obtained as indicators for cell toxicity. All data was normalized against DMSO (vehicle) only controls. Data represents the mean and standard deviation of 3 independent experiments.

\section{TEM}

Human astrocytes were plated onto 8 well chamber slides (Lab-Tek, Nunc, Thermo Scientific, cat\# 177445) and were administered PFF conjugated with gold. Cells were then fixed with glutaraldehyde $2.5 \%$ in $0.1 \mathrm{M}$ sodium cacodylate buffer (Electron Microscopy Sciences), postfixed with $1 \% \mathrm{OsO}_{4}$ and $1.5 \%$ potassium ferrocyanide in sodium cacodylate buffer. Cells were then en bloc stained with $4 \%$ uranyl acetate. Post-embedding, some grids were stained with uranyl acetate for enhanced membrane staining. Samples were viewed with a Tecnai Spirit 120 kV electron microscope and captured using a Gatan Ultrascan 4000 camera.

\section{Quantification and statistics}

For all quantifications, including uptake and colocalization, the Leica LAS X and ImageJ (imagej.net) software were used. Readout from the LAS X software included Pearson Correlation Coefficient and colocalization rate expressed in percentage. In each experiment, images were selected from a large field imaged at low quality using the Leica SP8 spiral scan. From the large field, regions were selected that contained a minimum of 4 cells. A $5 \%$ background threshold was set to eliminate background fluorescence and fluorescent bleedthrough across channels when using ImageJ. Colocalization rate was used for graphs and statistical calculations. Graphs were then prepared using GraphPad Prism 9 software. All graphs include individual data points, denoted by gray diamonds. For statistical comparisons, Student's t-test (two-tailed) and one-way ANOVA were used. When significance was detected under ANOVA, multiple comparisons Tukey's test was conducted to assess significance 
Trafficking of pathological $\alpha$-synuclein

compared to control. All data is shown as mean $+/$ - SEM. For statistical significance, $p<0.05$ was used. Detailed information regarding the statistical analyses used for the creation of graphs are included along with the raw data in the Supplemental Dataset spreadsheet.

\section{Data Availability}

All data generated or analysed during this study are included in this published article (in the supplementary information files). This includes all statistical tests, the result of these tests, the complete analytic values such as mean, SD, SEM, P value, df, etc.

\section{Acknowledgements}

We acknowledge the Neuro Microscopy Imaging Centre and Advanced Biolmaging Facility and the Facility for Electron Microscopy Research at McGill University. We thank Dr. Michael Davidson and Dr. Paul Luzio for the LAMP1 and CD63 plasmids, respectively. We also thank Drs. Sabatini and Zoncu for the HA-TMEM192 plasmids. AB is supported by Fonds de recherche du Québec doctoral award and a studentship from the Parkinson Society of Canada. This work was supported by a grant from the Canada First Research Excellence Fund, Healthy Brain, Healthy Lives, McGill University, awarded to PSM. PSM is a Distinguished James McGill Professor and Fellow of the Royal Society of Canada.

\section{Author Contributions}

AB planned and conducted the experiments and wrote the manuscript with PSM. EB performed lysosomal immunoprecipitation experiment along with analyzing protein expression through western blotting. $\mathrm{CH}$ provided NPCs and differentiated iPSCs into cortical and dopaminergic neurons. WL produced and characterized PFFs. CZ provided us with additional NPCs and differentiated iPSCs. WR conducted 24 h PFF uptake experiment with dopaminergic NPCs using LatA. BV suggested experiments investigating macropinocytosis. HMM, EAF and TMD 
bioRxiv preprint doi: https://doi.org/10.1101/2022.01.06.475207; this version posted January 7, 2022. The copyright holder for this preprint (which was not certified by peer review) is the author/funder. All rights reserved. No reuse allowed without permission.

Trafficking of pathological $\alpha$-synuclein

edited the manuscript and helped provide overall direction of the project. PSM funded and

supervised the project, aided $A B$ in planning the experiments, and wrote the manuscript with

$A B$.

\section{Competing interests}

The authors declare that they have no competing interests. 
Trafficking of pathological $\alpha$-synuclein

\section{References}

Abounit, S., Bousset, L., Loria, F., Zhu, S., de Chaumont, F., Pieri, L., Olivo-Marin, J.C., Melki, R., and Zurzolo, C. (2016). Tunneling nanotubes spread fibrillar alpha-synuclein by intercellular trafficking of lysosomes. EMBO J 35, 2120-2138.

Abu-Remaileh, M., Wyant, G.A., Kim, C., Laqtom, N.N., Abbasi, M., Chan, S.H., Freinkman, E., and Sabatini, D.M. (2017). Lysosomal metabolomics reveals V-ATPase- and mTOR-dependent regulation of amino acid efflux from lysosomes. Science 358, 807-813.

Arias, R.L., Sung, M.L., Vasylyev, D., Zhang, M.Y., Albinson, K., Kubek, K., Kagan, N., Beyer, C., Lin, Q., Dwyer, J.M., et al. (2008). Amiloride is neuroprotective in an MPTP model of Parkinson's disease. Neurobiol Dis 31, 334-341.

Bayati, A., Kumar, R., Francis, V., and McPherson, P.S. (2021). SARS-CoV-2 infects cells following viral entry via clathrin-mediated endocytosis. J Biol Chem, 100306.

Betemps, D., Verchere, J., Brot, S., Morignat, E., Bousset, L., Gaillard, D., Lakhdar, L., Melki, R., and Baron, T. (2014). Alpha-synuclein spreading in M83 mice brain revealed by detection of pathological alpha-synuclein by enhanced ELISA. Acta Neuropathol Commun 2, 29.

Bieri, G., Gitler, A.D., and Brahic, M. (2018). Internalization, axonal transport and release of fibrillar forms of alpha-synuclein. Neurobiol Dis 109, 219-225.

Braak, H., Tredici, K.D., Rüb, U., de Vos, R.A.I., Jansen Steur, E.N.H., and Braak, E. (2003). Staging of brain pathology related to sporadic Parkinson's disease. Neurobiology of Aging 24, 197-211.

Bryant, D.M., Kerr, M.C., Hammond, L.A., Joseph, S.R., Mostov, K.E., Teasdale, R.D., and Stow, J.L. (2007). EGF induces macropinocytosis and SNX1-modulated recycling of E-cadherin. J Cell Sci 120, 1818-1828.

Chen, C.X.-Q., Abdian, N., Maussion, G., Thomas, R.A., Demirova, I., Cai, E., Tabatabaei, M., Beitel, L.K., Karamchandani, J., Fon, E.A., et al. (2021). Standardized quality control workflow to evaluate the reproducibility and differentiation potential of human iPSCs into neurons. bioRxiv,

2021.2001.2013.426620.

Commisso, C., Flinn, R.J., and Bar-Sagi, D. (2014). Determining the macropinocytic index of cells through a quantitative image-based assay. Nat Protoc 9, 182-192.

Condon, N.D., Heddleston, J.M., Chew, T.L., Luo, L., McPherson, P.S., loannou, M.S., Hodgson, L., Stow, J.L., and Wall, A.A. (2018). Macropinosome formation by tent pole ruffling in macrophages. J Cell Biol 217, 3873-3885.

Conway, K.A., Harper, J.D., and Lansbury, P.T. (1998). Accelerated in vitro fibril formation by a mutant alpha-synuclein linked to early-onset Parkinson disease. Nat Med 4, 1318-1320.

Cox, D., Chang, P., Zhang, Q., Reddy, P.G., Bokoch, G.M., and Greenberg, S. (1997). Requirements for both Rac1 and Cdc42 in membrane ruffling and phagocytosis in leukocytes. J Exp Med 186, 1487-1494. Danzer, K.M., Haasen, D., Karow, A.R., Moussaud, S., Habeck, M., Giese, A., Kretzschmar, H., Hengerer, B., and Kostka, M. (2007). Different species of alpha-synuclein oligomers induce calcium influx and seeding. J Neurosci 27, 9220-9232.

Datta, A., Kim, H., Lal, M., McGee, L., Johnson, A., Moustafa, A.A., Jones, J.C., Mondal, D., Ferrer, M., and Abdel-Mageed, A.B. (2017). Manumycin A suppresses exosome biogenesis and secretion via targeted inhibition of Ras/Raf/ERK1/2 signaling and hnRNP H1 in castration-resistant prostate cancer cells. Cancer Lett 408, 73-81.

Del Cid Pellitero, E., Shlaifer, R., Luo, W., Krahn, A., Nguyen-Renou, E., Manecka, D.-L., Rao, T., Beitel, L., and Durcan, T.M. (2019). Quality Control Characterization of $\alpha$-Synuclein Preformed Fibrils (PFFs).

Zenodo.

Desplats, P., Lee, H.-J., Bae, E.-J., Patrick, C., Rockenstein, E., Crews, L., Spencer, B., Masliah, E., and Lee, S.-J. (2009a). Inclusion formation and neuronal cell death through neuron-to-neuron transmission of $\alpha$ synuclein. Proceedings of the National Academy of Sciences 106, 13010-13015. 
Trafficking of pathological $\alpha$-synuclein

Desplats, P., Lee, H.J., Bae, E.J., Patrick, C., Rockenstein, E., Crews, L., Spencer, B., Masliah, E., and Lee, S.J. (2009b). Inclusion formation and neuronal cell death through neuron-to-neuron transmission of alpha-synuclein. Proc Natl Acad Sci U S A 106, 13010-13015.

Dieriks, B.V., Park, T.I., Fourie, C., Faull, R.L., Dragunow, M., and Curtis, M.A. (2017). alpha-synuclein transfer through tunneling nanotubes occurs in SH-SY5Y cells and primary brain pericytes from Parkinson's disease patients. Sci Rep 7, 42984.

Erami, Z., Khalil, B.D., Salloum, G., Yao, Y., LoPiccolo, J., Shymanets, A., Nürnberg, B., Bresnick, A.R., and Backer, J.M. (2017). Rac1-stimulated macropinocytosis enhances G $\beta \gamma$ activation of PI3K $\beta$. Biochemical Journal 474, 3903-3914.

Fortin, D.L., Troyer, M.D., Nakamura, K., Kubo, S., Anthony, M.D., and Edwards, R.H. (2004). Lipid rafts mediate the synaptic localization of alpha-synuclein. J Neurosci 24, 6715-6723.

Fujiwara, I., Zweifel, M.E., Courtemanche, N., and Pollard, T.D. (2018). Latrunculin A Accelerates Actin Filament Depolymerization in Addition to Sequestering Actin Monomers. Curr Biol 28, 3183-3192 e3182. Furstner, A., De Souza, D., Turet, L., Fenster, M.D., Parra-Rapado, L., Wirtz, C., Mynott, R., and Lehmann, C.W. (2007). Total syntheses of the actin-binding macrolides latrunculin A, B, C, M, S and 16-epilatrunculin B. Chemistry 13, 115-134.

Galvez, T., Teruel, M.N., Heo, W.D., Jones, J.T., Kim, M.L., Liou, J., Myers, J.W., and Meyer, T. (2007). siRNA screen of the human signaling proteome identifies the Ptdlns $(3,4,5)$ P3-mTOR signaling pathway as a primary regulator of transferrin uptake. Genome Biol 8, R142.

Grimmer, S., van Deurs, B., and Sandvig, K. (2002). Membrane ruffling and macropinocytosis in A431 cells require cholesterol. 115, 2953-2962.

Grozdanov, V., and Danzer, K.M. (2018). Release and uptake of pathologic alpha-synuclein. Cell Tissue Res 373, 175-182.

Gu, C., Yaddanapudi, S., Weins, A., Osborn, T., Reiser, J., Pollak, M., Hartwig, J., and Sever, S. (2010). Direct dynamin-actin interactions regulate the actin cytoskeleton. EMBO J 29, 3593-3606.

Hansen, C., Angot, E., Bergstrom, A.L., Steiner, J.A., Pieri, L., Paul, G., Outeiro, T.F., Melki, R., Kallunki, P., Fog, K., et al. (2011). alpha-Synuclein propagates from mouse brain to grafted dopaminergic neurons and seeds aggregation in cultured human cells. J Clin Invest 121, 715-725.

Henley, J.R., Krueger, E.W., Oswald, B.J., and McNiven, M.A. (1998). Dynamin-mediated internalization of caveolae. J Cell Biol 141, 85-99.

Hoffmann, A.C., Minakaki, G., Menges, S., Salvi, R., Savitskiy, S., Kazman, A., Vicente Miranda, H., Mielenz, D., Klucken, J., Winkler, J., et al. (2019). Extracellular aggregated alpha synuclein primarily triggers lysosomal dysfunction in neural cells prevented by trehalose. Sci Rep 9, 544. Holmes, B.B., DeVos, S.L., Kfoury, N., Li, M., Jacks, R., Yanamandra, K., Ouidja, M.O., Brodsky, F.M., Marasa, J., Bagchi, D.P., et al. (2013). Heparan sulfate proteoglycans mediate internalization and propagation of specific proteopathic seeds. Proc Natl Acad Sci U S A 110, E3138-3147.

Humphries, W.H.t., Szymanski, C.J., and Payne, C.K. (2011). Endo-lysosomal vesicles positive for Rab7 and LAMP1 are terminal vesicles for the transport of dextran. PLoS One 6, e26626.

Huotari, J., and Helenius, A. (2011). Endosome maturation. EMBO J 30, 3481-3500.

Ihse, E., Yamakado, H., van Wijk, X.M., Lawrence, R., Esko, J.D., and Masliah, E. (2017). Cellular internalization of alpha-synuclein aggregates by cell surface heparan sulfate depends on aggregate conformation and cell type. Sci Rep 7, 9008.

Iversen, T.G., Frerker, N., and Sandvig, K. (2012). Uptake of ricinB-quantum dot nanoparticles by a macropinocytosis-like mechanism. J Nanobiotechnology 10, 33.

Jao, C.C., Der-Sarkissian, A., Chen, J., and Langen, R. (2004). Structure of membrane-bound alphasynuclein studied by site-directed spin labeling. Proc Natl Acad Sci U S A 101, 8331-8336. 
Trafficking of pathological $\alpha$-synuclein

Jefri, M., Bell, S., Peng, H., Hettige, N., Maussion, G., Soubannier, V., Wu, H., Silveira, H., Theroux, J.F., Moquin, L., et al. (2020). Stimulation of L-type calcium channels increases tyrosine hydroxylase and dopamine in ventral midbrain cells induced from somatic cells. Stem Cells Transl Med 9, 697-712. Karpowicz, R.J., Jr., Haney, C.M., Mihaila, T.S., Sandler, R.M., Petersson, E.J., and Lee, V.M. (2017). Selective imaging of internalized proteopathic alpha-synuclein seeds in primary neurons reveals mechanistic insight into transmission of synucleinopathies. J Biol Chem 292, 13482-13497.

Kawahata, I., Sekimori, T., Wang, H., Wang, Y., Sasaoka, T., Bousset, L., Melki, R., Mizobata, T., Kawata, Y., and Fukunaga, K. (2021). Dopamine D2 Long Receptors Are Critical for Caveolae-Mediated alphaSynuclein Uptake in Cultured Dopaminergic Neurons. Biomedicines 9.

Kerr, M.C., and Teasdale, R.D. (2009). Defining macropinocytosis. Traffic 10, 364-371.

Kim, M.L., Sorg, I., and Arrieumerlou, C. (2011). Endocytosis-independent function of clathrin heavy chain in the control of basal NF-kappaB activation. PLoS One 6, e17158.

King, J.S., and Kay, R.R. (2019). The origins and evolution of macropinocytosis. Philos Trans R Soc Lond B Biol Sci 374, 20180158.

Koivusalo, M., Welch, C., Hayashi, H., Scott, C.C., Kim, M., Alexander, T., Touret, N., Hahn, K.M., and Grinstein, S. (2010). Amiloride inhibits macropinocytosis by lowering submembranous $\mathrm{pH}$ and preventing Rac1 and Cdc42 signaling. J Cell Biol 188, 547-563.

Konno, M., Hasegawa, T., Baba, T., Miura, E., Sugeno, N., Kikuchi, A., Fiesel, F.C., Sasaki, T., Aoki, M., Itoyama, Y., et al. (2012). Suppression of dynamin GTPase decreases alpha-synuclein uptake by neuronal and oligodendroglial cells: a potent therapeutic target for synucleinopathy. Mol Neurodegener 7, 38. Krueger, E.W., Orth, J.D., Cao, H., and McNiven, M.A. (2003). A dynamin-cortactin-Arp2/3 complex mediates actin reorganization in growth factor-stimulated cells. Mol Biol Cell 14, 1085-1096.

Kumar, S.T., Jagannath, S., Francois, C., Vanderstichele, H., Stoops, E., and Lashuel, H.A. (2020). How specific are the conformation-specific alpha-synuclein antibodies? Characterization and validation of 16 alpha-synuclein conformation-specific antibodies using well-characterized preparations of alphasynuclein monomers, fibrils and oligomers with distinct structures and morphology. Neurobiol Dis 146, 105086.

Lee, H.J., Choi, C., and Lee, S.J. (2002). Membrane-bound alpha-synuclein has a high aggregation propensity and the ability to seed the aggregation of the cytosolic form. J Biol Chem 277, 671-678.

Lee, H.J., Patel, S., and Lee, S.J. (2005). Intravesicular localization and exocytosis of alpha-synuclein and its aggregates. J Neurosci 25, 6016-6024.

Lee, H.J., Suk, J.E., Bae, E.J., Lee, J.H., Paik, S.R., and Lee, S.J. (2008). Assembly-dependent endocytosis and clearance of extracellular alpha-synuclein. Int J Biochem Cell Biol 40, 1835-1849.

Lee, H.J., Suk, J.E., Patrick, C., Bae, E.J., Cho, J.H., Rho, S., Hwang, D., Masliah, E., and Lee, S.J. (2010). Direct transfer of alpha-synuclein from neuron to astroglia causes inflammatory responses in synucleinopathies. J Biol Chem 285, 9262-9272.

Lee, J.G., Takahama, S., Zhang, G., Tomarev, S.I., and Ye, Y. (2016). Unconventional secretion of misfolded proteins promotes adaptation to proteasome dysfunction in mammalian cells. Nat Cell Biol 18, 765-776.

Lewy, F. (1912). Handbuch der Neurologie (Berlin: Julius Springer).

Li, J., Uversky, V.N., and Fink, A.L. (2002). Conformational Behavior of Human $\alpha$-Synuclein is Modulated by Familial Parkinson's Disease Point Mutations A30P and A53T. NeuroToxicology 23, 553-567.

Li, J.Y., Englund, E., Holton, J.L., Soulet, D., Hagell, P., Lees, A.J., Lashley, T., Quinn, N.P., Rehncrona, S., Bjorklund, A., et al. (2008). Lewy bodies in grafted neurons in subjects with Parkinson's disease suggest host-to-graft disease propagation. Nat Med 14, 501-503.

Li, J.Y., Englund, E., Widner, H., Rehncrona, S., Bjorklund, A., Lindvall, O., and Brundin, P. (2010). Characterization of Lewy body pathology in 12- and 16-year-old intrastriatal mesencephalic grafts surviving in a patient with Parkinson's disease. Mov Disord 25, 1091-1096. 
Trafficking of pathological $\alpha$-synuclein

Liu, J., Zhou, Y., Wang, Y., Fong, H., Murray, T.M., and Zhang, J. (2007). Identification of proteins involved in microglial endocytosis of alpha-synuclein. J Proteome Res 6, 3614-3627.

Luk, K.C., Covell, D.J., Kehm, V.M., Zhang, B., Song, I.Y., Byrne, M.D., Pitkin, R.M., Decker, S.C., Trojanowski, J.Q., and Lee, V.M. (2016). Molecular and Biological Compatibility with Host AlphaSynuclein Influences Fibril Pathogenicity. Cell Rep 16, 3373-3387.

Luk, K.C., Kehm, V., Carroll, J., Zhang, B., O'Brien, P., Trojanowski, J.Q., and Lee, V.M. (2012). Pathological alpha-synuclein transmission initiates Parkinson-like neurodegeneration in nontransgenic mice. Science 338, 949-953.

Luk, K.C., Song, C., O'Brien, P., Stieber, A., Branch, J.R., Brunden, K.R., Trojanowski, J.Q., and Lee, V.M. (2009). Exogenous alpha-synuclein fibrils seed the formation of Lewy body-like intracellular inclusions in cultured cells. Proc Natl Acad Sci U S A 106, 20051-20056.

Madeira, A., Yang, J., Zhang, X., Vikeved, E., Nilsson, A., Andren, P.E., and Svenningsson, P. (2011).

Caveolin-1 interacts with alpha-synuclein and mediates toxic actions of cellular alpha-synuclein overexpression. Neurochem Int 59, 280-289.

Maneca, D.-L., Luo, W., Krahn, A., Del Cid Pellitero, E., Shlaifer, I., Beitel, L.K., Rao, T., and Durcan, T.M. (2019). Production of Recombinant $\alpha$ Synuclein Monomers and Preformed Fibrils (PFFs). Zenodo. Mao, X., Ou, M.T., Karuppagounder, S.S., Kam, T.I., Yin, X., Xiong, Y., Ge, P., Umanah, G.E., Brahmachari, S., Shin, J.H., et al. (2016). Pathological alpha-synuclein transmission initiated by binding lymphocyteactivation gene 3 . Science 353.

Masaracchia, C., Hnida, M., Gerhardt, E., Lopes da Fonseca, T., Villar-Pique, A., Branco, T., Stahlberg, M.A., Dean, C., Fernandez, C.O., Milosevic, I., et al. (2018). Membrane binding, internalization, and sorting of alpha-synuclein in the cell. Acta Neuropathol Commun 6, 79.

Masuda-Suzukake, M., Nonaka, T., Hosokawa, M., Kubo, M., Shimozawa, A., Akiyama, H., and Hasegawa, M. (2014). Pathological alpha-synuclein propagates through neural networks. Acta Neuropathol Commun 2, 88.

Masuda-Suzukake, M., Nonaka, T., Hosokawa, M., Oikawa, T., Arai, T., Akiyama, H., Mann, D.M., and Hasegawa, M. (2013). Prion-like spreading of pathological alpha-synuclein in brain. Brain 136, 11281138.

Mayor, S., and Pagano, R.E. (2007). Pathways of clathrin-independent endocytosis. Nat Rev Mol Cell Biol 8, 603-612.

Mercer, J., and Helenius, A. (2009). Virus entry by macropinocytosis. Nat Cell Biol 11, 510-520. Mills, I.G., Jones, A.T., and Clague, M.J. (1998). Involvement of the endosomal autoantigen EEA1 in homotypic fusion of early endosomes. Current Biology 8, 881-884.

Morton, W.M., Ayscough, K.R., and McLaughlin, P.J. (2000). Latrunculin alters the actin-monomer subunit interface to prevent polymerization. Nat Cell Biol 2, 376-378.

Mougenot, A.L., Nicot, S., Bencsik, A., Morignat, E., Verchere, J., Lakhdar, L., Legastelois, S., and Baron, T. (2012). Prion-like acceleration of a synucleinopathy in a transgenic mouse model. Neurobiol Aging 33, 2225-2228.

Mulherkar, N., Raaben, M., de la Torre, J.C., Whelan, S.P., and Chandran, K. (2011). The Ebola virus glycoprotein mediates entry via a non-classical dynamin-dependent macropinocytic pathway. Virology $419,72-83$.

Nakamura, K., Nemani, V.M., Wallender, E.K., Kaehlcke, K., Ott, M., and Edwards, R.H. (2008). Optical reporters for the conformation of alpha-synuclein reveal a specific interaction with mitochondria. J Neurosci 28, 12305-12317.

Nakase, I., Kobayashi, N.B., Takatani-Nakase, T., and Yoshida, T. (2015). Active macropinocytosis induction by stimulation of epidermal growth factor receptor and oncogenic Ras expression potentiates cellular uptake efficacy of exosomes. Sci Rep 5, 10300. 
Trafficking of pathological $\alpha$-synuclein

Oh, P., McIntosh, D.P., and Schnitzer, J.E. (1998). Dynamin at the neck of caveolae mediates their budding to form transport vesicles by GTP-driven fission from the plasma membrane of endothelium. J Cell Biol 141, 101-114.

Oh, S.H., Kim, H.N., Park, H.J., Shin, J.Y., Bae, E.J., Sunwoo, M.K., Lee, S.J., and Lee, P.H. (2016). Mesenchymal Stem Cells Inhibit Transmission of alpha-Synuclein by Modulating Clathrin-Mediated Endocytosis in a Parkinsonian Model. Cell Rep 14, 835-849.

Park, J.Y., Kim, K.S., Lee, S.B., Ryu, J.S., Chung, K.C., Choo, Y.K., Jou, I., Kim, J., and Park, S.M. (2009). On the mechanism of internalization of alpha-synuclein into microglia: roles of ganglioside GM1 and lipid raft. J Neurochem 110, 400-411.

Park, R.J., Shen, H., Liu, L., Liu, X., Ferguson, S.M., and De Camilli, P. (2013). Dynamin triple knockout cells reveal off target effects of commonly used dynamin inhibitors. J Cell Sci 126, 5305-5312.

Pelkmans, L., Puntener, D., and Helenius, A. (2002). Local actin polymerization and dynamin recruitment in SV40-induced internalization of caveolae. Science 296, 535-539.

Preta, G., Cronin, J.G., and Sheldon, I.M. (2015). Dynasore - not just a dynamin inhibitor. Cell Commun Signal 13, 24.

Recasens, A., and Dehay, B. (2014). Alpha-synuclein spreading in Parkinson's disease. Front Neuroanat 8 , 159.

Recasens, A., Ulusoy, A., Kahle, P.J., Di Monte, D.A., and Dehay, B. (2018). In vivo models of alphasynuclein transmission and propagation. Cell Tissue Res 373, 183-193.

Reyes, J.F., Rey, N.L., Bousset, L., Melki, R., Brundin, P., and Angot, E. (2014). Alpha-synuclein transfers from neurons to oligodendrocytes. Glia 62, 387-398.

Rink, J., Ghigo, E., Kalaidzidis, Y., and Zerial, M. (2005). Rab conversion as a mechanism of progression from early to late endosomes. Cell 122, 735-749.

Rodriguez, L., Marano, M.M., and Tandon, A. (2018). Import and Export of Misfolded alpha-Synuclein. Front Neurosci 12, 344.

Samuel, F., Flavin, W.P., Iqbal, S., Pacelli, C., Sri Renganathan, S.D., Trudeau, L.E., Campbell, E.M., Fraser, P.E., and Tandon, A. (2016). Effects of Serine 129 Phosphorylation on alpha-Synuclein Aggregation, Membrane Association, and Internalization. J Biol Chem 291, 4374-4385.

Sandal, M., Valle, F., Tessari, I., Mammi, S., Bergantino, E., Musiani, F., Brucale, M., Bubacco, L., and Samori, B. (2008). Conformational equilibria in monomeric alpha-synuclein at the single-molecule level. PLoS Biol 6, e6.

Schlunck, G., Damke, H., Kiosses, W.B., Rusk, N., Symons, M.H., Waterman-Storer, C.M., Schmid, S.L., and Schwartz, M.A. (2004). Modulation of Rac localization and function by dynamin. Mol Biol Cell 15, 256-267.

Shahmoradian, S.H., Lewis, A.J., Genoud, C., Hench, J., Moors, T.E., Navarro, P.P., Castano-Diez, D., Schweighauser, G., Graff-Meyer, A., Goldie, K.N., et al. (2019). Lewy pathology in Parkinson's disease consists of crowded organelles and lipid membranes. Nat Neurosci 22, 1099-1109.

Shearer, L.J., Petersen, N.O., and Woodside, M.T. (2021). Internalization of alpha-synuclein oligomers into SH-SY5Y cells. Biophys J.

Sigismund, S., Woelk, T., Puri, C., Maspero, E., Tacchetti, C., Transidico, P., Di Fiore, P.P., and Polo, S. (2005). Clathrin-independent endocytosis of ubiquitinated cargos. Proc Natl Acad Sci U S A 102, 2760 2765.

Spillantini, M.G., Schmidt, M.L., Lee, V.M.-Y., Trojanowski, J.Q., Jakes, R., and Goedert, M.J.N. (1997). $\alpha-$ Synuclein in Lewy bodies. 388, 839-840.

Stephen, T.L., Fabri, M., Groneck, L., Rohn, T.A., Hafke, H., Robinson, N., Rietdorf, J., Schrama, D., Becker, J.C., Plum, G., et al. (2007). Transport of Streptococcus pneumoniae capsular polysaccharide in MHC Class II tubules. PLoS Pathog 3, e32. 
Trafficking of pathological $\alpha$-synuclein

Sung, J.Y., Kim, J., Paik, S.R., Park, J.H., Ahn, Y.S., and Chung, K.C. (2001). Induction of neuronal cell death by Rab5A-dependent endocytosis of alpha-synuclein. J Biol Chem 276, 27441-27448.

Tanaka, M., Kim, Y.M., Lee, G., Junn, E., Iwatsubo, T., and Mouradian, M.M. (2004). Aggresomes formed by alpha-synuclein and synphilin-1 are cytoprotective. J Biol Chem 279, 4625-4631.

Trischler, M., Stoorvogel, W., and Ullrich, O. (1999). Biochemical analysis of distinct Rab5- and Rab11positive endosomes along the transferrin pathway. 112, 4773-4783.

Underwood, R., Wang, B., Pathak, A., Volpicelli-Daley, L., and Yacoubian, T.A. (2020). Rab27 GTPases regulate alpha-synuclein uptake, cell-to-cell transmission, and toxicity. bioRxiv.

Vargas, K.J., Schrod, N., Davis, T., Fernandez-Busnadiego, R., Taguchi, Y.V., Laugks, U., Lucic, V., and Chandra, S.S. (2017). Synucleins Have Multiple Effects on Presynaptic Architecture. Cell Rep 18, 161-173. Volpicelli-Daley, L.A., Luk, K.C., and Lee, V.M. (2014). Addition of exogenous alpha-synuclein preformed fibrils to primary neuronal cultures to seed recruitment of endogenous alpha-synuclein to Lewy body and Lewy neurite-like aggregates. Nat Protoc 9, 2135-2146.

Volpicelli-Daley, L.A., Luk, K.C., Patel, T.P., Tanik, S.A., Riddle, D.M., Stieber, A., Meaney, D.F., Trojanowski, J.Q., and Lee, V.M. (2011). Exogenous alpha-synuclein fibrils induce Lewy body pathology leading to synaptic dysfunction and neuron death. Neuron 72, 57-71.

Wakatsuki, T., Schwab, B., Thompson, N.C., and Elson, E.L. (2001). Effects of cytochalasin D and latrunculin B on mechanical properties of cells. Journal of Cell Science 114, 1025-1036.

Westphal, C.H., and Chandra, S.S. (2013). Monomeric synucleins generate membrane curvature. J Biol Chem 288, 1829-1840.

Williams, T.D., and Kay, R.R. (2018). The physiological regulation of macropinocytosis during Dictyostelium growth and development. 131, jcs213736.

Willox, A.K., Sahraoui, Y.M., and Royle, S.J. (2014). Non-specificity of Pitstop 2 in clathrin-mediated endocytosis. Biol Open 3, 326-331.

Yoshida, S., Pacitto, R., Inoki, K., and Swanson, J. (2018). Macropinocytosis, mTORC1 and cellular growth control. Cell Mol Life Sci 75, 1227-1239.

Zeineddine, R., Pundavela, J.F., Corcoran, L., Stewart, E.M., Do-Ha, D., Bax, M., Guillemin, G., Vine, K.L., Hatters, D.M., Ecroyd, H., et al. (2015). SOD1 protein aggregates stimulate macropinocytosis in neurons to facilitate their propagation. Mol Neurodegener 10, 57.

Zhang, Q., Xu, Y., Lee, J., Jarnik, M., Wu, X., Bonifacino, J.S., Shen, J., and Ye, Y. (2020). A myosin-7Bdependent endocytosis pathway mediates cellular entry of alpha-synuclein fibrils and polycation-bearing cargos. Proc Natl Acad Sci U S A 117, 10865-10875.

Zhang, W., Wang, T., Pei, Z., Miller, D.S., Wu, X., Block, M.L., Wilson, B., Zhang, W., Zhou, Y., Hong, J.S., et al. (2005). Aggregated alpha-synuclein activates microglia: a process leading to disease progression in Parkinson's disease. FASEB J 19, 533-542.

Zwartkruis, F.J., and Burgering, B.M. (2013). Ras and macropinocytosis: trick and treat. Cell Res 23, 982983. 
bioRxiv preprint doi: https://doi.org/10.1101/2022.01.06.475207; this version posted January 7, 2022. The copyright holder for this preprint (which was not certified by peer review) is the author/funder. All rights reserved. No reuse allowed without permission.

\section{Trafficking of pathological $\alpha$-synuclein}

\section{Tables}

Table 1: previous studies on $\alpha$-syn endocytosis

\begin{tabular}{|c|c|c|c|c|c|}
\hline Type of $\alpha$-syn & Inhibition/Inhibitors used & $\begin{array}{l}\text { Incubation } \\
\text { time } \\
\text { following } \\
\alpha \text {-syn } \\
\text { addition } \\
\end{array}$ & $\begin{array}{l}\text { Reported } \\
\text { Intracellular } \\
\text { trafficking }\end{array}$ & Findings & Publication \\
\hline Monomer & & $1 \mathrm{~h}$ & Rab5A & Rab5A-mediated uptake of $\alpha$-syn & $\begin{array}{l}\text { (Sung et al., } \\
\text { 2001) }\end{array}$ \\
\hline Fibril & Cytochalasin D & 2 and $12 \mathrm{~h}$ & & $\begin{array}{l}\text { Cytochalasin } D \text { treatment resulted in } \\
\text { decreased } \alpha \text {-syn uptake in microglia }\end{array}$ & $\begin{array}{l}\text { (Zhang et } \\
\text { al., 2005) }\end{array}$ \\
\hline Fibril & & $3 \mathrm{~h}$ & & $\begin{array}{l}\text { Co-immunoprecipitation of clathrin and } \alpha \text { - } \\
\text { syn; colocalization of } \alpha \text {-syn and clathrin }\end{array}$ & $\begin{array}{l}\text { (Liu et al., } \\
\text { 2007) }\end{array}$ \\
\hline Fibril & dynamin-1 K44A & $1 \mathrm{~h}$ & $\begin{array}{l}\text { Partial } \\
\text { colocalization } \\
\text { of } \alpha \text {-syn with } \\
\text { EEA1 and } \\
\text { LAMP2. }\end{array}$ & $\begin{array}{l}\text { Internalization of } \alpha \text {-syn fibrils was inhibited } \\
\text { by low temperature and dynamin dominant } \\
\text { negative, while monomeric } \alpha \text {-syn entered } \\
\text { cells through diffusion. Concluded that } \\
\text { endolysosomal pathway is involved. }\end{array}$ & $\begin{array}{l}\text { (Lee et al., } \\
2008)\end{array}$ \\
\hline Monomer & $\begin{array}{l}\text { Dynamin dominant negative } \\
\text { and dynasore }\end{array}$ & $1 \mathrm{~h}$ & & $\begin{array}{l}\text { Internalization of } \alpha \text {-syn was not inhibited with } \\
\text { dynamin dominant negative nor dynasore, } \\
\text { but is lipid-raft mediated. }\end{array}$ & $\begin{array}{l}\text { (Park et al., } \\
\text { 2009) }\end{array}$ \\
\hline $\begin{array}{l}\text { Cellular synuclein } \\
\text { expression }\end{array}$ & $\begin{array}{l}\text { Dynamin-1 K44A (dominant } \\
\text { negative) }\end{array}$ & 24 and $48 \mathrm{~h}$ & & $\begin{array}{l}\text { Synuclein transmission was inhibited with the } \\
\text { use of dynamin dominant negative }\end{array}$ & $\begin{array}{l}\text { (Desplats et } \\
\text { al., 2009b) }\end{array}$ \\
\hline $\begin{array}{l}\text { Vector expression } \\
\text { of } \alpha \text {-syn }\end{array}$ & Dynamin dominant negative & $\begin{array}{l}\text { Coculture - } \\
3 \text { days }\end{array}$ & $\begin{array}{l}\text { Endolysosomal } \\
\text { system }\end{array}$ & $\begin{array}{l}\text { a-syn endocytosis is inhibited in cells } \\
\text { expressing dynamin dominant negative }\end{array}$ & $\begin{array}{l}\text { (Lee et al., } \\
2010)\end{array}$ \\
\hline $\begin{array}{l}\text { Transfected and } \\
\text { exogenous } \alpha \text {-syn } \\
\text { monomer }\end{array}$ & $\begin{array}{l}\text { Dynasore, } \\
\text { monodansylcadaverine }\end{array}$ & $\begin{array}{l}\text { Coculture, } \\
\text { injection in } \\
\text { rat cortex }\end{array}$ & & $\begin{array}{l}\text { a-syn endocytosis and transfer occurs in a } \\
\text { dynamin dependent manner }\end{array}$ & $\begin{array}{l}\text { (Hansen et } \\
\text { al., 2011) }\end{array}$ \\
\hline Monomeric $\alpha$-syn & $\begin{array}{l}\text { siRNA knockdown of } \\
\text { dynamin, inhibition of } \\
\text { dynamin GTPase activity by } \\
\text { sertraline }\end{array}$ & $24 \mathrm{~h}$ & $\begin{array}{l}\text { Rab5A and } \\
\text { LAMP1 }\end{array}$ & $\begin{array}{l}\text { Synuclein endocytosis was decreased by } \\
\text { inhibiting dynamin GTPases }\end{array}$ & $\begin{array}{l}\text { (Konno et } \\
\text { al., 2012) }\end{array}$ \\
\hline $\begin{array}{l}\text { Tau and } \alpha-s y n \\
\text { fibrils, TAT }\end{array}$ & $\begin{array}{l}\text { Inhibition of tau uptake via } \\
\text { Cytochalasin, Latrunculin, } \\
\text { Rottlerin, Amiloride. Tau } \\
\text { uptake not inhibited by } \\
\text { dynasore. } \\
\text { a-syn uptake was inhibited by } \\
\text { heparin and chlorate }\end{array}$ & 3 and $5 \mathrm{~h}$ & & $\begin{array}{l}\text { When administered together, tau, TAT, and } \\
\text { a-syn colocalize, suggesting } \alpha \text {-syn fibrils are } \\
\text { endocytosed via macropinocytosis. Tau } \\
\text { fibrils did not colocalize with clathrin } \\
\text { antibody. }\end{array}$ & $\begin{array}{l}\text { (Holmes et } \\
\text { al., 2013) }\end{array}$ \\
\hline $\begin{array}{l}\text { Monomer, oligomer } \\
\text { and fibril }\end{array}$ & Dynasore & $\begin{array}{l}0,3,6,12,24 \\
\mathrm{~h}\end{array}$ & & $\begin{array}{l}\text { Dynasore inhibited synuclein uptake, in a } \\
\text { concentration-dependent manner }\end{array}$ & $\begin{array}{l}\text { (Reyes et } \\
\text { al., 2014) }\end{array}$ \\
\hline $\begin{array}{l}\text { Transfection: } \alpha \text {-syn } \\
\text { expression }\end{array}$ & Dynasore, Pitstop 2, & & $\begin{array}{l}\text { EEA1, NR1, } \\
\text { NR2A }\end{array}$ & Clathrin-mediated internalization of $\alpha$-syn & $\begin{array}{l}\text { (Oh et al., } \\
2016)\end{array}$ \\
\hline Fibril & EIPA & & & $\begin{array}{l}\alpha \text {-syn induced membrane ruffling, but its } \\
\text { internalization was not inhibited by EIPA, a } \\
\text { macropinocytic inhibitor }\end{array}$ & $\begin{array}{l}\text { (Zeineddine } \\
\text { et al., 2015) }\end{array}$ \\
\hline Fibrils & Dynamin 1 dominant negative & $1 \mathrm{~h}$ & LAMP1 & $\begin{array}{l}\text { Dynamin is partially required for the uptake, } \\
\text { but not the intercellular transfer of } \alpha \text {-syn } \\
\text { fibrils. }\end{array}$ & $\begin{array}{l}\text { (Abounit et } \\
\text { al., 2016) }\end{array}$ \\
\hline $\begin{array}{l}\text { Fibrils and } \\
\text { phospho-fibrils }\end{array}$ & Dynasore & $20 \min$ & & $\begin{array}{l}\text { Inhibition of clathrin-mediated endocytosis } \\
\text { through dynasore; decrease uptake of fibrils }\end{array}$ & $\begin{array}{l}\text { (Samuel et } \\
\text { al., 2016) }\end{array}$ \\
\hline Fibrils & LAG3 KO, LAG3 antibodies & $\begin{array}{l}5,10,20 \\
\text { min and } \\
\text { more }\end{array}$ & $\begin{array}{l}\text { Rab5, Rab7, } \\
\text { LAMP1 }\end{array}$ & $\begin{array}{l}\text { LAG3 mediated endocytosis of a-syn PFF, } \\
\text { which then undergo receptor mediated } \\
\text { endocytosis }\end{array}$ & $\begin{array}{l}\text { (Mao et al., } \\
2016 \text { ) }\end{array}$ \\
\hline Fibrils & chloroquine & $\begin{array}{l}3,15,60 \mathrm{~min} \\
\text { and longer }\end{array}$ & $\begin{array}{l}\text { Endolysosomal } \\
\text { pathway, } \\
\text { LAMP1 staining }\end{array}$ & $\begin{array}{l}\text { PFF are transported through the } \\
\text { endolysosomal pathway }\end{array}$ & $\begin{array}{l}\text { (Karpowicz } \\
\text { et al., 2017) }\end{array}$ \\
\hline Fibrils & & 4 and $24 \mathrm{~h}$ & & $\begin{array}{l}\text { Amyloid fibrils depend on Heparan sulfate for } \\
\text { internalization }\end{array}$ & $\begin{array}{l}\text { (Ihse et al., } \\
2017 \text { ) }\end{array}$ \\
\hline Monomer and fibril & Dyngo, Pitstop & $24 \mathrm{~h}$ & $\begin{array}{l}\text { Endosomal } \\
\text { maturation, and } \\
\text { finally } \\
\text { lysosomes }\end{array}$ & $\begin{array}{l}\text { a-syn monomers use dynamin-mediated } \\
\text { endocytosis, colocalize with Rab4, } 5 \text {, and } 7, \\
\text { and trafficking through the endosomal } \\
\text { system. } \alpha \text {-syn fibrils undertake a different } \\
\text { pathway }\end{array}$ & $\begin{array}{l}\text { (Masaracchi } \\
\text { a et al., } \\
\text { 2018) }\end{array}$ \\
\hline $\begin{array}{l}\text { Monomer, oligomer } \\
\text { and fibril }\end{array}$ & & $24 \mathrm{~h}$ & $\begin{array}{l}\text { Colocalization } \\
\text { with endosomal } \\
\text { and lysosomal } \\
\text { markers }\end{array}$ & $\begin{array}{l}\text { Clathrin-mediated endocytosis of } \alpha \text {-syn } \\
\text { colocalization of synuclein and transferrin }\end{array}$ & $\begin{array}{l}\text { (Hoffmann } \\
\text { et al., 2019) }\end{array}$ \\
\hline Monomer and fibril & Dynasore, caveolin-1 siRNA, & $48 \mathrm{~h}$ & & $\begin{array}{l}\text { Caveolae-dependent uptake of } \alpha \text {-syn in } \\
\text { dopaminergic neurons }\end{array}$ & $\begin{array}{l}\text { (Kawahata } \\
\text { et al., 2021) }\end{array}$ \\
\hline $\begin{array}{l}\text { Various oligomers } \\
\text { (varying sizes) }\end{array}$ & Pitstop & $2 \mathrm{~h}$ & $\begin{array}{l}\text { Rab5 and } \\
\text { LAMP-1 }\end{array}$ & $\begin{array}{l}\text { Larger oligomers are more dependent on } \\
\text { clathrin-mediated endocytosis, colocalization } \\
\text { with early endosomes and lysosomes }\end{array}$ & $\begin{array}{l}\text { (Shearer et } \\
\text { al., 2021) }\end{array}$ \\
\hline
\end{tabular}


Trafficking of pathological $\alpha$-synuclein

\section{Main Figures}

Figure 1. Rapid internalization and transport of PFF to lysosomes. (A) U2OS cells were stained with Lyso-Cytopainter and placed in a live-cell imaging chamber at $37^{\circ} \mathrm{C}$. Imaging was performed at 1 frame/sec. PFF tagged with Alexa488 at $2 \mu \mathrm{g} / \mathrm{mL}$ was added to cells while imaging. PFF (green) colocalization with lysosomes (red) can be seen in as early as 1 min in both low mag and inset. Arrowheads point to lysosomes accumulating PFF. Scale bars $=10 \mu \mathrm{m}$ for low mag images, and $5 \mu \mathrm{m}$ for insets. Inset location shown at $-1 \mathrm{~min}$. (B/C) Quantification of PFF uptake and colocalization with LAMP1 in U2OS. Cells were plated on coverslips and transfected with LAMP1-TurboRFP. PFF were added to each coverslip at $2 \mu \mathrm{g} / \mathrm{ml}$. Cells were incubated for $0,2,10,30$ min at $37^{\circ} \mathrm{C}$ following addition of PFF. Cells were washed with trypsin and fixed. PFF colocalization with LAMP1 can be seen in as early as 2 min using confocal microscopy. $n=12$ for each condition (i.e., $n=120$ total), from three independent experiments, mean \pm SEM; one-way ANOVA; multiple comparisons Tukey's test was conducted to assess significance from control. $p<0.0001$ denoted as ***. (D) PFF uptake in U2OS cells was quantified over the course of 72 h. PFF endocytosis plateaus at 24 h. $n=5$ for each condition (i.e., $n=40$ ). (E) Lysosomes were immunoprecipitated from U2OS cells stably expressing HATMEM192-RFP using HA-magnetic beads. Starting material (SM), unbound material (UB), and Immunoprecipitated (IP) sample for each time point were collected and processed for Western blot with the indicated antibodies. (F) IP samples from the experiments in $\mathbf{E}$ were fixed and placed on coverslips and imaged using confocal microscopes. HA-TMEM192-RFP construct allowed us to visualize the lysosomes (red), many of which contained PFF tagged with Alexa Fluor 488 (green). Scale bars $=5 \mu \mathrm{m}$ for low mag and $2.5 \mu \mathrm{m}$ for inset. (G) Confocal samples of U2OS cells described as in A imaged using STED microscopy. Scale bar $=10 \mu \mathrm{m}$ for low magnification, and $0.5 \mu \mathrm{m}$ for insets. 
Trafficking of pathological $\alpha$-synuclein

Figure 2. Rapid PFF colocalization with lysosomes in human dopaminergic NPCs, dopaminergic neurons, and astrocytes. (A) Dopaminergic NPCs were incubated for 0, 2, 10, $30 \mathrm{~min}$ at $37^{\circ} \mathrm{C}$ following addition of Alex488-labelled PFF at $2 \mu \mathrm{g} / \mathrm{mL}$. The cells were then washed with trypsin, fixed, and stained with lysotracker. Scale bar $=20 \mu \mathrm{m}$. (B) NPCs differentiated into dopaminergic neurons were processed as in A. Scale bar $=20 \mu \mathrm{m}$. (C) Human astrocytes were grown and mounted on coverslips. PFF was added to each coverslip at $1 \mu \mathrm{g} / \mathrm{ml}$. Cells were incubated for $0,2,10,30 \mathrm{~min}$ at $37^{\circ} \mathrm{C}$ following addition of Alex488-labelled PFF. Cells were washed with trypsin, fixed, permeabilized, and stained with LAMP1. Scale bar $=20 \mu \mathrm{m}$ and $2.5 \mu \mathrm{m}$ insets. (D/E) Colocalization of Lysotracker with PFF from experiments as in A and B. $n=6$ for neurons and $n=6$ for NPCs in each condition (i.e., $n=48$ total), performed in three independent experiments. (F) Colocalization rate of LAMP1 with PFF from experiments as in A. $n=9$ for each condition (i.e., $n=36$ total), from three independent experiments, mean \pm SEM; one-way ANOVA; multiple comparisons Tukey's test was conducted to assess significance from control. $\mathrm{p}<0.0001$ denoted as ${ }^{* * *}$.

Figure 3. PFF remains in lysosomes days after exposure in dopaminergic neurons and astrocytes. (A) Dopaminergic neurons derived from human iPSCs mounted onto coverslips were given PFF488 at $2 \mu \mathrm{g} / \mathrm{ml}$ on ice for $1 \mathrm{~h}$. Cells were removed from ice, given fresh media and were then incubated for $0 \mathrm{~h}, 1$ day or 7 days at $37^{\circ} \mathrm{C}$. Following incubation, cells were trypsin washed and fixed. Lysosomes were stained using LAMP1 (red) antibody. PFF remains localized to lysosomes 7 days following its addition to the cell. Scale bar $=20 \mu \mathrm{m}$ for low magnification and $5 \mu \mathrm{m}$ for insets. (B) Human astrocytes were mounted on coverslips and treated as described in A. PFF fluorescence builds in lysosomes over 7 days. Arrowheads point to LAMP1 and PFF colocalization. Scale bar $=20 \mu \mathrm{m}$ for low magnification and $5 \mu \mathrm{m}$ for insets. 
Trafficking of pathological $\alpha$-synuclein

Figure 4. PFF endocytosis is unaffected by CHC KD but decreased using macropinocytic inhibitors. (A) U2OS cells previously transfected with EBFP2-LAMP1 were transfected with CHC siRNA or control siRNA. Cell lysates were immunoblotted with antibodies recognizing the indicated proteins (B) At $24 \mathrm{~h}$, control and CHC siRNA-treated cells were re-plated as a mosaic onto coverslips. PFF was added to each coverslip at $2 \mu \mathrm{g} / \mathrm{ml}$. Cells were incubated for $0,2,10$, $30 \mathrm{~min}$ at $37^{\circ} \mathrm{C}$ following addition of PFF. Cells were washed with trypsin and fixed. Arrowheads show large LAMP1- and PFF-positive vesicles in both $\mathrm{CHC}$ positive and $\mathrm{CHC}$ negative cells. KD cells are outlined with dashed lines. Scale bar $=20 \mu \mathrm{m}$. (C) Internalization of PFF in CHC KD vs control cells at 2 min were quantified from experiments as in B. $n=6$ for each condition (i.e., $n=$ 12 total), from three independent experiments, mean \pm SEM; unpaired t-test; $p>0.05$ denoted as ns for not significant. (D) Astrocytes were grown and mounted on coverslips. Cell media was replaced with serum-free media containing $20 \mu \mathrm{M}$ EIPA, $5 \mu \mathrm{M}$ LatB or DMSO (vehicle control) for $30 \mathrm{~min}$. PFF (green) was added to each coverslip at $2 \mu \mathrm{g} / \mathrm{ml}$ for $0,2,10,30 \mathrm{~min}$ at $37^{\circ} \mathrm{C}$. Cells were trypsin washed and fixed. Cell nuclei were stained with DRAQ7. Scale bar $=20 \mu \mathrm{m}$. (E/F) Quantification of PFF and EGF uptake from experiments as in D. At each timepoint, control was compared to LatB and EIPA using unpaired samples t-test. $n=8$ for each condition (i.e., $n=48$ total), from three independent experiments, mean \pm SEM; one-way ANOVA done for neurons and NPC separately; multiple comparisons Tukey's test was conducted to assess significance from control; $p<0.001$ denoted as ${ }^{* * *}$ and $p<0.0001$ denoted as ${ }^{* * *}$. (G). Human dopaminergic NPCs were treated with LatA and PFF for $24 \mathrm{~h}$ before fixation. $y$-axis: \% intracellular PFF-Alexa fluorescence relative to DMSO (vehicle) only control (DMSO=100\%). Xaxis: Latrunculin $\mathrm{A}$ treatment concentration in $\mu \mathrm{M}$.

Figure 5. Trafficking itinerary of PFF revealed by nanogold-labelled PFF and EM. (A) Early events involved in the internalization of PFF were captured with EM. To allow direct detection, PFF were conjugated with $5 \mathrm{~nm}$ gold. Astrocytes were plated on permanox 8 well plates, 
Trafficking of pathological $\alpha$-synuclein

administered PFF-gold for 2-3 min, fixed, and processed for EM. Uranyl acetate staining was conducted both pre-embedding and post-embedding (on the grid). (i) shows the membrane protrusion/ruffle forming around PFF-gold and the subsequent closure of the ruffle, leading to the internalization of PFF. (ii) shows the a closed membrane ruffle, leading to a macropinosome containing PFF-gold. (iii) shows the internalized PFF in a macropinosome. (iv) shows PFF in large forming MVBs in proximity to the membrane, suggesting PFF and membrane interaction. Scale bar $=200 \mathrm{~nm}$ for low magnification images, and $50 \mathrm{~nm}$ for insets. (B) Images of PFF detected under a membrane ruffle and dextran at the open mouth of a highly curved coated vesicular structure. (C) In order to visualize the contents of lysosomes, which appear as highly electron dense using EM, astrocytes exposed to PFF for 3-5 min were fixed and processed for EM; however, only en bloc uranyl acetate staining was conducted. Without staining of grids using uranyl acetate, PFF was easily visualized in multiple electron dense, lysosomal structures. Scale bar $=100 \mathrm{~nm}$. (D) Uranyl-stained grids show highly electron dense lysosomes with PFF contents. Scale bar $=100 \mathrm{~nm}$ and $50 \mathrm{~nm}$ for insets.

Figure 6. PFF trafficking to lysosomes and MVBs. (A) Astrocytes administered PFF for 10 min localize PFF in larger newly forming MVBs, always in proximity to the vesicular membrane, sometimes causing invaginations, signifying the early stages of exosome formation. Scale bar = $100 \mathrm{~nm}$ for low magnification, $80 \mathrm{~nm}$ for moderate magnification, $50 \mathrm{~nm}$ for highest magnification inset. (B) Localization of PFF outside of vesicles in electron dense MVBs signifies the progression of MVB maturation. Scale bar= $100 \mathrm{~nm}$ and $50 \mathrm{~nm}$ for inset. (C) Similar findings regarding the formation of MVBs (LAMP1 positive; red) containing PFF (green) was confirmed using STED microscopy. Scale bar $=20 \mu \mathrm{m}$ for low magnification, and $2.5 \mu \mathrm{m}$ for high magnification images. (D) Large-field image showing colocalization of PFF with lysosomes. Arrows point to the appearance of large multi-vesicular structure at $20 \mathrm{~min}$. Enhancement of lysosomal structures and their contents at 0 and 20 min was carried out using "Find Edges" 
Trafficking of pathological $\alpha$-synuclein

function in ImageJ, showing hollow lysosomal structures. (E) Scale bar $=10 \mu \mathrm{m}$. Higher magnification of images in D showing multiple budding events (arrowheads). Scale bar $=5 \mu \mathrm{m}$.

Figure 7. PFF containing exosomes play a role in the transmission of PFF from donor to acceptor cells. (A) U2OS cells stably expressing CD63-GFP were exposed to PFF or PBS (vehicle control) for $24 \mathrm{~h}$. CD63-GFP (donor cells) were then trypsin washed three times, pelleted, trypsinized again, pelleted and PBS washed, prior to being co-plated with acceptor cells (PFF naïve cells stably expressing LAMP1-RFP). Donor and Acceptor cells were then incubated for 12 or $24 \mathrm{~h}$. Half of the $24 \mathrm{~h}$ sample were given Manumycin A (MA) at $1.2 \mu \mathrm{M}$ while the other half was given DMSO (vehicle control) at the time of plating. Both $12 \mathrm{~h}$ and $24 \mathrm{~h}$ samples show PFF and CD63 fluorescence in acceptor cells, while the acceptor cells in the PBS and the MA condition show very little PFF and CD63 fluorescence. Arrows point to LAMP1 positive compartments in acceptor cells that contain both CD63 and PFF fluorescence within them. Scale bar $=10 \mu \mathrm{m}$ for low magnification and $5 \mu \mathrm{m}$ for insets. (B/C) Quantification of CD63 and PFF fluorescence in acceptor cells, respectively. $n=8$ for each condition (i.e., $n=36$ total), from three independent experiments, mean \pm SEM. No PFF, $12 \mathrm{~h}$ and $24 \mathrm{~h}$ condition were statistically compared to the $24 \mathrm{~h}$ samples with MA; $p<0.0001$ denoted as ${ }^{* * *}, \mathrm{p}<0.01$ denoted as ${ }^{* *}$. There was a significant reduction in CD63 and PFF in acceptor cells with MA was administered. (D) At $24 \mathrm{~h}$ following the exposure of donor cells (CD63 positive) to PFF, cells were thoroughly trypsin washed and passaged onto plates and incubated for $48 \mathrm{~h}$. The media was then collected, centrifuged for $5 \mathrm{~min}$ at 1000 RPM to pellet any floating cells, and given to acceptor cells (U2OS cells transiently expressing LAMP1-RFP). The cells were fixed $1 \mathrm{~h}$ after and processed for EM. Scale bar $=100 \mathrm{~nm}$ for low magnification images and $100 \mathrm{~nm}$ for inset. 
Trafficking of pathological $\alpha$-synuclein

\section{Supplementary Figures}

Figure S1. Characterization of PFF, trypan blue exclusion assay, live PFF uptake, trypsin wash and characterization of cell types.

(A) Sonication of al $\alpha$-syn fibrils results in significantly smaller fibril length, allowing the $\alpha$-syn oligomers to be characterized as PFF with a length of below $100 \mathrm{~nm}$. (B) The mean length of samples used includes 51.72, 52.89, 58.28, 67.95, $95.04 \mathrm{~nm}$. Once confirmed with electron microscopy, the corresponding batches were tagged with Alexa Fluor 488, Alexa Fluor 633, or 5 $\mathrm{nm}$ gold (C). Scale Bar $=100 \mathrm{~nm}$. (D) Trypan blue exclusion assay used to discriminate against intra- and extracellular PFF. HeLa cells were grown on glass-bottomed plates and placed on ice for $30 \mathrm{~min}$. They were then transferred to an imaging chamber chamber for live imaging. For the top two rows, $\left(4^{\circ} \mathrm{C}\right)$, the chamber was not heated with the cells remaining at low temperature. Images were taken from before and after PFF addition. Trypan blue was added to cells 2 min following PFF addition. No PFF was internalized in this condition, as trypan blue was able to quench all PFF fluorescence. For the bottom two rows $\left(37^{\circ} \mathrm{C}\right)$, the chamber was heated to $37^{\circ} \mathrm{C}$ prior to the addition of PFF. PFF was then added, and 2 min following PFF addition, trypan blue was added. PFF fluorescence not quenched by trypan blue is internalized PFF. Scale bar $=20$ $\mu \mathrm{m}$ for low magnification and $5 \mu \mathrm{m}$ for insets. (E) PFF was added to cells at $4^{\circ} \mathrm{C}$ for $30 \mathrm{~min}$ to allow the binding of PFF to the cell surface without internalization. Cells were then transferred to a pre-heated live imaging chamber. Arrows point to specific PFF punctae that colocalize with lysosomes over time. Scale bar $=10 \mu \mathrm{m}$ for the low magnification image and $5 \mu \mathrm{m}$ for the insets. (F) Unlike cargo proteins like Tf and EGF, trypsinization for $90 \mathrm{sec}$ on ice is needed to remove extracellular PFF. In this experiment, Cells were incubated with PFF for 30 min at $4^{\circ} \mathrm{C}$. Since PFF internalization is temperature dependent, we expected no PFF internalization. We then assessed the efficacy of PBS, Acid, and Trypsin wash on their ability to remove extracellular PFF. We found that trypsinization was the only method that removes extracellular PFF. Scale bar $=20 \mu \mathrm{m}$. (G) To further confirm the efficacy of trypsin wash for the removal of 
Trafficking of pathological $\alpha$-synuclein

extracellular PFF, PBS (control) or PFF were added to cells. Cells were incubated at $4^{\circ} \mathrm{C}$ for 30 min. Cells exposed to PFF were then washed with either PBS or with trypsin. Cell lysates were then immunoblotted for $\alpha$-syn, to assess the presence of PFF. Samples washed with trypsin showed no a-syn signal, while the cells washed with PBS did, confirming the efficacy of trypsin in removing extracellular PFF. (H) To confirm the identity of astrocytes, glioblastoma cell lines, and the iPSC derived neural progenitor cells along with differentiated neurons, marker antibodies were used. Astrocytic and glial identity was confirmed using the glial fibrillary associated protein (GFAP) antibody. As expected, fetal astrocytes, and U251 had high levels of GFAP fluorescence while U343 had less, and U87 do not show any GFAP fluorescence. For neurons, neuronal markers such as microtubule-associated protein 2 (MAP2) was used. To confirm the identity of dopaminergic neurons, tyrosine hydroxylase antibody (TH) was used. The confirm the identity of neural progenitor cells beta-III tubulin was used. Finally, to confirm the identity of dopaminergic neural progenitor cells, Forkhead box protein A2 (FOXA2) was used. Scale bar $=20 \mu \mathrm{m}$.

Figure S2. PFF colocalization with lysosomes in glioblastomas and cortical neurons. (A) U87 cells were plated on coverslips and transfected with LAMP1-TurboRFP. PFF was added to each coverslip at $2 \mu \mathrm{g} / \mathrm{ml}$. Cells were incubated for $0,2,10,30 \mathrm{~min}$ at $37^{\circ} \mathrm{C}$ following addition of PFF. Cells were washed with trypsin and fixed. PFF colocalization with LAMP1 can be seen in as early as $2 \mathrm{~min}$. Formation of large LAMP1-positive vesicles shortly after exposure (arrowheads) to PFF can be seen. Scale bar $=20 \mu \mathrm{m}$ and $5 \mu \mathrm{m}$ for insets. (B) U251 cells transduced with LAMP1-RFP lentivirus, were mounted onto coverslips and were exposed to the PFF endocytosis assay. Cells were then trypsin washed and fixed. The colocalization of PFF internalized as early as 2 min, confirmed our findings using other cell lines. Arrowheads point to large lysosomes containing PFF. Scale bar $=20 \mu \mathrm{m}$. (C) Cortical NPCs were mounted on coverslips. Cells were then stained with lysotracker for 30 min at $37^{\circ} \mathrm{C}$. PFF was added to each 
Trafficking of pathological $\alpha$-synuclein

coverslip at $2 \mu \mathrm{g} / \mathrm{ml}$. Cells were incubated for $0,2,10,30 \mathrm{~min}$ at $37^{\circ} \mathrm{C}$ following addition of PFF. Cells were washed with trypsin and fixed. PFF colocalization with lysotracker can be seen in as early as 2 min. Scale bar $=20 \mu \mathrm{m}$. (D/E) Uptake and colocalization of LAMP1 with PFF from experiments as in A. $\mathrm{n}=9$ for each condition (i.e., $\mathrm{n}=36$ total for U87); (F/G) Uptake and colocalization of LAMP1 with PFF from experiments as in B. $n=7$ for each condition (i.e. $n=28$ total for U251, from three independent experiments, mean \pm SEM; one-way ANOVA; multiple comparisons Tukey's test was conducted to assess significance from control; $p<0.0001$ denoted as $^{* * *}$. (H/I) Uptake and colocalization of LAMP1 with PFF from experiments as in C. $n$ $=6$ for each condition (i.e., $n=24$ total), from three independent experiments, mean $\pm S E M$; one-way ANOVA; Tukey's test was conducted to assess significance from control; $p<0.0001$ denoted as ${ }^{* * *}, \mathrm{p}<0.001$ denoted as ${ }^{* *}, \mathrm{p}<0.05$ denoted as *.

Figure S3. PFF remains in lysosomes over 10 days in U343 cells. U343 human glioblastoma cells were mounted on coverslips given PFF488 or EGF488 at $2 \mu \mathrm{g} / \mathrm{ml}$ and 0.2 $\mathrm{ug} / \mathrm{ml}$ concentration respectively on ice for $1 \mathrm{~h}$. Cells were removed from ice, replaced with fresh media and were then incubated for $0 \mathrm{~h}, 1$ day or 10 days at $37^{\circ} \mathrm{C}$. Following incubation, cells were trypsin washed and fixed. Samples were then permeabilized, blocked and stained with LAMP1 antibody. PFF fluorescence builds over 10 days while EGF fluorescence dissipates. Arrowheads point to large PFF and LAMP1 structures which only present in cells exposed to PFF. Scale bar $=20 \mu \mathrm{m}$ for low magnification and $5 \mu \mathrm{m}$ for insets.

Figure S4. PFF is not trafficked through early/recycling endosomes. (A) PFF and Tf were added to coverslips with U2OS cells at $2 \mu \mathrm{g} / \mathrm{ml}$ and $0.2 \mu \mathrm{g} / \mathrm{ml}$, respectively, and the cells were incubated for $2,10,30 \mathrm{~min}$ at $37^{\circ} \mathrm{C}$. Cells were washed with trypsin and fixed. Scale bar $=20$ $\mu \mathrm{m}$ and $10 \mu \mathrm{m}$ for insets. (B) U2OS cells were mounted on coverslips. PFF was added to each coverslip at $2 \mu \mathrm{g} / \mathrm{ml}$ and the cells were incubated for $0,2,10,30 \mathrm{~min}$ at $37^{\circ} \mathrm{C}$. Cells were 
Trafficking of pathological $\alpha$-synuclein

washed with trypsin, fixed, permeabilized, and stained with EEA1 antibody. Arrowheads point to large PFF punctae. Scale bar $=20 \mu \mathrm{m}$ and $5 \mu \mathrm{m}$. (C) PFF colocalization with early endosome markers: Rab4 and Rab5; Rab8; and lysosomal markers: Rab9 and LAMP1 was examined using antibodies. PFF colocalized only with Rab9 and LAMP1 at 5 and 60 min. Scale bar for low magnification images is $10 \mu \mathrm{m}$ and $5 \mu \mathrm{m}$ for insets.

(D) Colocalization rate of Tf with PFF from experiments as in A. $\mathrm{n}=9$ for each condition (i.e., $\mathrm{n}$ = 36 total), from three independent experiments, mean \pm SEM; one-way ANOVA; $p>0.05$ denoted as ns for not significant. (E) Colocalization of EEA1 with PFF from experiments in B. $n$ $=6$ for each condition (i.e., $n=24$ total), from three independent experiments, mean $\pm S E M$; one-way ANOVA; $p$ > 0.05 denoted as ns for not significant. (F) U2OS cells were incubated with PFF at $2 \mu \mathrm{g} / \mathrm{ml}$ for 5 minutes. Cells were washed with trypsin, fixed, permeabilized, and stained with Rab5 antibody. Scale bar $=20 \mu \mathrm{m}$. (G) Colocalization rate of Rab5 with PFF from experiments as in F. $\mathrm{n}=9$ for each condition (i.e., $\mathrm{n}=36$ total), from three independent experiments, mean \pm SEM; one-way ANOVA; $p>0.05$ denoted as ns for not significant.

\section{Figure S5. Exposure to PFF leads to actin membrane ruffling and Rac1 recruitment. (A)}

Astrocytes were grown and mounted on coverslips. PFF was added to each coverslip at $2 \mu \mathrm{g} / \mathrm{ml}$ and cells were incubated for $0,2,10,30 \mathrm{~min}$ at $37^{\circ} \mathrm{C}$. Cells were washed with trypsin, fixed, permeabilized, and stained with Rac1 and F-actin (phalloidin). Arrows point to colocalization of F-actin and Rac1 at the cell surface, a sign of membrane ruffling. Scale bar $=20 \mu \mathrm{m}$. (B) Phalloidin (red) was used to stain F-actin in astrocytes with different PFF (green) incubation times. The Z-stacks were then combined to produce 3D images. Arrowheads point to actin ruffles. Scale bar $=20 \mu \mathrm{m}$ and $5 \mu \mathrm{m}$ for $X Y$ and $Y Z$ insets. (C) EM of astrocytes exposed to PBS or PFF for $5 \mathrm{~min}$. Arrows point to membrane protrusions and ruffling. Scale bar $=1 \mu \mathrm{m}$. (D) Astrocytes were grown and mounted on coverslips. PFF, EGF, or Tf was added to each coverslip at $2 \mu \mathrm{g} / \mathrm{ml}$. Cells were then incubated for 0 or 30 min at $37^{\circ} \mathrm{C}$. Cells were washed with 
Trafficking of pathological $\alpha$-synuclein

trypsin, fixed, permeabilized, and stained with Rac1 and F-actin (phalloidin) antibodies. Arrowheads point to colocalization of F-actin and Rac1 at the cell surface, a marker for membrane ruffling. Scale bar $=20 \mu \mathrm{m}$.

Figure S6. PFF induces membrane ruffling at the cell membrane and is trafficked to multivesicular bodies via macropinosomes (A) Astrocytes exposed to 5 min PFF-gold, showed PFF-gold localized to macropinosomes (B-D). (E) PFF is also found in multi-vesicular bodies. (F) PFF can also be found in electron dense multi-vesicular bodies and lysosomes. Scale bar = $2 \mu \mathrm{m}$ for low magnification, and $100 \mathrm{~nm}$ for all insets.

Figure S7. CD63 positive exosomes play a role in the intercellular transmission of PFF from donor to acceptor cells. U2OS cells stably expressing CD63-GFP were exposed to PFF or PBS (vehicle control) for 24 h. CD63-GFP (donor cells) were then trypsin washed three times, pelleted, trypsinized again, pelleted and PBS washed, prior to being coplated with acceptor cells (PFF naïve cells stably expressing CD9-mCherry). Donor and Acceptor cells were then incubated for 12 or $24 \mathrm{~h}(\mathbf{A} / \mathbf{B})$. Both $12 \mathrm{~h}$ and $24 \mathrm{~h}$ samples show PFF and CD63 fluorescence in acceptor cells. The left insets show PFF and CD63 composite image without the CD9 channel, while the right insets show a closeup of the composite. Arrows point to compartments in acceptor cells that contain both CD63 and PFF. Scale bar $=20 \mu \mathrm{m}$ for low magnification images and, and $10 \mu \mathrm{m}$ for inset. 


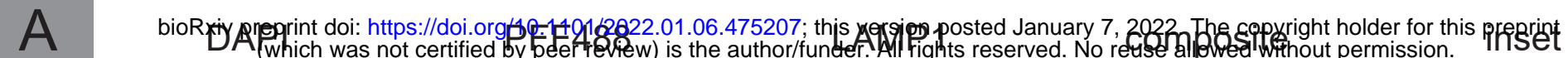

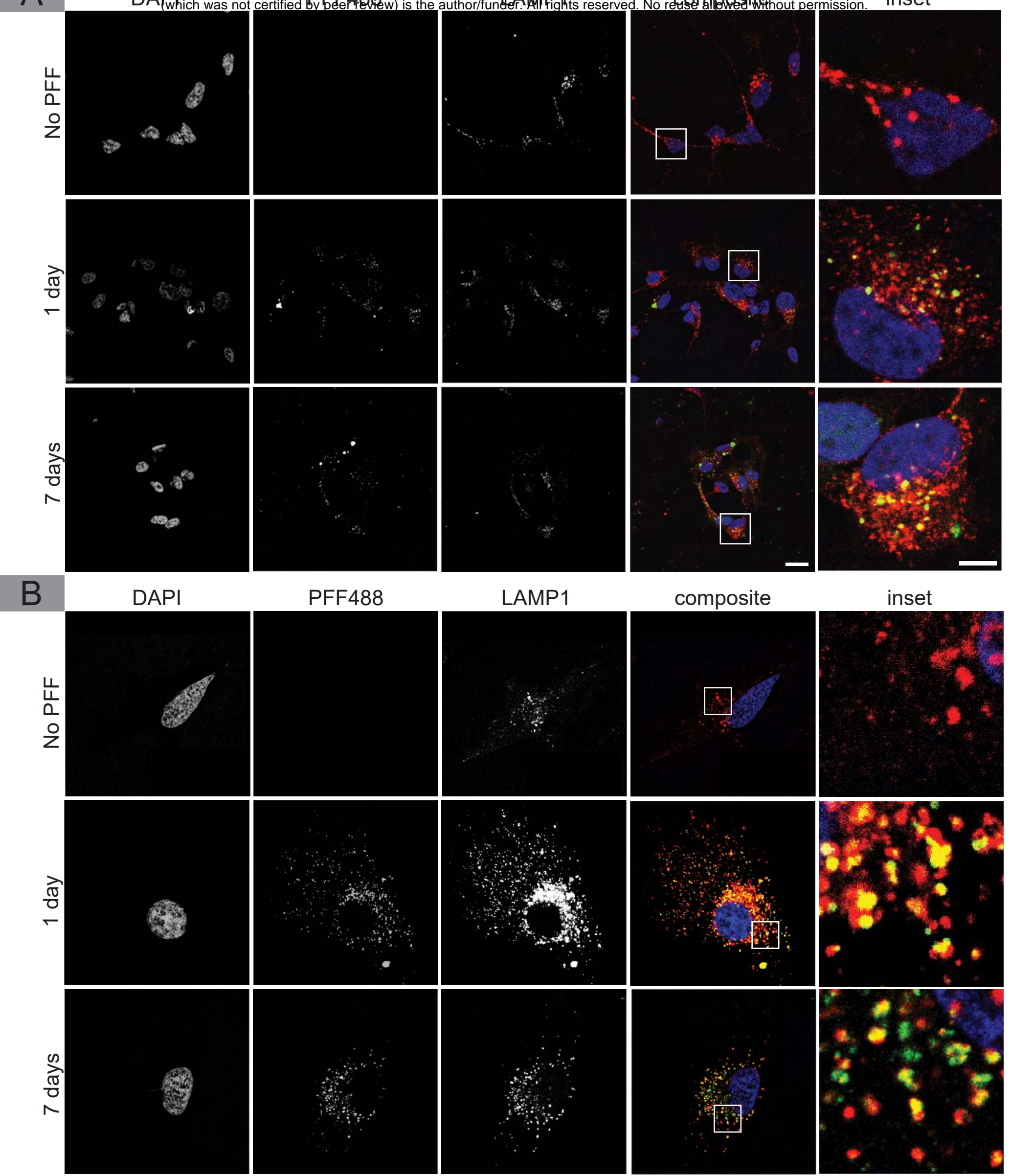

Bayati et al., Fig. 3 


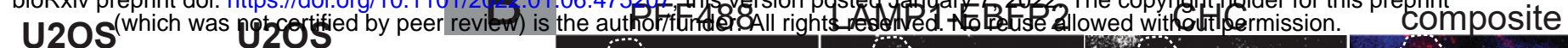
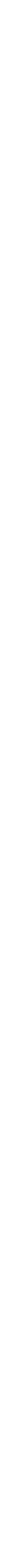

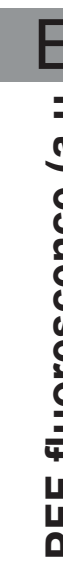

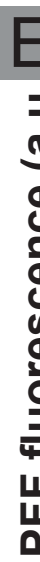

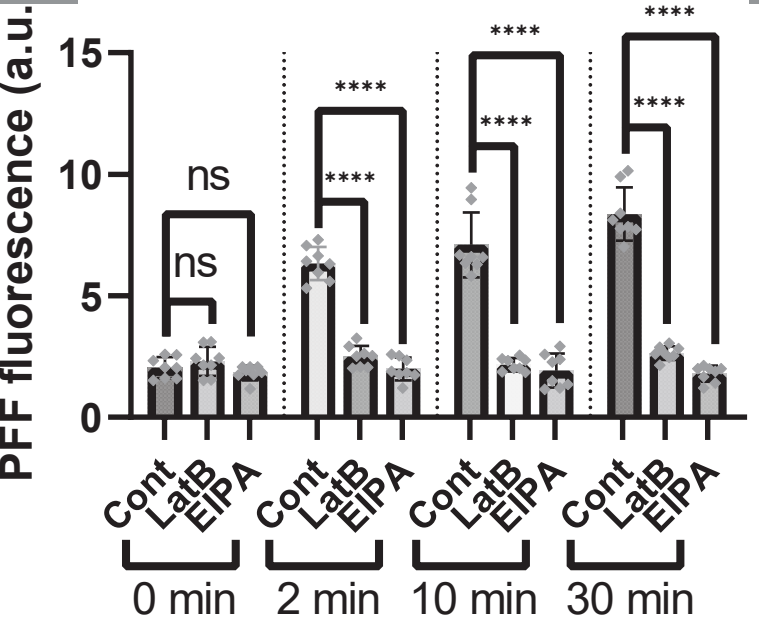

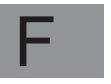

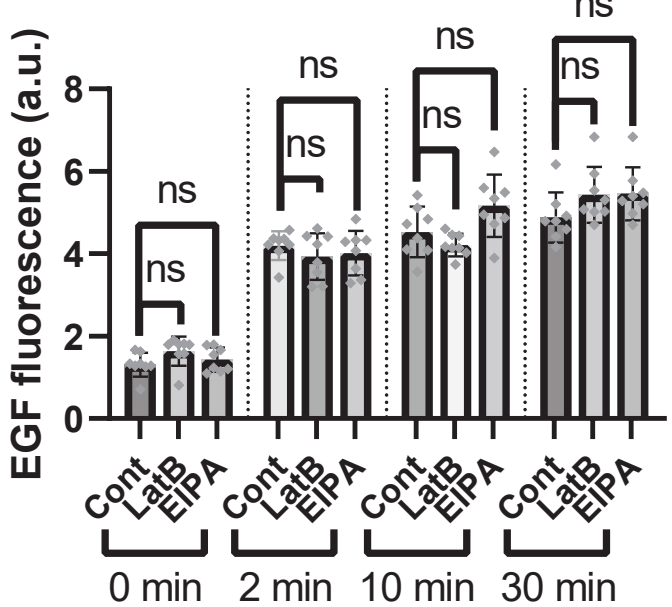

\section{G}

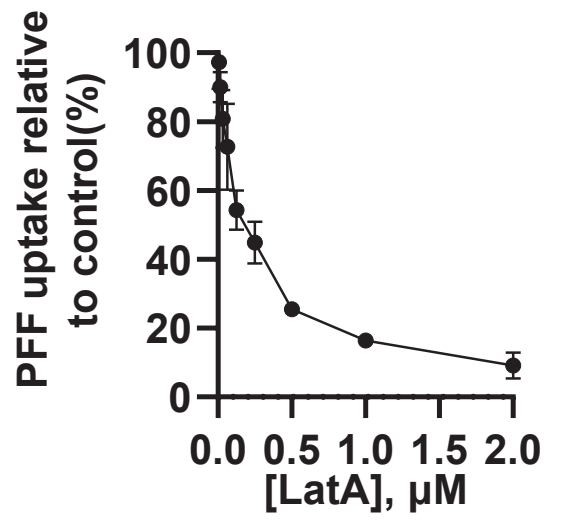

Bayati et al., Fig. 4 

(which was not certified by peer review) is the author/funder. All rights reserved. No reuse allowed without permission.
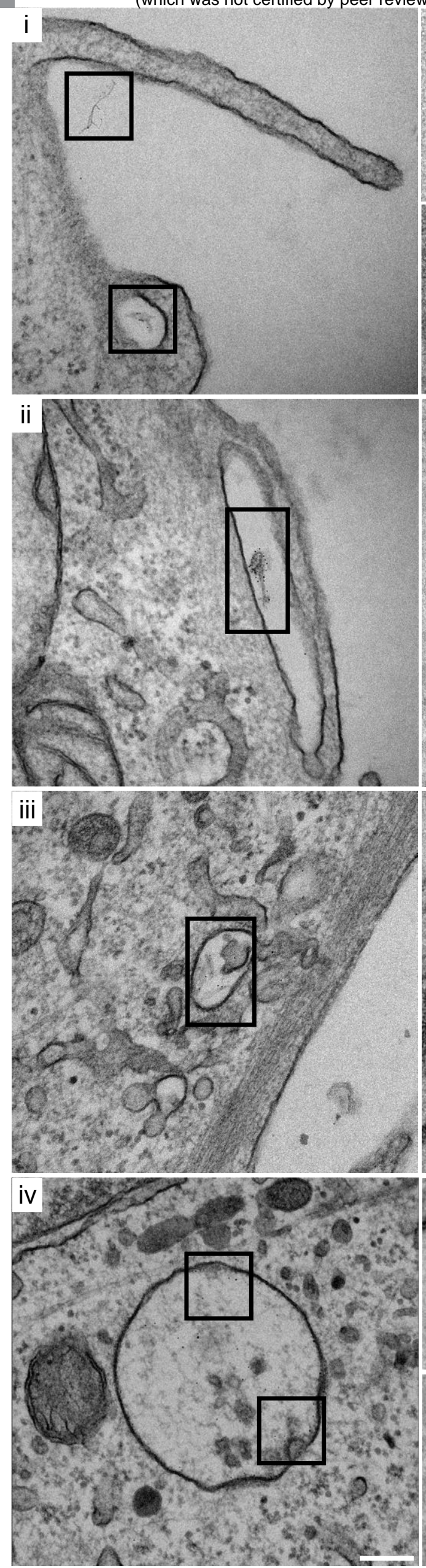
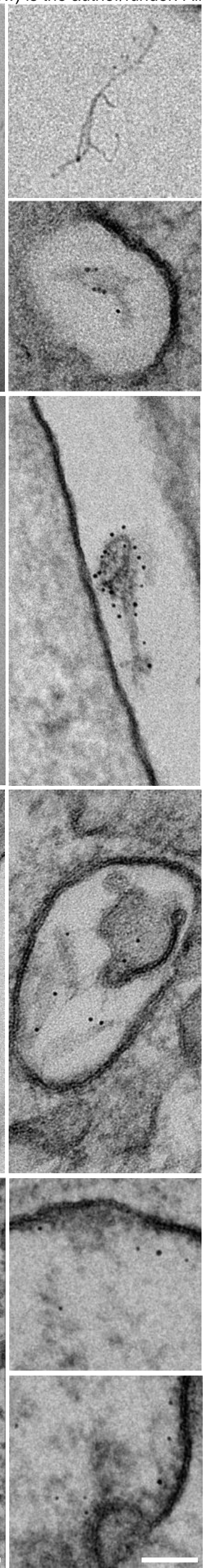
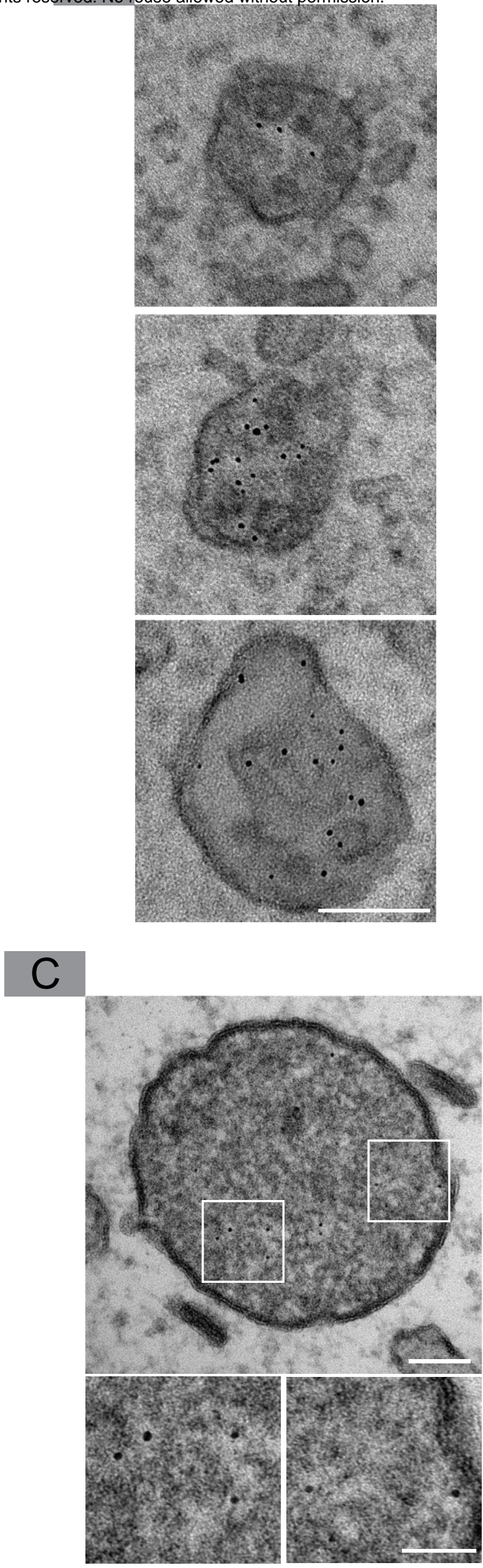


\section{A \\ bioRxiv preprint doi: https://doi.org/10.1101/2022.01.06.475207; this version posted January 7, 20尺2. The copyright holder for this preprint}

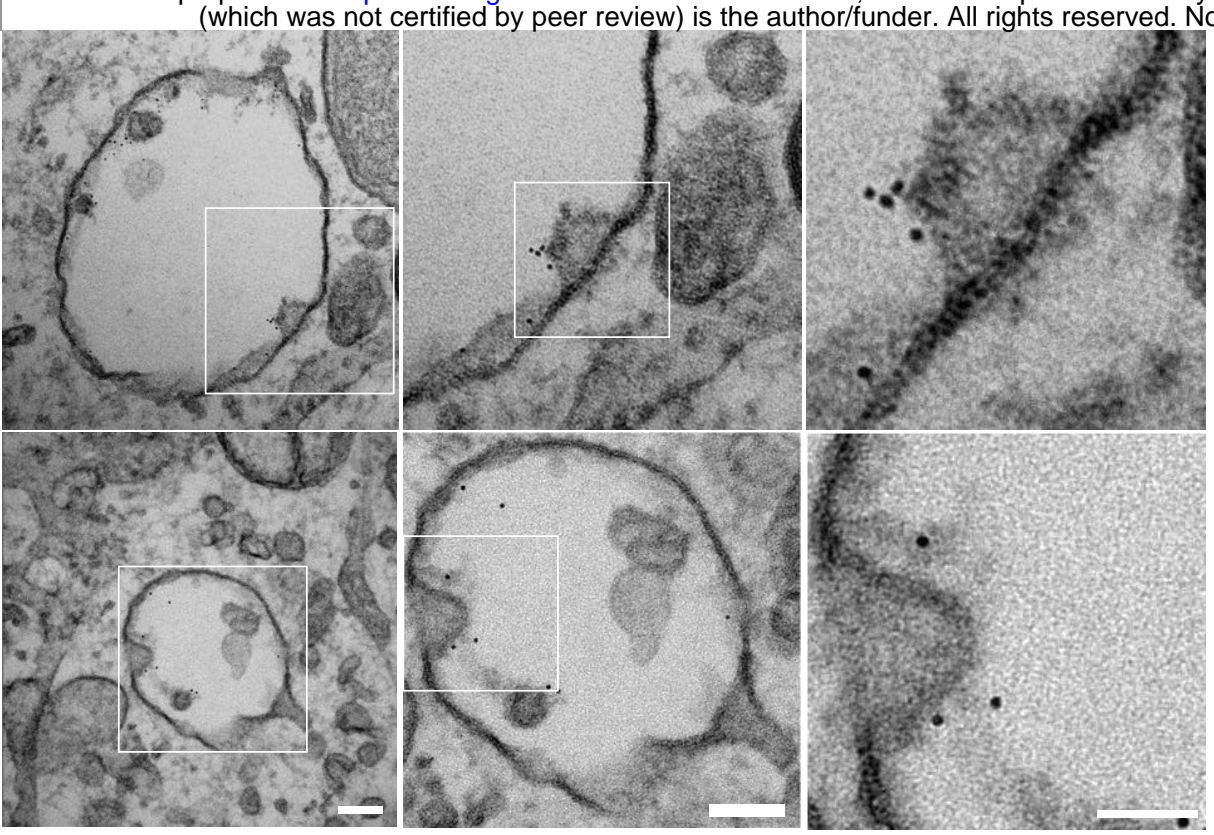

B
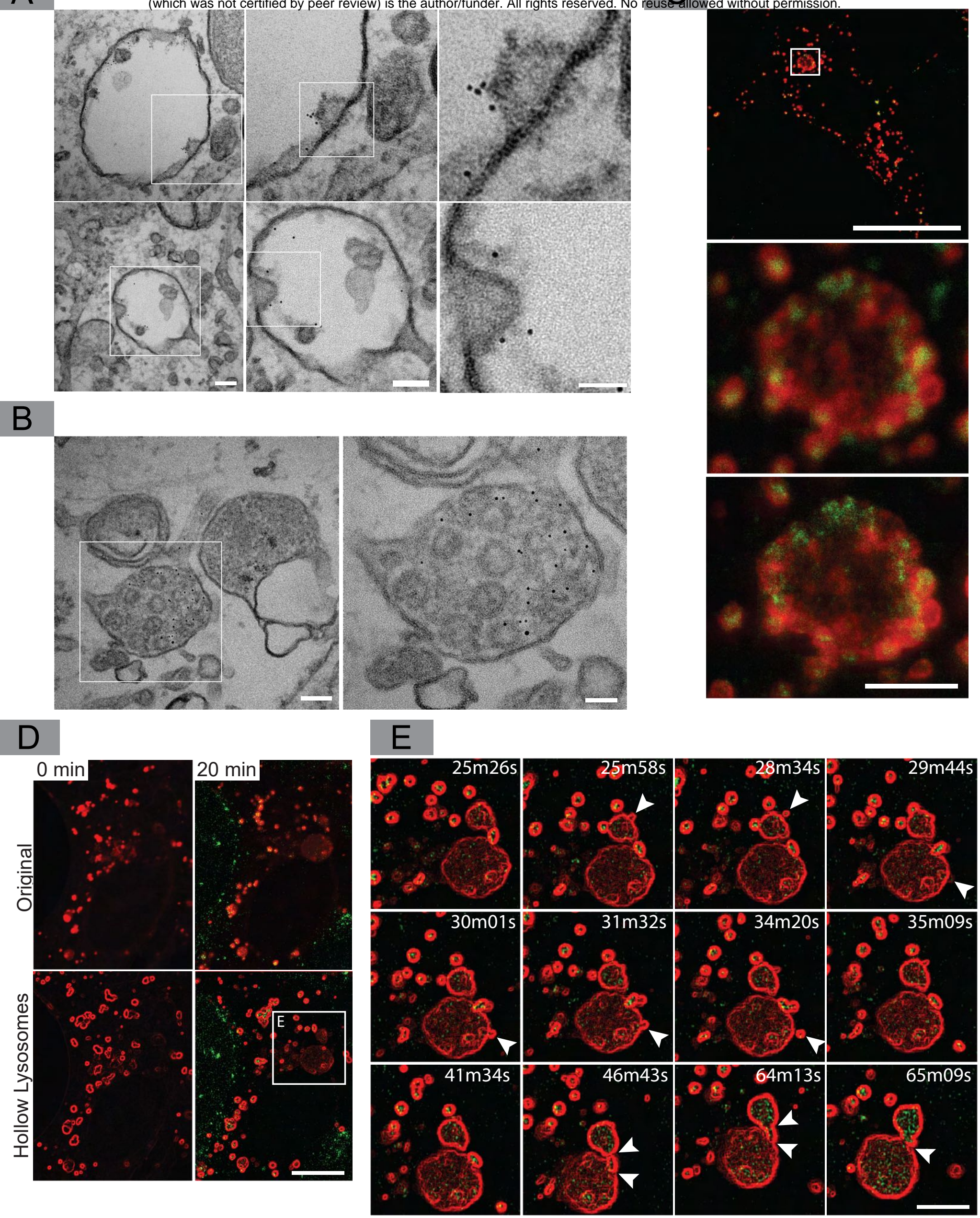

Bayati et al., Fig. 6 


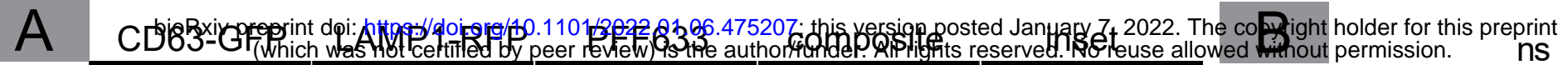

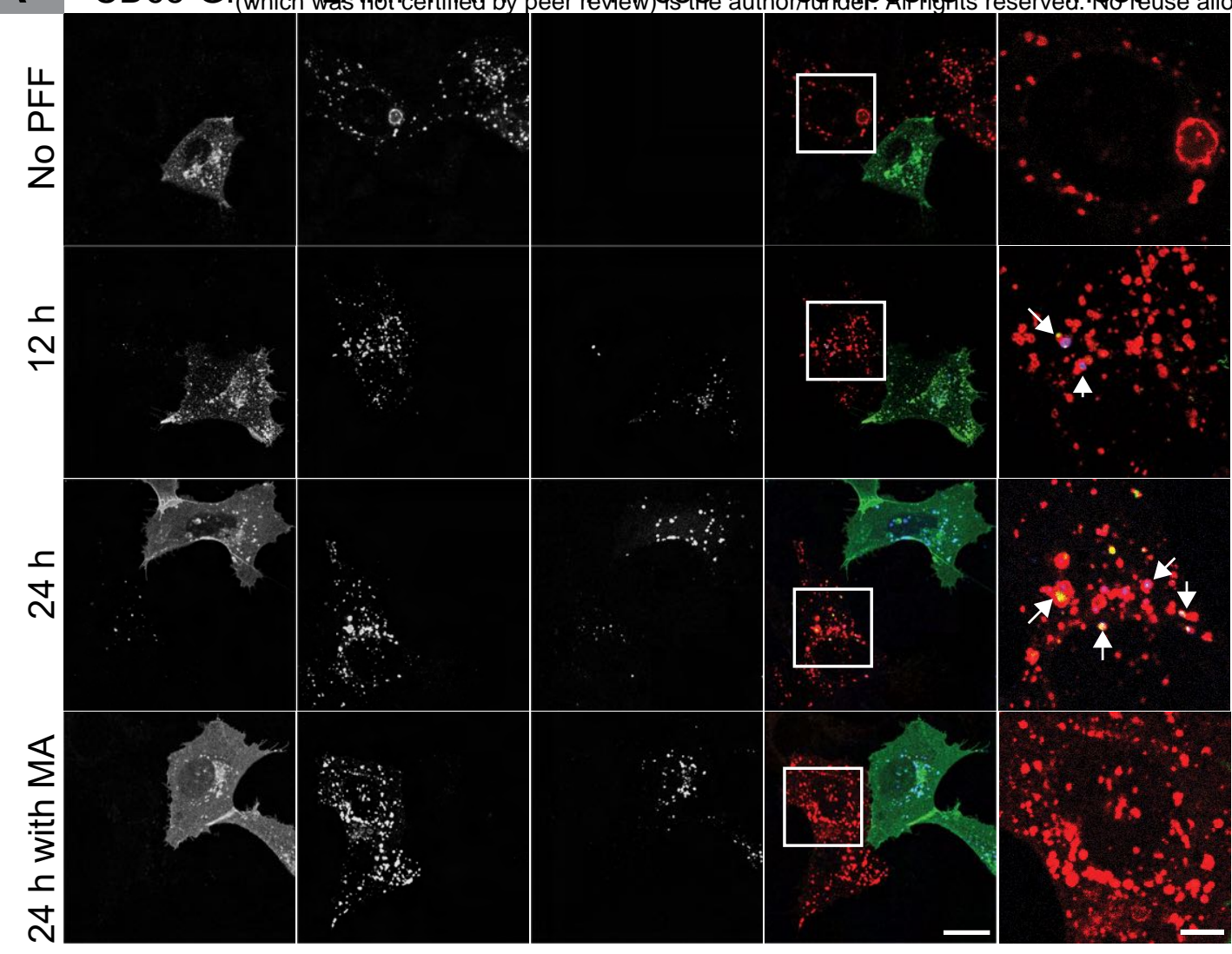

\section{C}

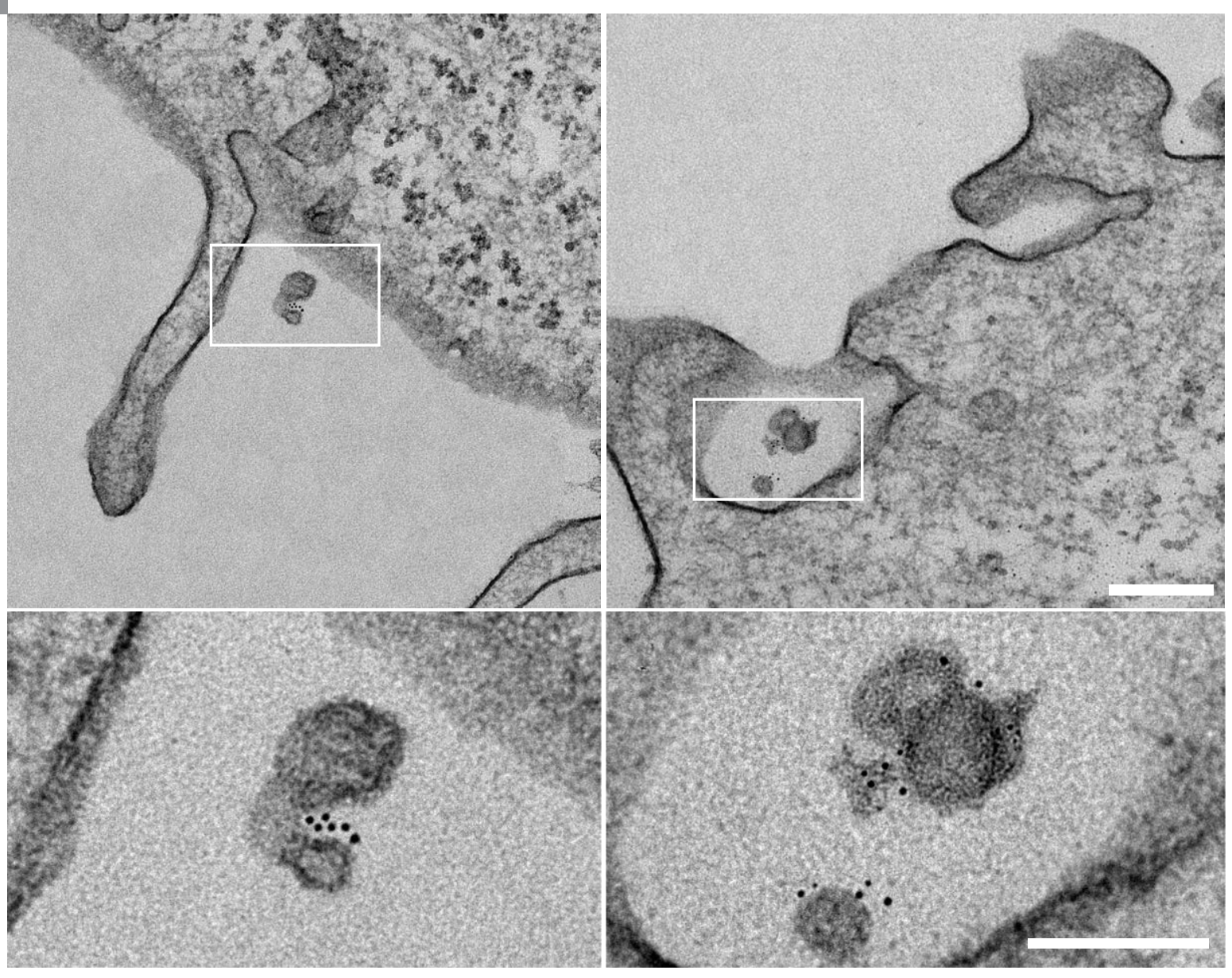


bioRxiv preprint doi: https;/doi.org/10.1101/2022.01.06.475207; this version posted January 7, 2022. The co/ Pight holder for this preprint

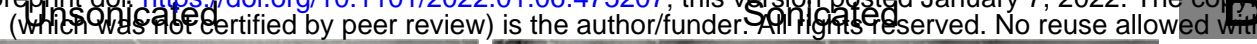

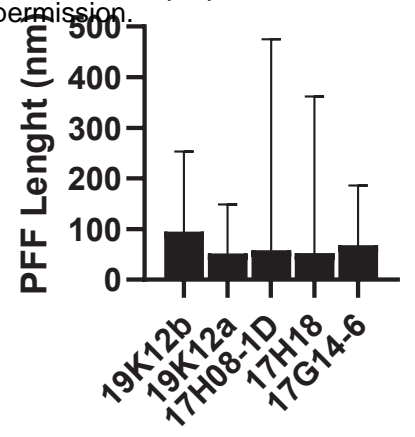

Batch ID

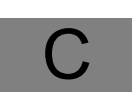

$\because$
E

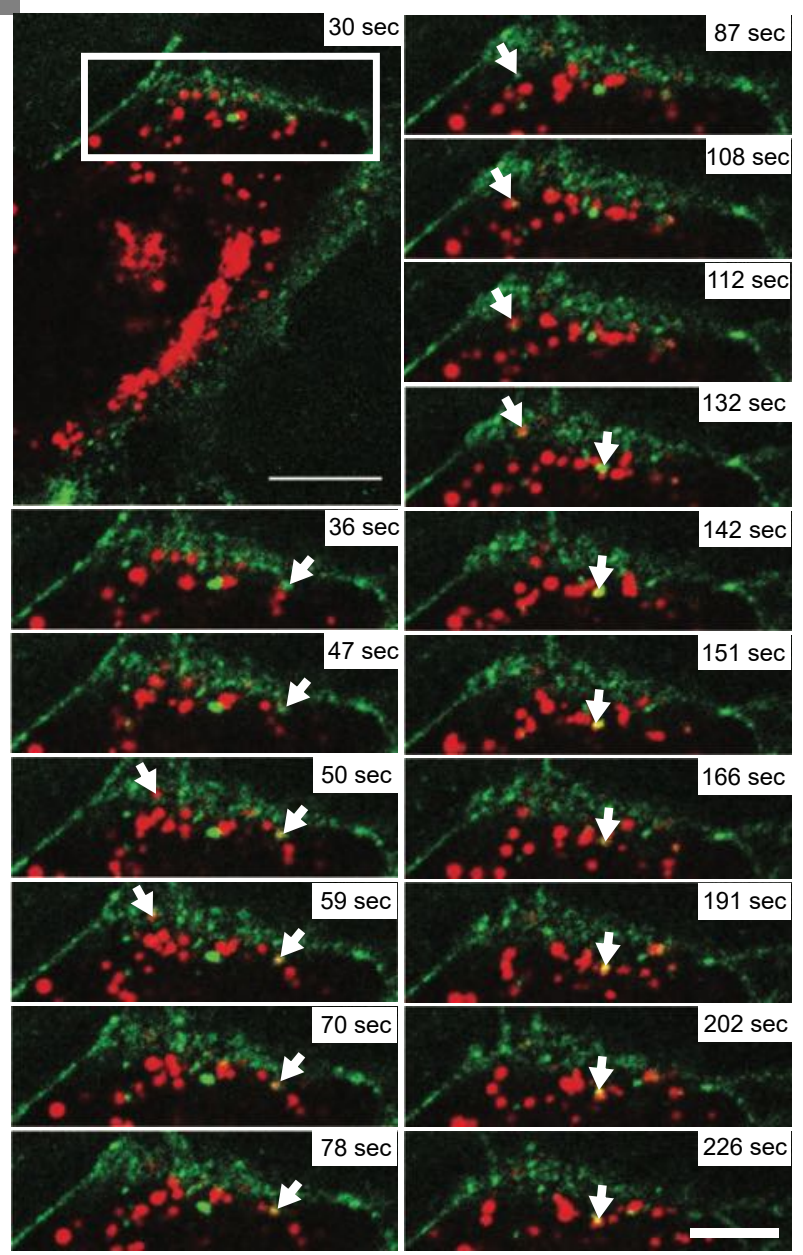

D

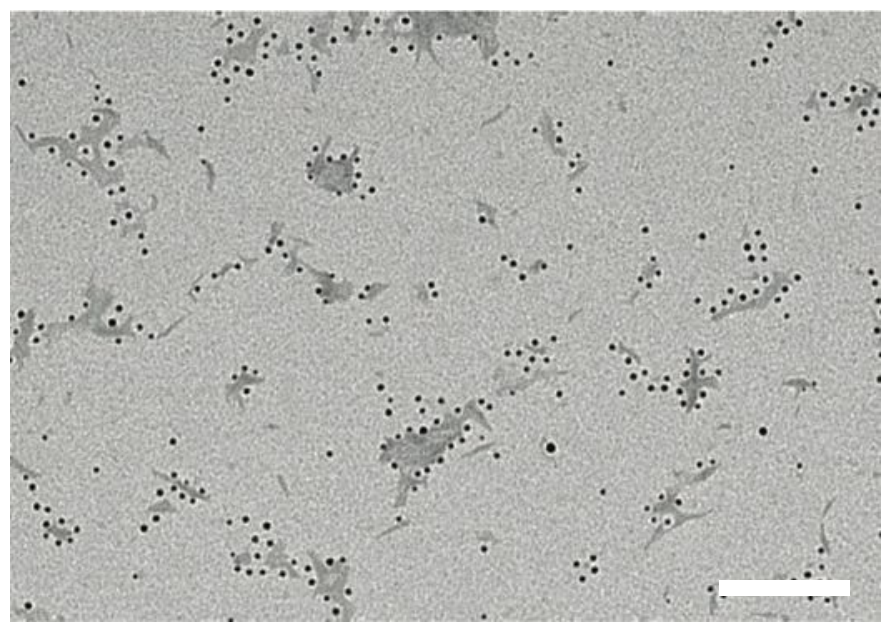

$\underset{\checkmark}{\checkmark}$

$-8 \mathrm{sec}$

PFF added

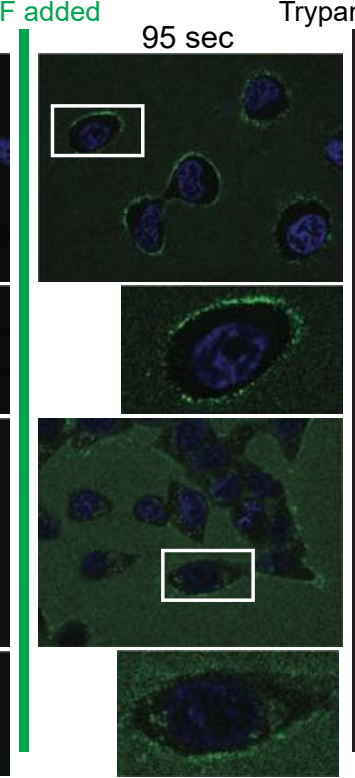

Acid Wash
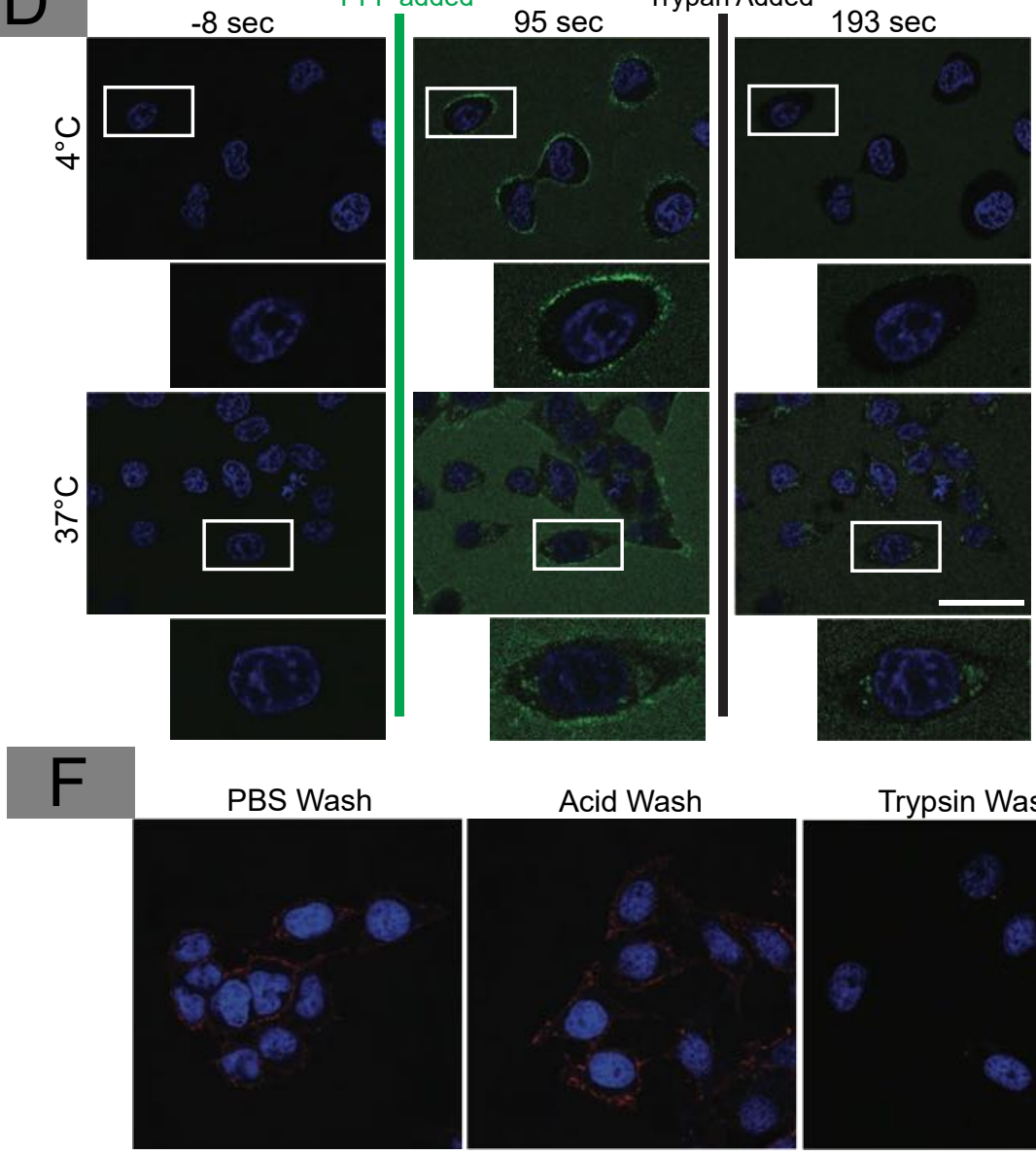

Trypsin Wash
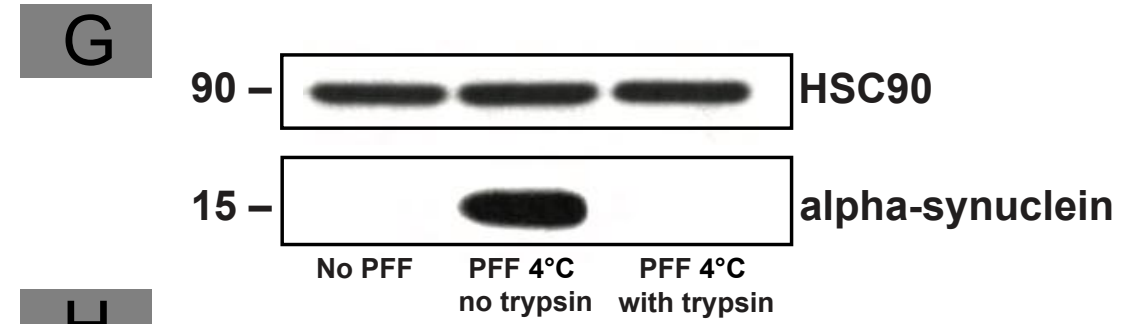

$\mathrm{H}$

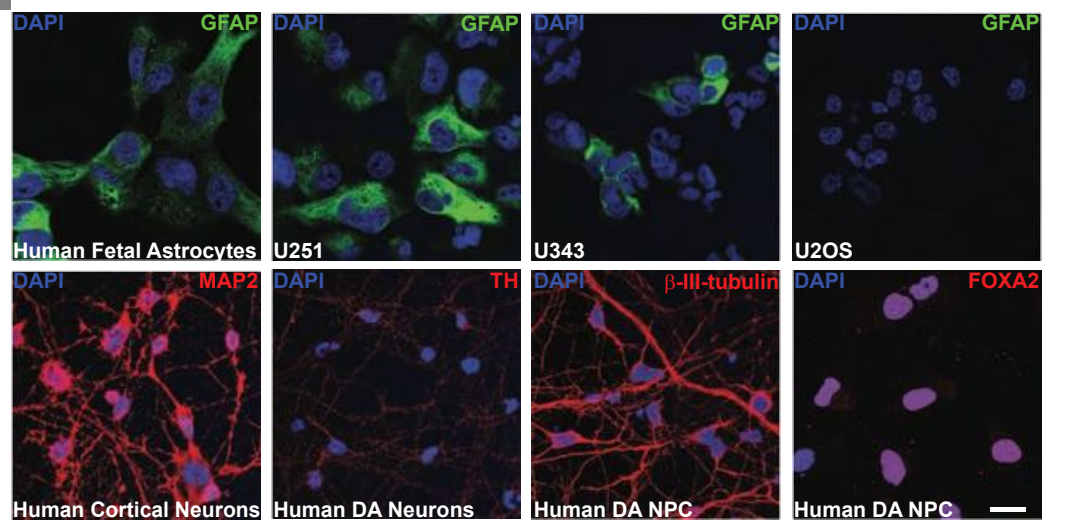

Bayati et al., Fig. S1 


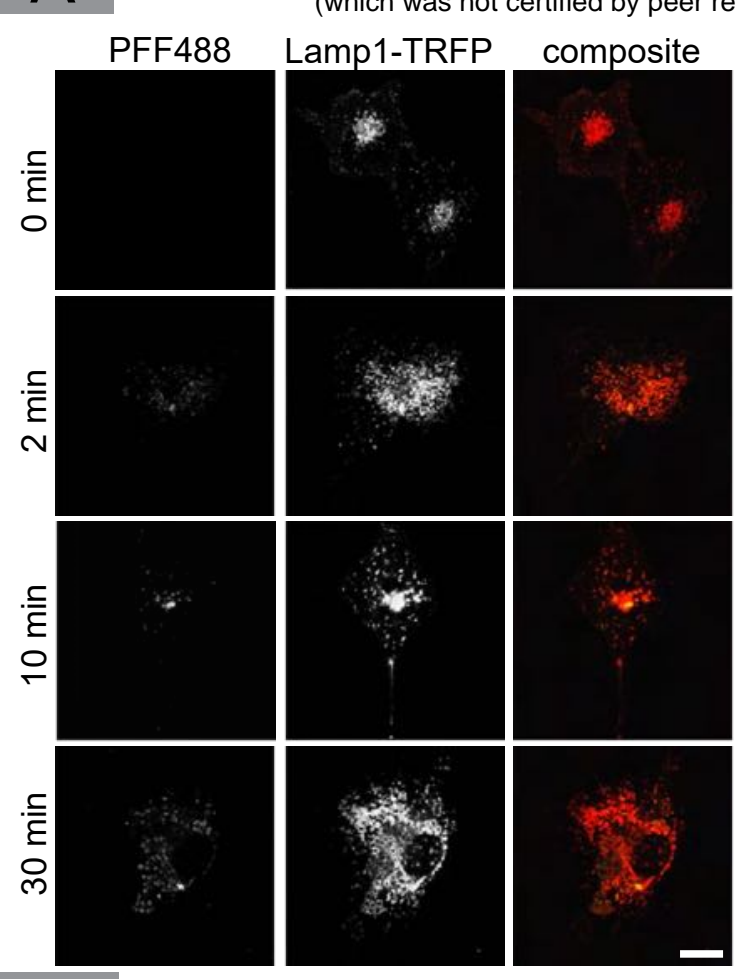
C

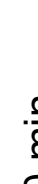

DAPI

$\frac{. \sqsubseteq}{\varepsilon}$

हᄐ

हᄐ

हᄃ

틈

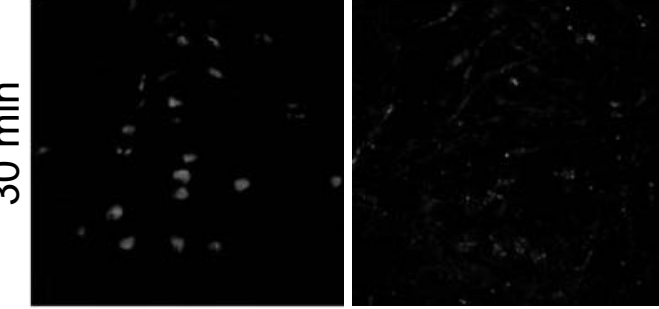

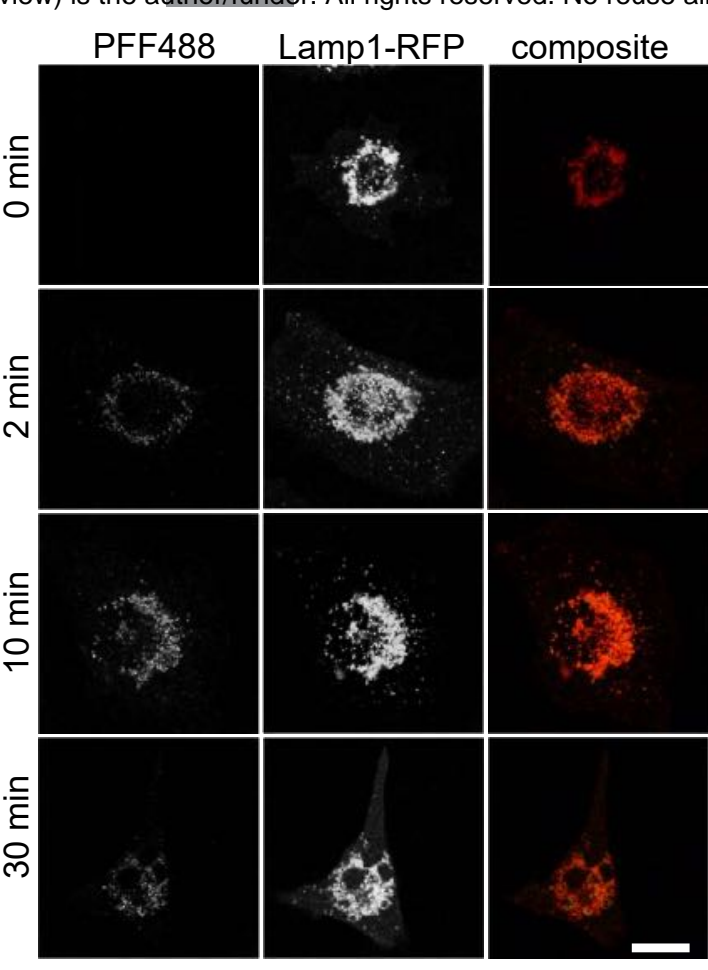

PFF488

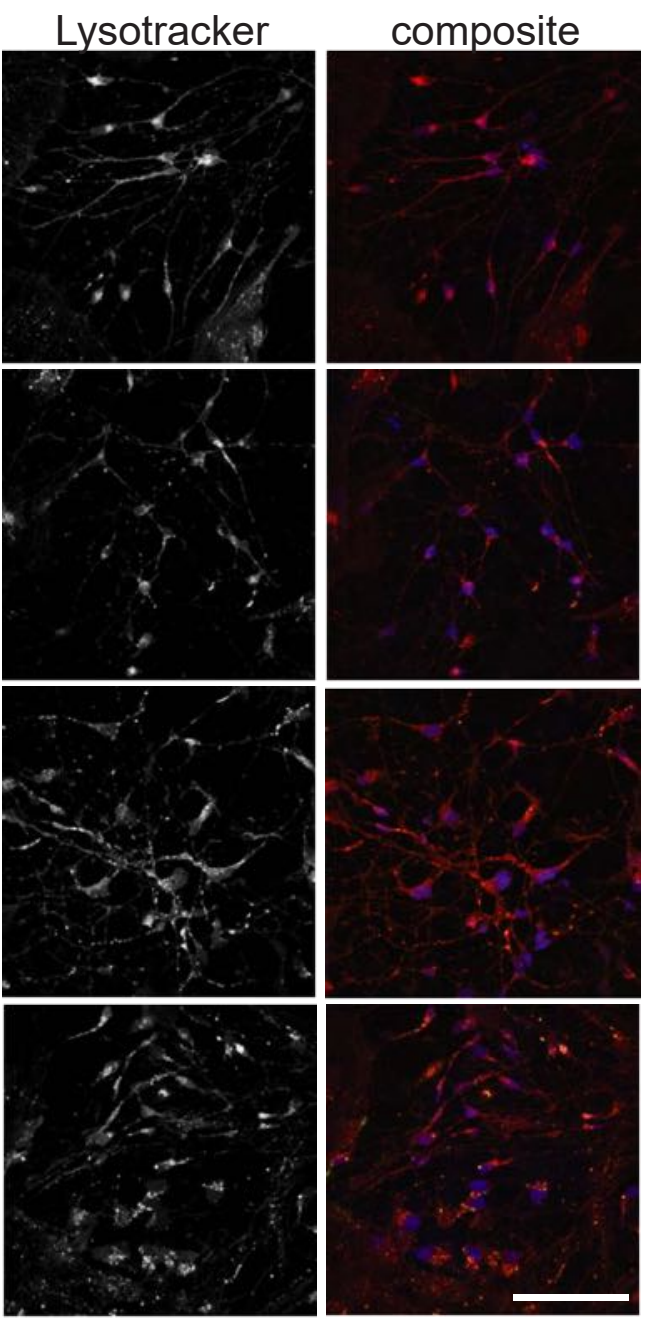

Bayati et al., Fig. S2

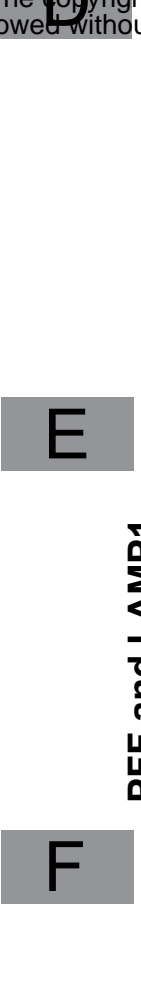

germission. $10 * * * *$

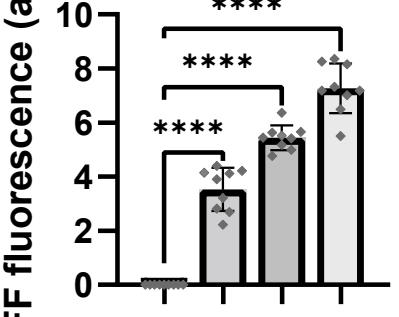

$\frac{11}{0}$

$\frac{1}{2}$

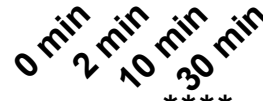

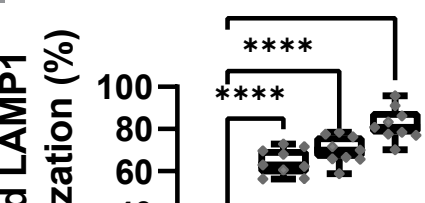
을 $\quad 40-$ สิ ชั

능으

눙

$20-$ ن
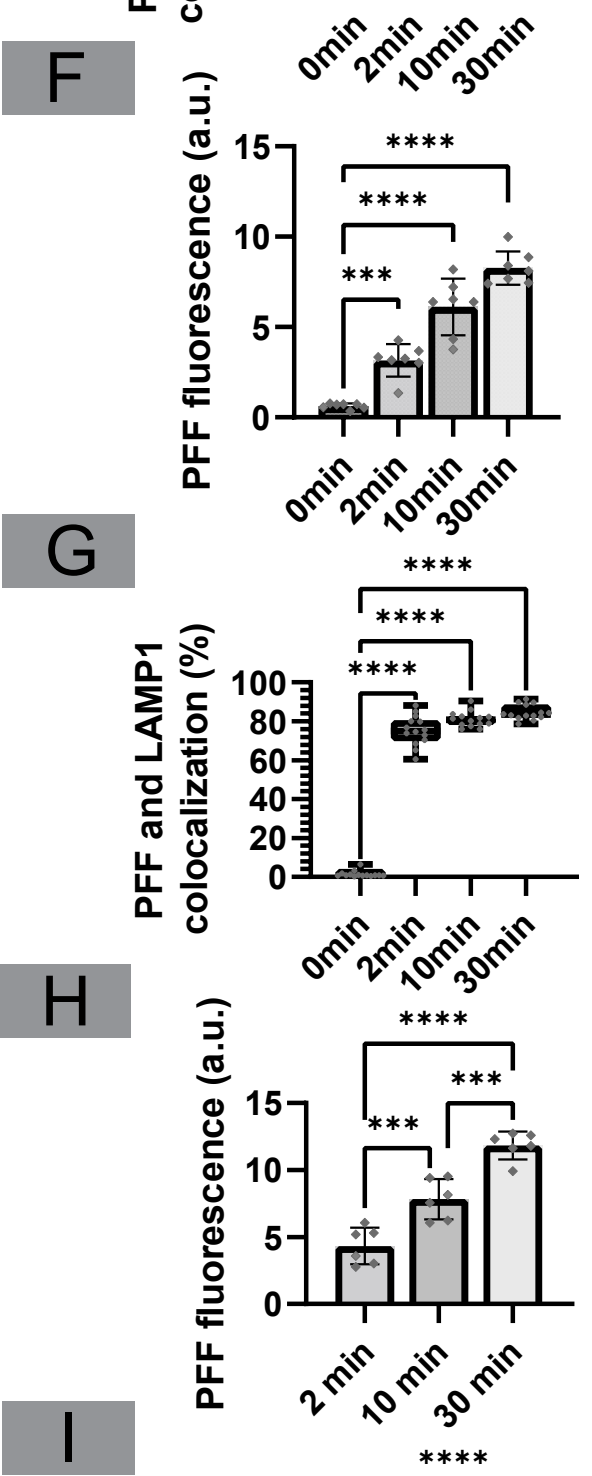

㟧
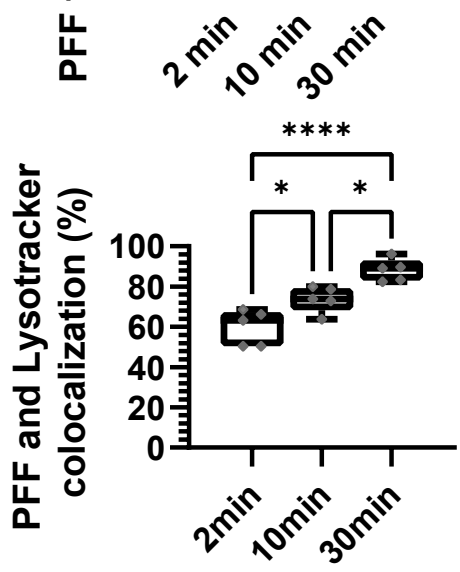
bioRxiv preprint doi: https://doi.org/10.1101/2022.01.06.475207; this version posted January 7, 2022. The copyright holder for this preprint (which was not certified by peer review) is the author/funder. All rights reserved. No reuse allowed without permission.

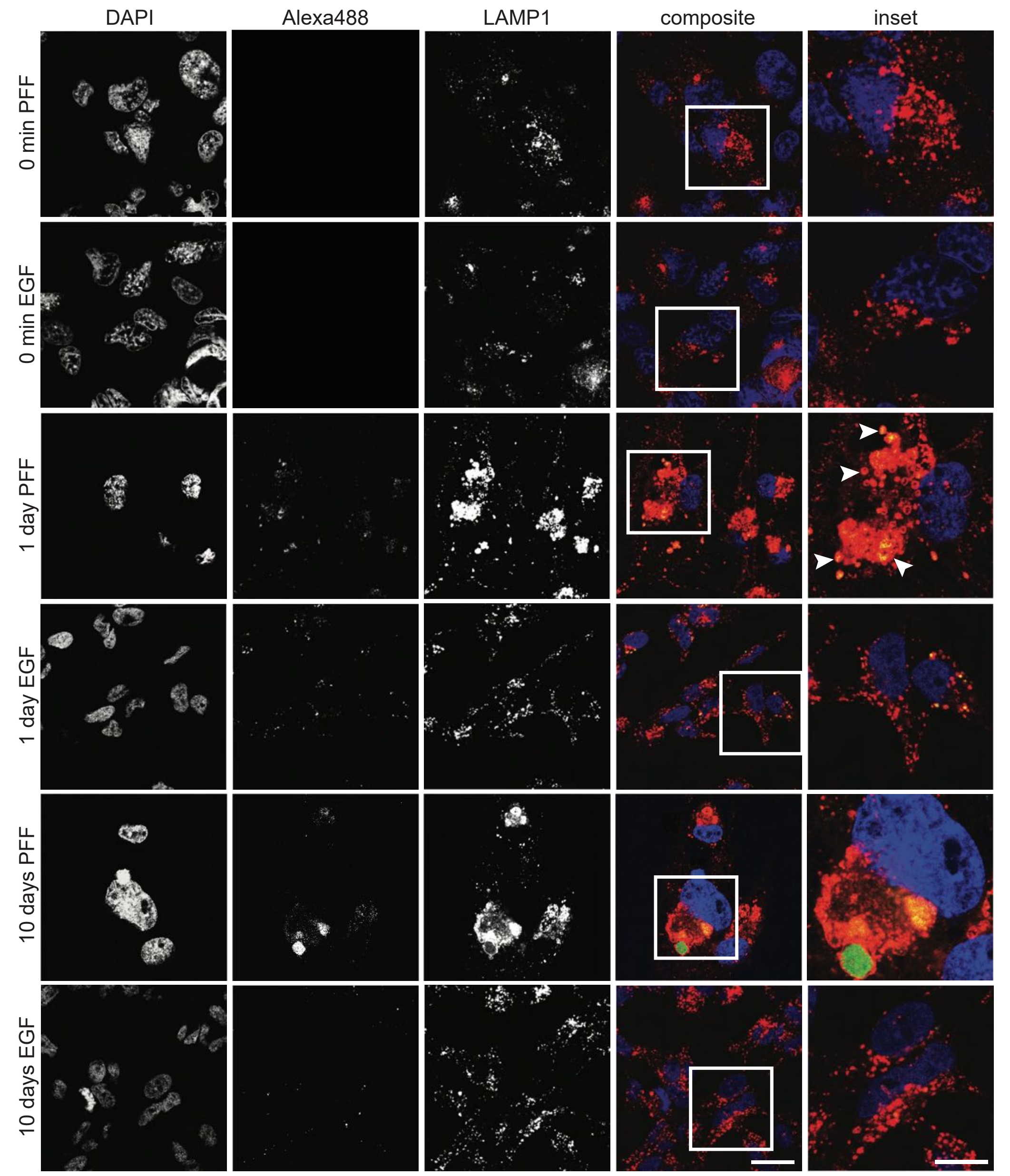

Bayati et al., Fig. S3 
bioRxiv preprint doi: https://doi.org/10.1101/2022.01.06.475207; this versior Posted January 7, 2022. The copyright holder for this preprint

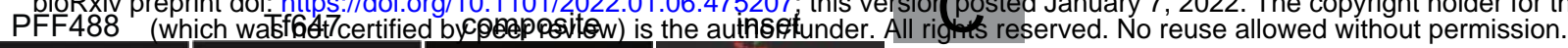
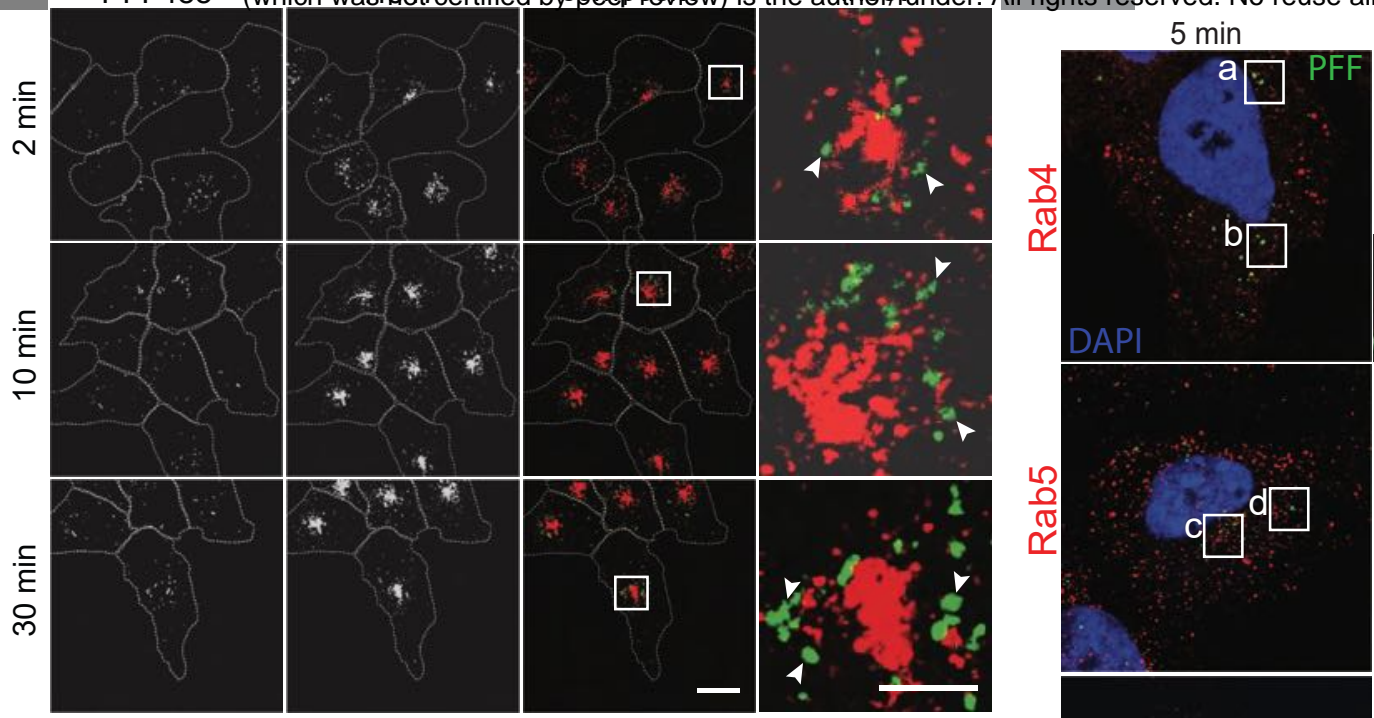

$60 \mathrm{~min}$

\section{B}

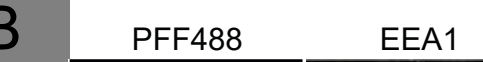

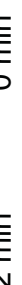

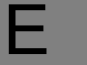

G

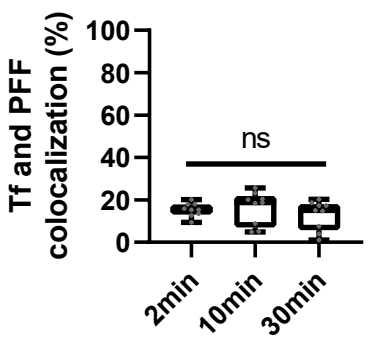

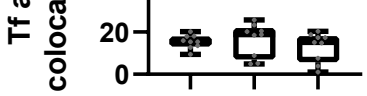

composite inset

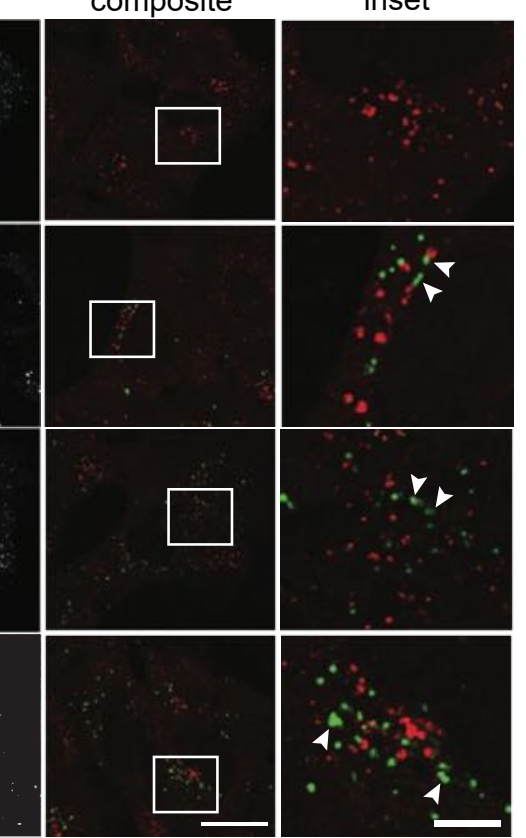

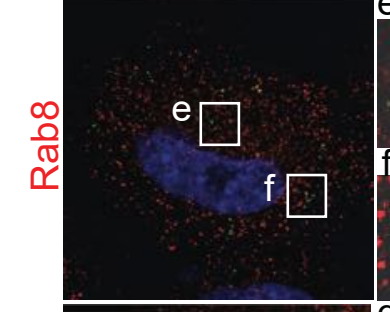

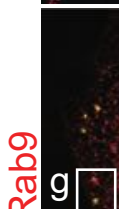

h? g:

$\mathrm{j}: \mathrm{s}$
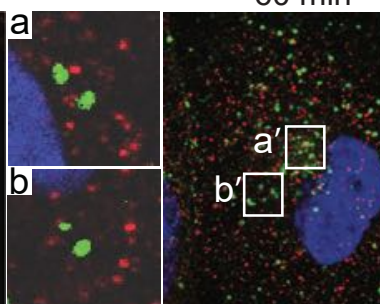

$a^{\prime}$
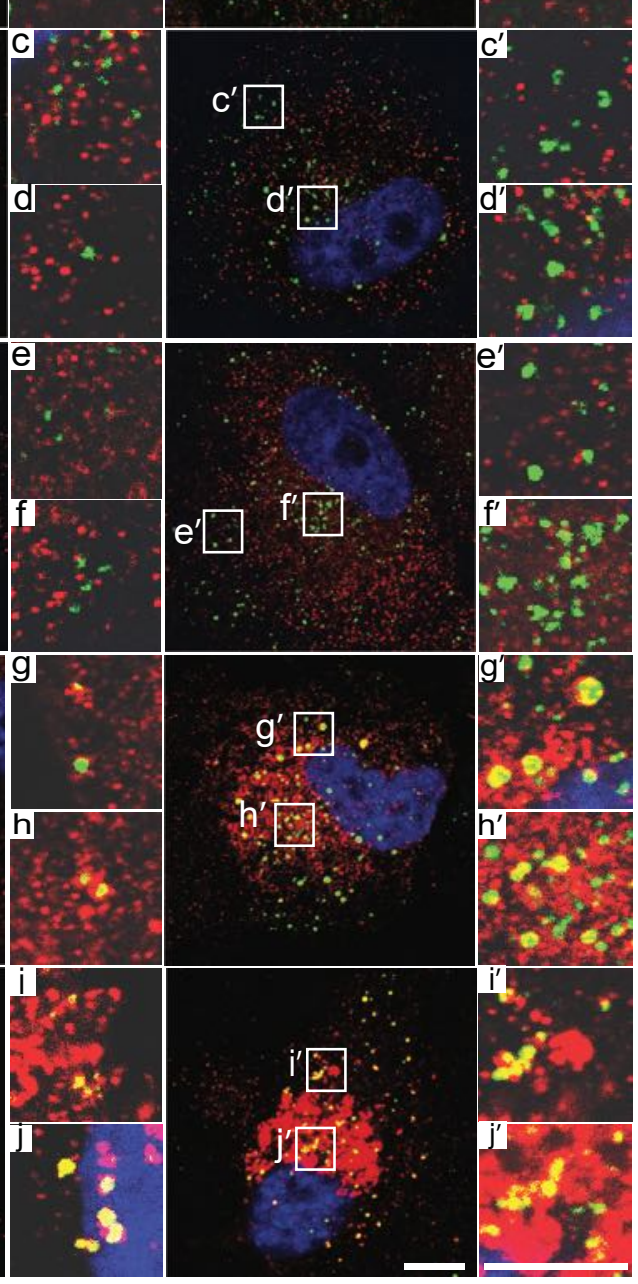

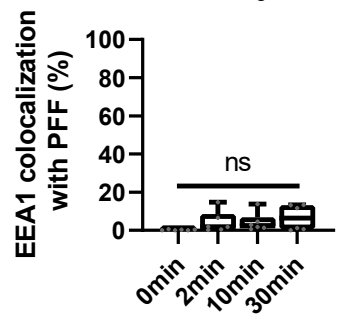

늠 음 $80-$

尊 $60-$

出

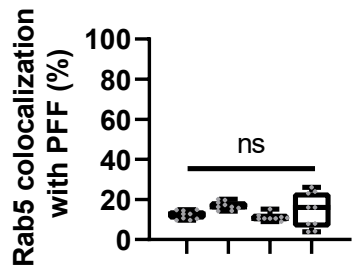

م
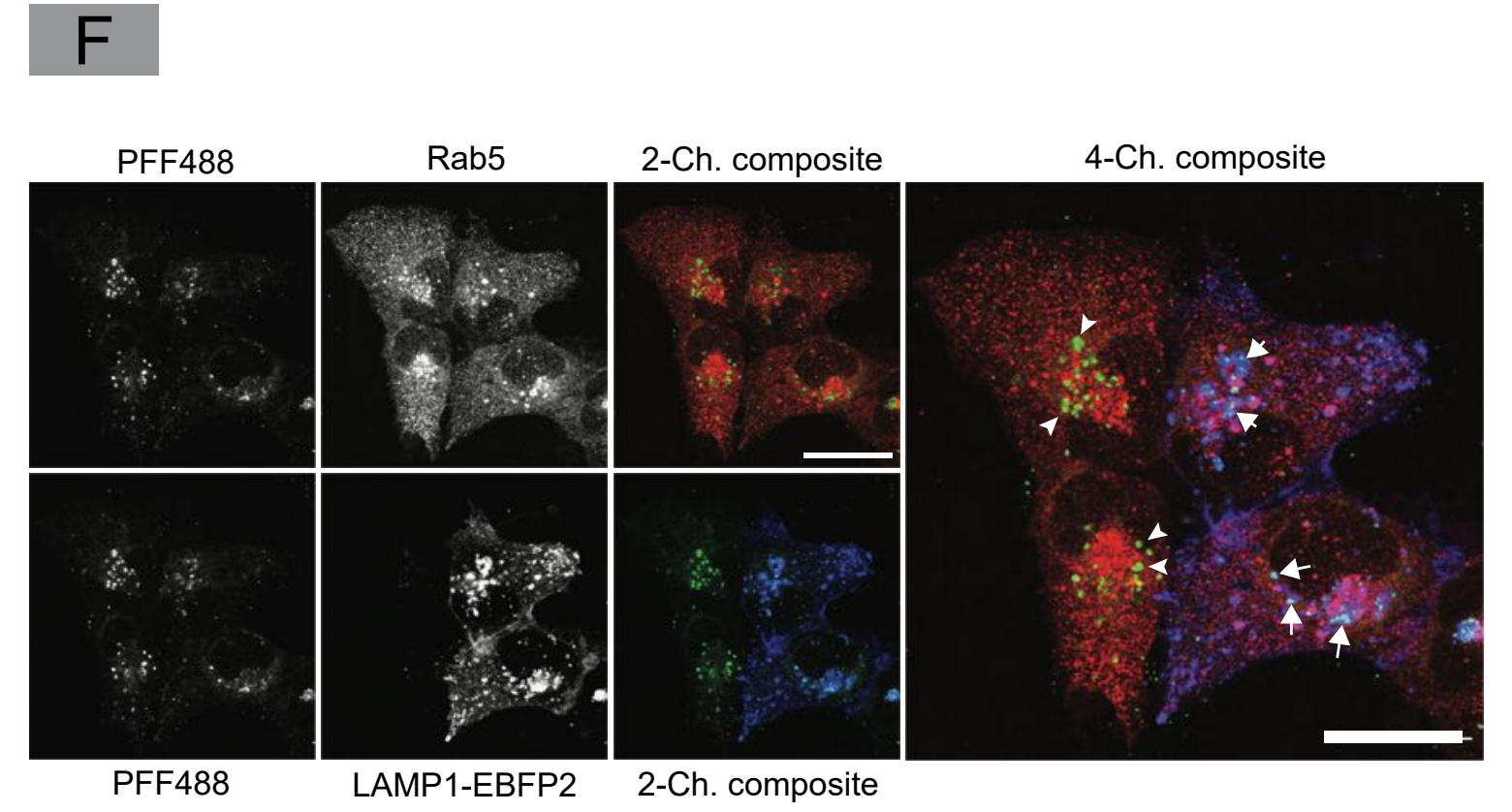

Bayati et al., Fig. S4 


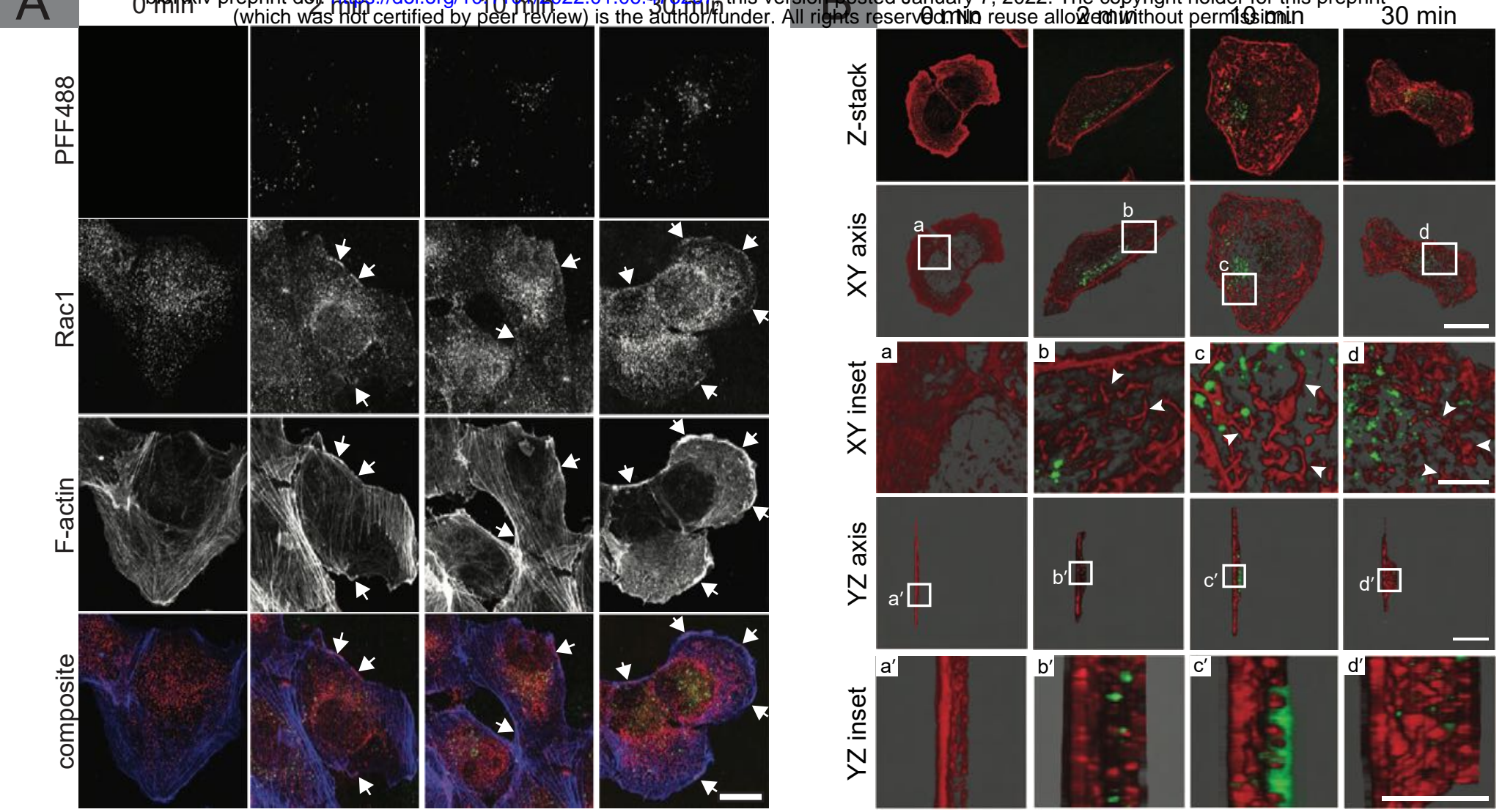

\section{C}

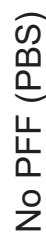
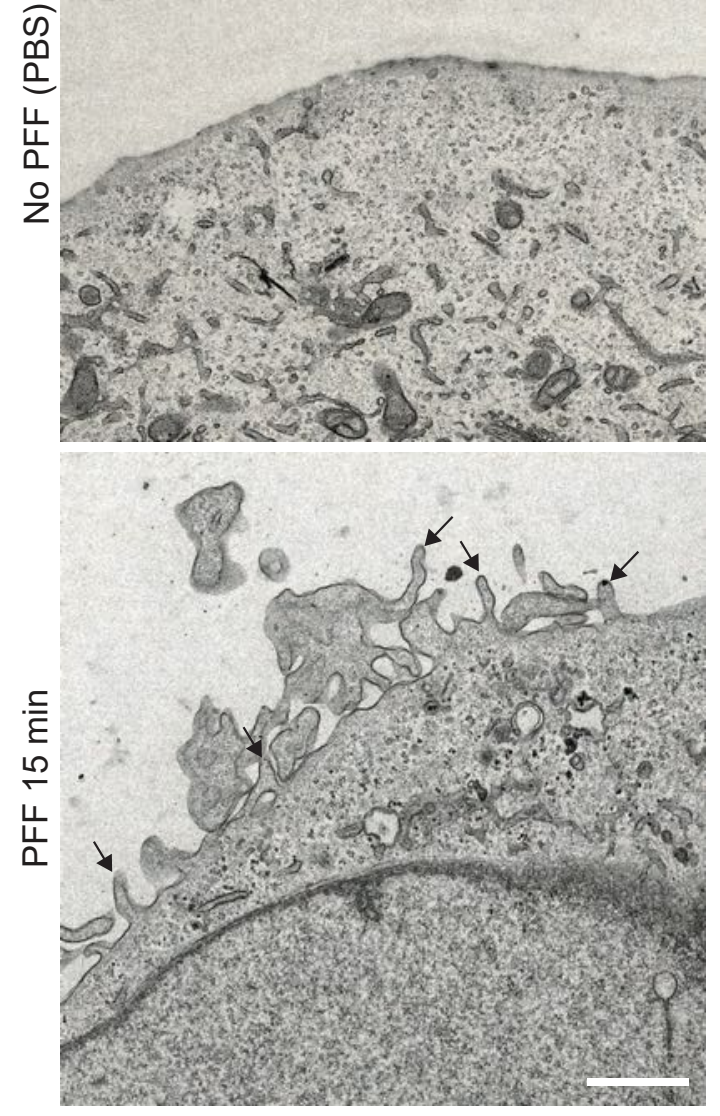
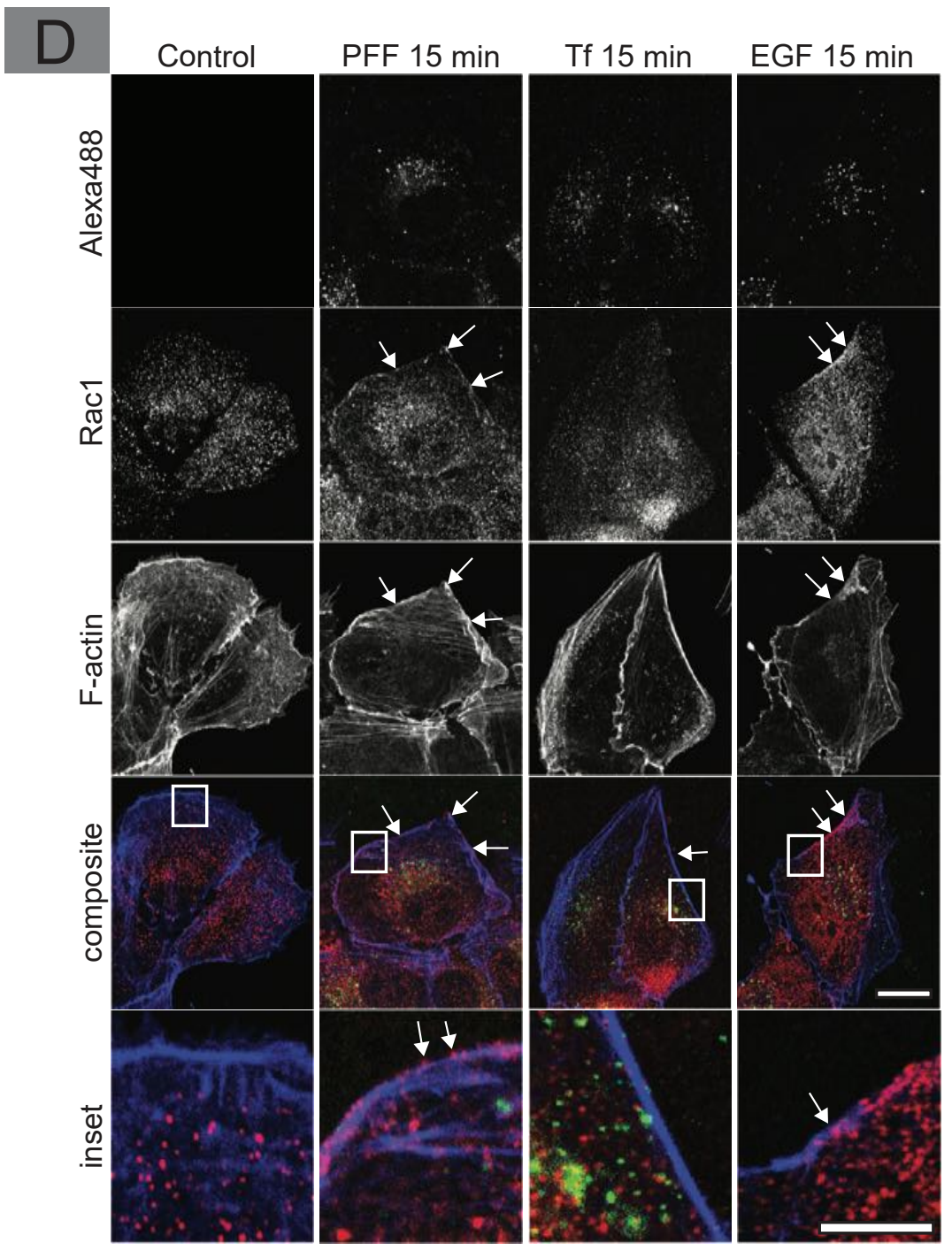

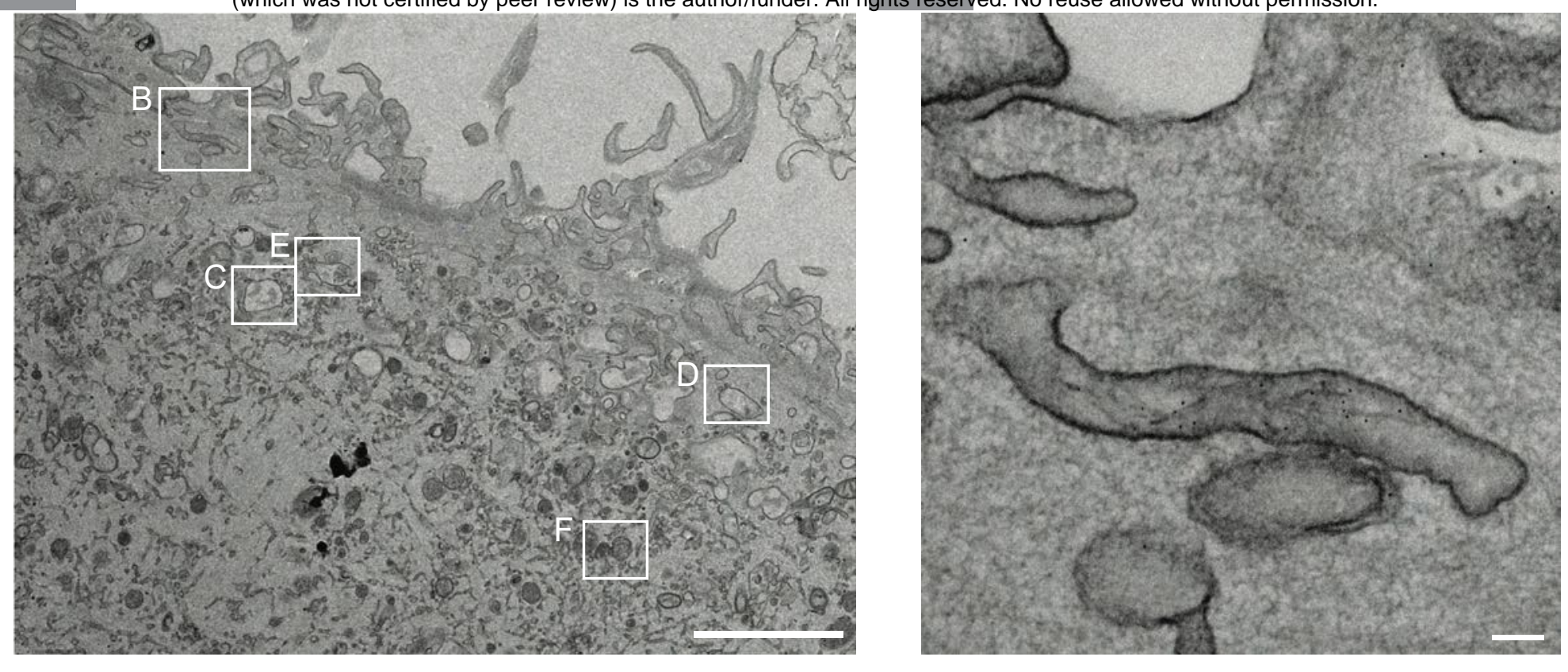

\section{C}

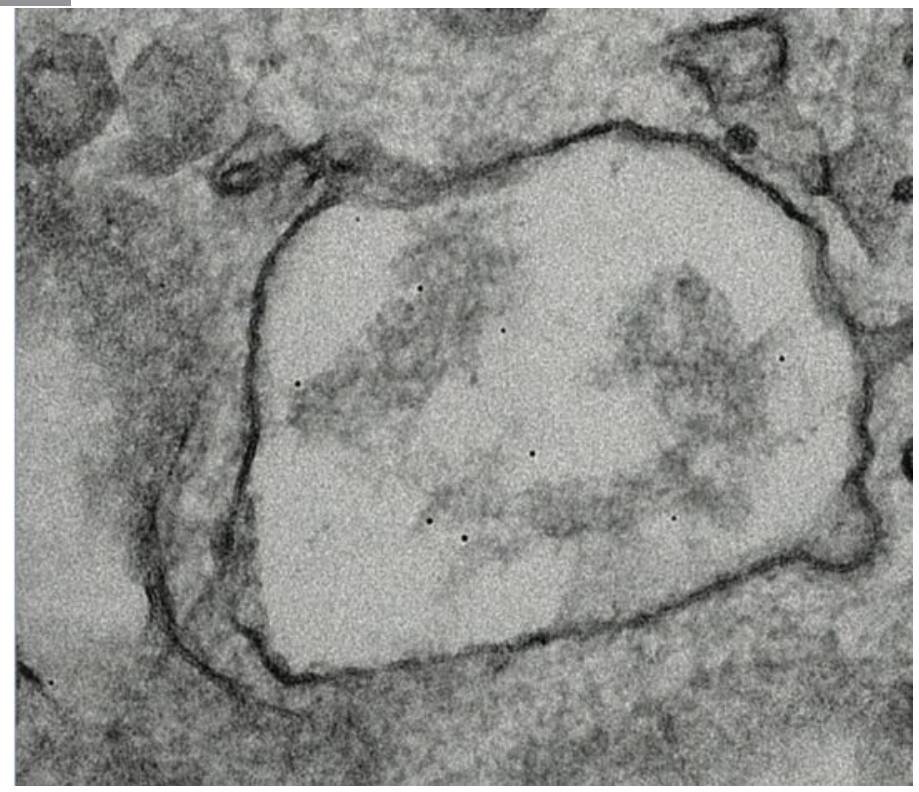

E

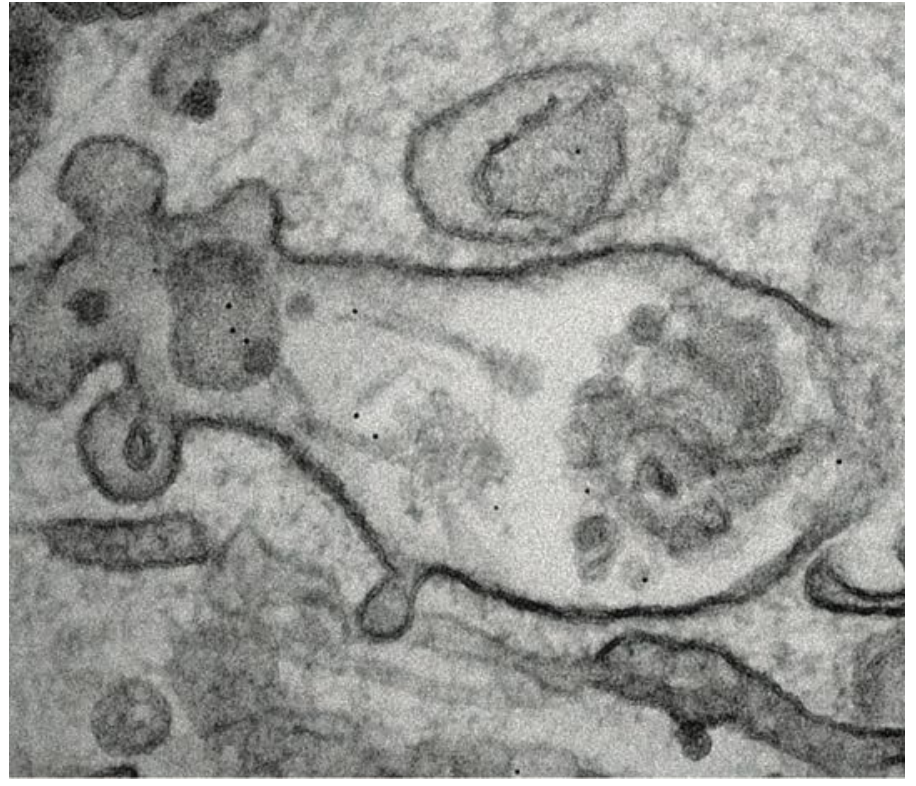

D

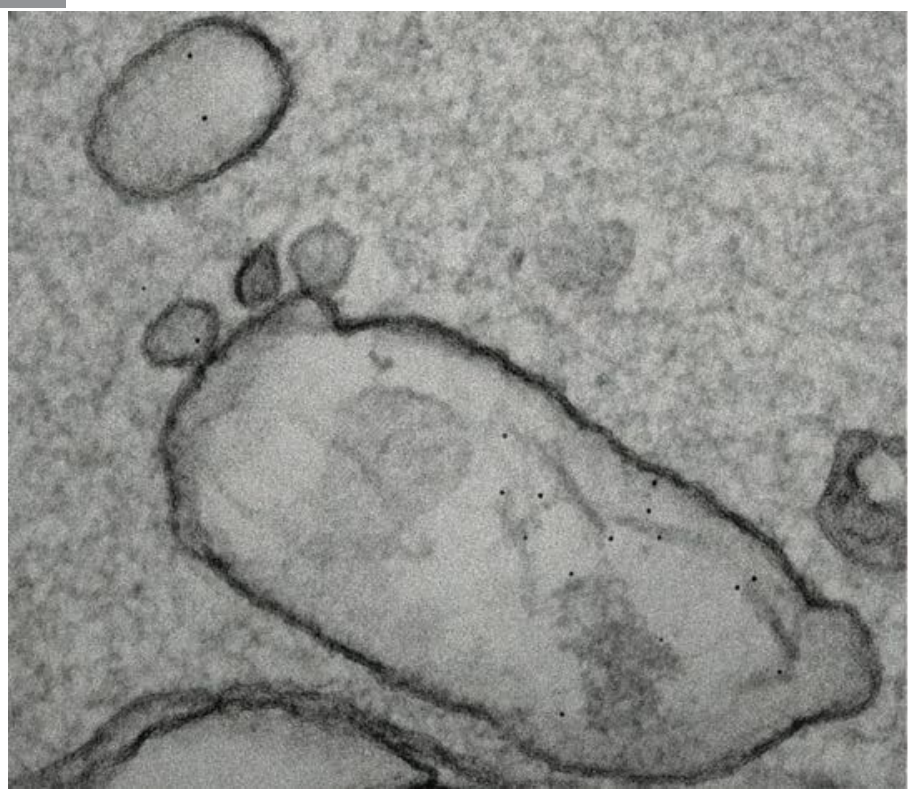

$\mathrm{F}$

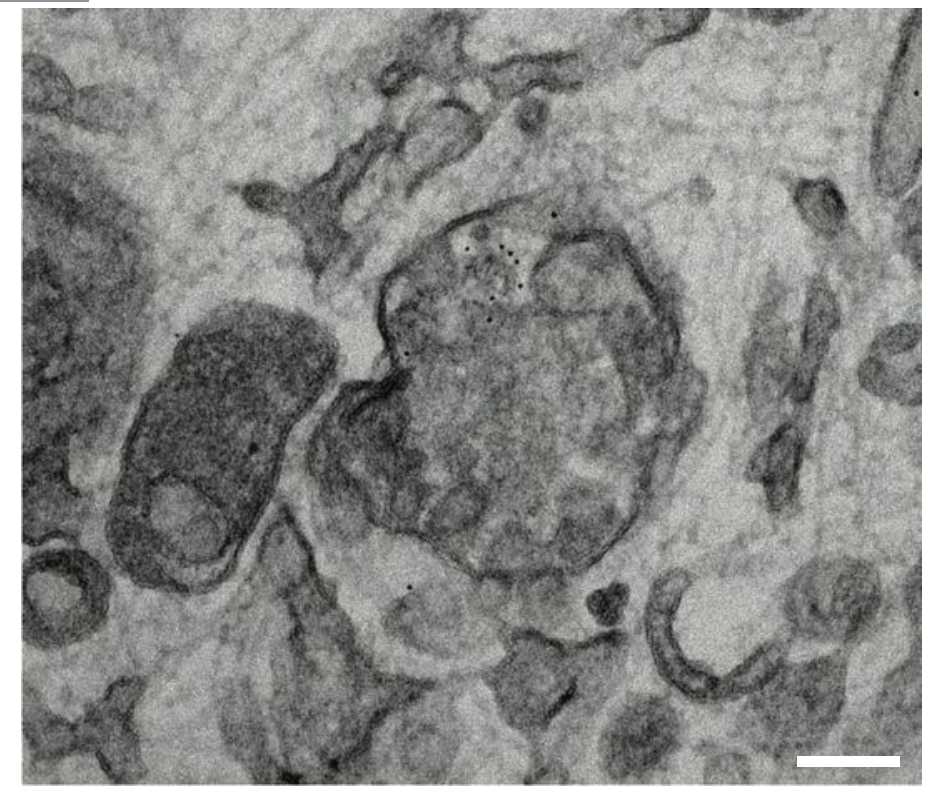

Bayati et al., Fig. S6 


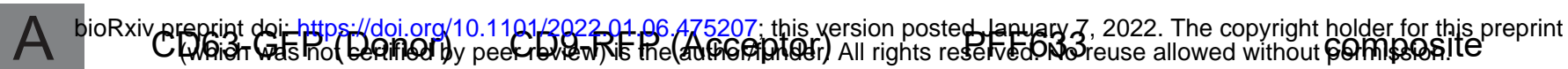
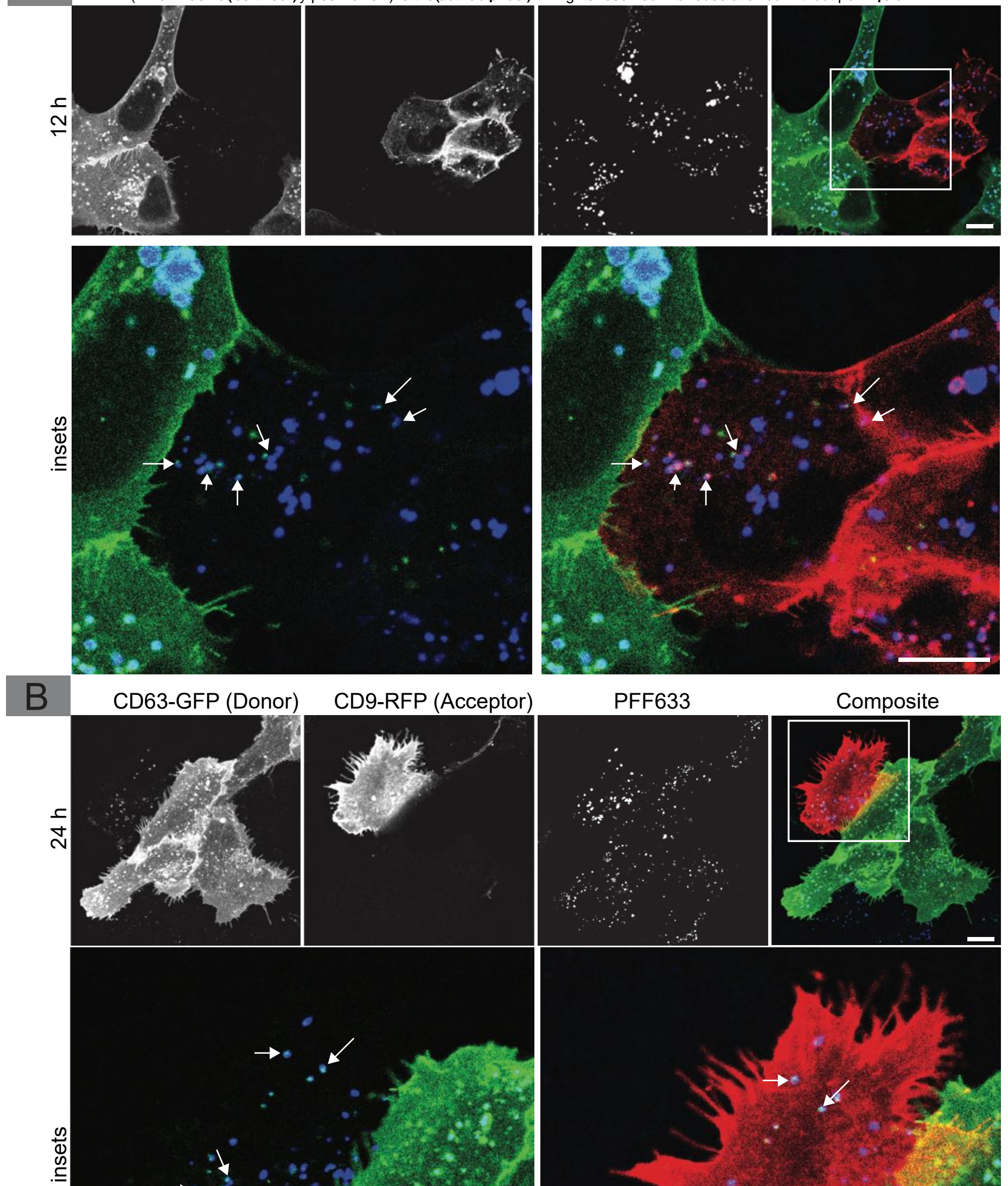

$\stackrel{\infty}{\stackrel{\infty}{ \pm}}$

Bayati et al., Fig. S7 